\title{
ATTITUDES OF COUNTY EXTENSION \\ AGENTS TOWARD \\ AGENT SPECIALIZATION IN OHIO
}

\author{
DISSERTATION
}

Presented in Partial Fulfillment of the Requirements for the Degree of Doctor of Philosophy in the Graduate School of The Ohio state University

By

Jose M. Huerta, B.S.,M.S.

The Ohio State University

1993

Dissertation Committee

Dr. Keith I. Smith, Adviser

Dr . Jo M. Jones, Co-Adviser

Dr. Janet L. Henderson
Approved By:

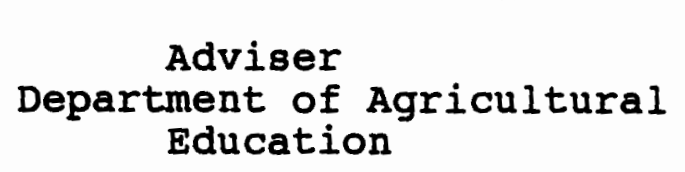




\title{
ATTITUDES OF COUNTY EXTENSION AGENTS \\ TOWARD AGENT SPECIALIZATION IN OHIO
}

\author{
BY \\ Jose M. Huerta Ph.D. \\ The Ohio State University/ 1993 \\ Professor Keith L. Smith, Adviser
}

The purpose of the study was to determine the attitudes of county Extension agents toward agent specialization in Ohio. Furthermore, this study sought to determine the extent to which attitudes toward agent specialization were associated with major personal and organizational characteristics. Independent variables included: 1) personal characteristics/2) organizational characteristics/ and 3) training needs. The dependent variable was attitudes toward agent specialization.

Data for the study were gathered in January, 1993, by a mailed instrument which was divided in four parts. The population consisted of all Ohio State University Extension county agents $(\mathrm{N}=285)$, Descriptive statistics were used first to summarize and organize the data. ( $T$ test and anova were performed to test for groups significant differences). 
Correlation statistics was also used to test if attitudes toward agent specialization were associated with the independent variables. Findings and conclusions were based on a data sample of 261 agents (91.6\% response rate). Overall, attitude of county Extension agents toward age specialization was moderately high. Agents liked the following about agent specialization: 1) specializing in a area of interest, 2) getting more recognition and 3) access to more specialized training. The problems with agent specialization were: 1) time consuming, 2.) lack of local support and 3.) need for more generalization. Suggestions for agent specialization were: 1) more guidelines and support, 2) more coordination and 3) more flexibility..

Training needs identified included balancing agent specialization with other program responsibilities, making content meaningful and acquiring in-depth subject matter skills. The training preferences of county Extension agents were: state-wide conference, district conference and formal classes. There were no correlation between independent variables and dependent variable.

The findings support the need for additional research to investigate agent specialization as Extension explores new staffing patterns and new specialization areas. 
Copyright by José M. Huerta

1993 


\section{DEDICATION}

Dedicated to my lovely wife Lillian,

for her infinite faith in me

and for being the ideal wife and companion.

Thank you Lord, for all your daily blessings, and for

granting me her love and make me the luckiest person in the world. The beautiful and rich language of Miguel de Cervantes is not sufficient to express my true feelings. Iillian, you are a very special person. Thank you Lord for our love. 


\section{ACKNOWLEDGMENTS}

I express sincere appreciation to my advisor Dr. Keith L. Smith and my co-advisor Dr Jo M. Jones for their insights throughout this research. Special thanks to Jill king, for her continued help and support, and for being an outstanding secretary. Thanks are extended to Dr Janet Henderson, for serving in the advisory committee, for her suggestions and comments, and for being my advisor during my coursework. Gratitude is expressed to the graduate student and friend Ruben Nieto for his technical assistance, and especially, for his sincere friendship. 
VITA

February 8, 1956 Born- La Habana, Cuba

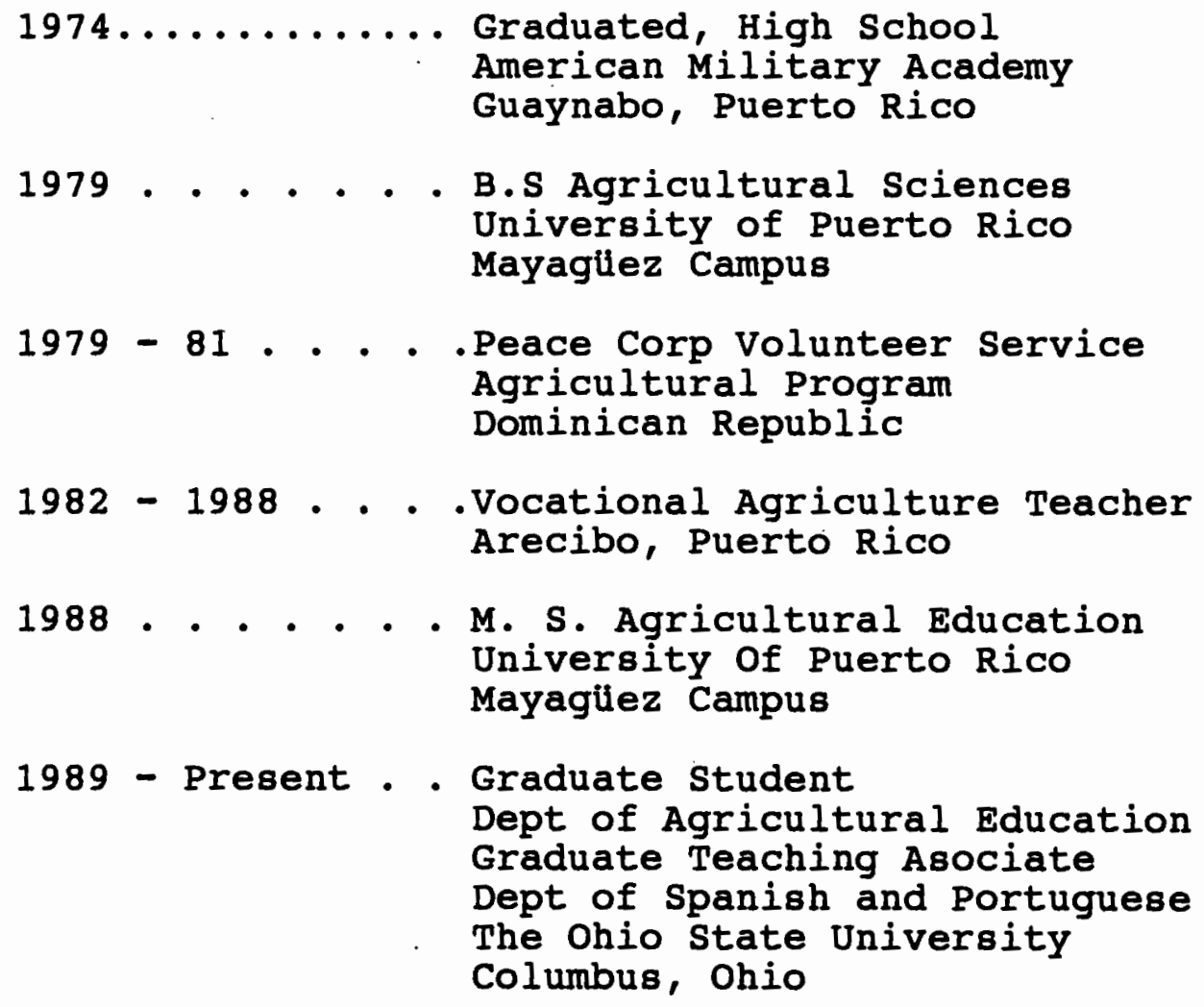

Field of study

Major Field: Agricultural Education

Major Area of Emphasis: Extension Education

Secondary Emphasis: Rural Sociology International Agriculture Research And statistics 
TABLE OF CONTENTS

DEDICATION...........................

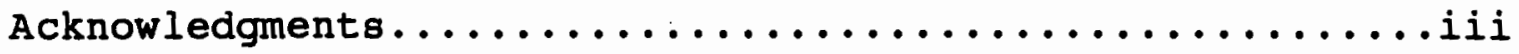
VITA................................ List of Tables........................... vi

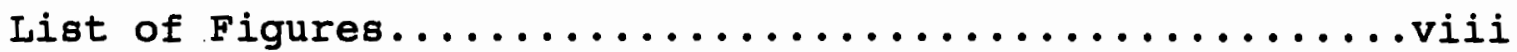

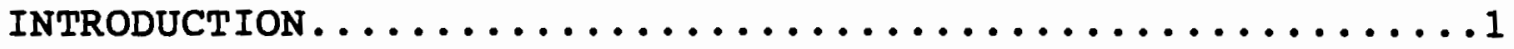

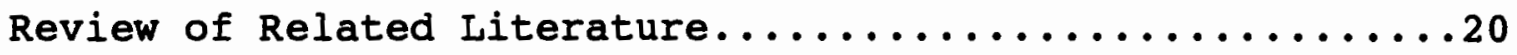
METHODOLOGY.............................64

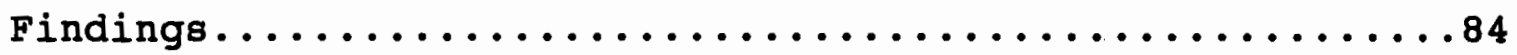
SUMMARY, IMPLICATIONS, AND RECOMMENDATIONS..........146 APPENDIX A Mailing Procedures, and Panel of Experts.....170 APPENDIX B Instrument for the study..............178 REFERENCES ................................... 189 
Table

\section{LIST OF TABLES}

1 Summary of Internal Reliability of the Instrument...76

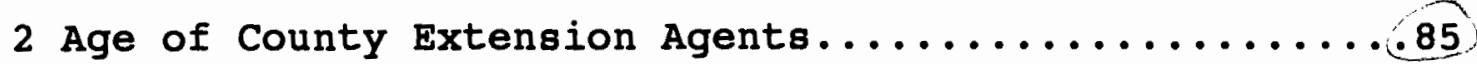

3 Gender of Respondents...................... 86

4 Marital Status of Respondents...............86

5 Tenure with ohio State University Extension.......87

6 Highest Academic Degree of County Extension Agents... 88

7 Major Area of Highest Degree Obtained by Respondents..89

8 Position of Respondents...................90

9 Extension Program Area.........................

10 County Staffing Pattern..................92

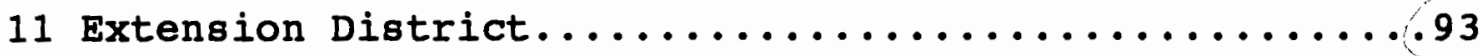

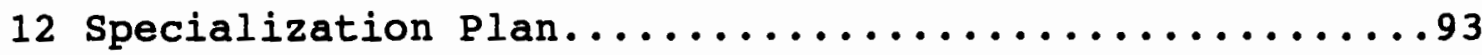

13 Response to Individual Items on Attitude scale......995

14 Attitudes and Early and Late Respondents..........97

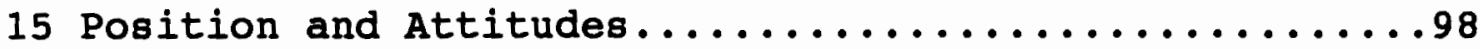

16 Extension Program Area and Attitudes.............99

17 Highest Academic Degree and Attitudes............101

18 Area of Study and Attitudes...................

19 Extension Staffing Patterns and Attitudes.........104

20 Extension Districts and Attitudes................ 105

21 Gender and Attitudes...................... 107 


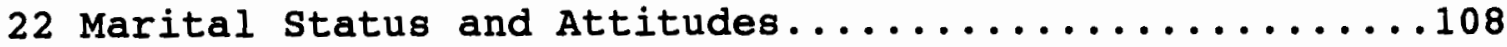

23 Plan for Specialization and Attitudes..............109

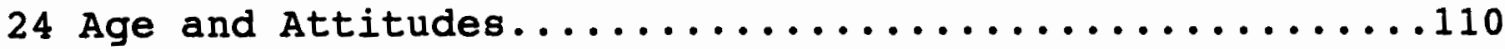

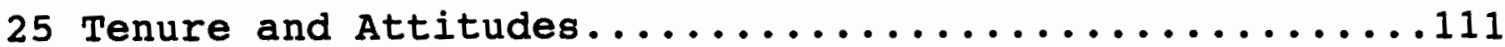

26 Mean Scores for Perceptions of Importance, Knowledge and Ability to Implement Selected Competencies.......121

27 Perceptions of Importance of Selected Agent

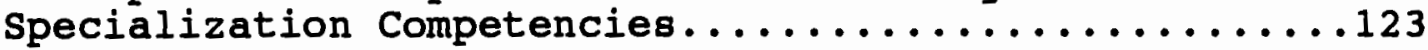

28 Perceptions of Rnowledge on Selected Agent

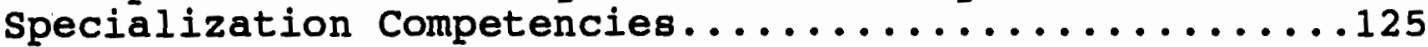

29 Perceptions on Ability to Implement selected Agent Specialization Competencies..............127

30 Rnowledge and Ability to Implement Discrepancy Scores

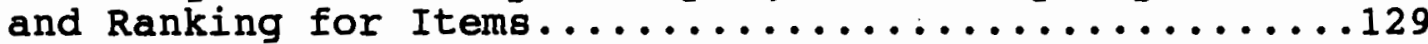

31 High Priority Items Based on Knowledge Discrepancy scores...............................131

32 High Priority Items for Training Based on Ability to Implement Discrepancy Scores...............131

33 Ranking of the Training Preferences..............133

34 Dummy-Variable Coding of Highest Academic Degree......137

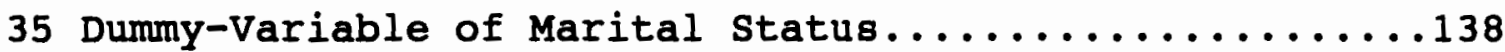

36 Dummy-Variable Coding of Extension Program Area......138

37 Dumy-Variable Coding of Extension Staffing Pattern...136

38 Dummy Coding of Major Area of study...................

39 Correlation Between Independent Variables and Attitudes Toward Agent Specialization............140

40 Intercorrelations Among Variables................ 144 


\section{LIST OF FIGURES}

Figure

Page

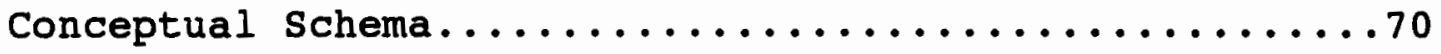

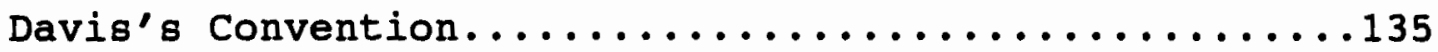


CHAPTER I

INTRODUCTION

The Cooperative Extension Service (CES) as a national educational network, links research, science, and technology to the needs of people where they live and work. Extension's purpose is educational, practical education for U.S citizens to use in dealing with the critical issues that impact their daily lives and the nation's. future, (United States Department of Agriculture Extension Service and Land-Grant University $1989)$.

Extension is a national resource. For nearly three quarters of a century, the Cooperative Extension service has been an important influence in the development of rural America. Extension was created by the Smith-Lever Act in 1914 as a third arm of the land grant system to transmit information from colleges and the U.S.D.A to local people. According to the purposes specified in the original legislation, Extension is to disseminate and encourage the application of useful and practical information relating to agriculture, home 
economics and related subjects among the people of the United States not enrolled in land-grant colleges (Warner, Christenson, 1984).

The 1862 Morrill Act is credited to have been not only the most significant legislation regarding Agricultural Extension, but the most important piece of social legislation in the history of the United States (Blackburg, 1984). The main goal for the creation of Extension was to provide education to anyone, not only the privileged few. The United States was an agrarian society until the end of the 19th century. During that time, the land grant universities formed Extension systems as arms of their institutions and began grassroots, off-campus educational activities.

By 1945, however, six million farms existed in the United States. Only 9.4 percent of the population lived on farms in 1945 and only 5 percent in 1959. By 1980, food and fiber for 232 million people in the United States and agricultural exports worth $\$ 40$ billion were provided by 1.66 million farms. Today's farmers are still coping with problems, but they are new ones, specialization, declining farm numbers, and changing cultural patterns (Prawl, 1984). In 1992, the farmer population was 28 . 
In the last decade, The Extension Service has extended its range of responsibility beyond agriculture. The mentioned trend resulted in the Expanded Food and Nutritional Educational Program (EFNEP); expansion of its $4-H$ and youth programs, especially in urban areas; emphasis on consumer education, and improvement of family relations and community improvements (The Cooperative Extension Service, 1981). It is increasingly important for Extension and other related organizations to be aware of how people within the organization respond to change.

Calson (1970) stated that the early purposes of the Cooperative Extension Service were to increase agricultural production and maintain a rural way of life. However, Calson concludes that Extension has been unable to fulfill both goals, that indeed increasing agricultural production has led to the liquidation of the rural way of life and the development of corporate farms (Hebert, 1968).

Extension preserved the rural way of life in helping a small sector of family farms to survive by emphasizing specialty crops or by incorporating as family enterprises and competing on a level with the corporate farms. Such an arrangement, however, would 
have done little favor with those who enacted the Smith-Level act (Calson, 1970).

statement of the problem

An important question remains to be answered "should the mission of extension be broad or narrowly defined"? (Warner, Christenson, 1984). With a mission narrowly defined as farm and rural, some opponents of CES believe too many resources are being allocated for a small population segment. The National Agricultural Research and Extension Users Advisory Board calls for Extension to redirect or eliminate programs and to shift personnel so they directly serve the needs of producers of U.S food and fiber (1982).

In contrast, the National Association of States Universities and Grant Land Colleges, (NASULGC, 1983) argues for a broad flexible statement of purpose so the organization can remain relevant and respond to the dynamics of change.

Another question is: Should staff be specialists or generalists"? Naisbett (1982), stated that the "days of the specialists are over." Today, people who can integrate have more to offer and can view and treat educational efforts on any problem, for that matter, from a holistic stand point. On the other hand, the traditional Extension staffing pattern across the U.S 
is being examined considering a shrinking resource base and changing program needs.

In the early years of the Cooperative Extension Service, the nature of the work was that of providing farmers with information generated through research to improve agricultural production practices. Today, the Extension's clientele is more diversified and sophisticated than it used to be. Despite all the changes, the theme of Extension still is "helping people to help themselves", and working with clientele to meet their needs and attain their goals (Prawl, $1984)$.

The orientation and focus of Extension requires that the agents work with clientele in various situations over a long period. Today, more than ever, for extensionists to be fully effective in their educational role, it is imperative that Extension agents become more specialists and less of a generalist (Purdue CES, 1991). (Purdue Cooperative Extension Service recommends specialization, particularly in agriculture and natural resources, where the work should focus on crop production and farm business management whereas home horticulture programing will continue at selected sites). 
In 1987, The Minnesota Extension Service (MES) introduced the agent specialization concept for. providing more expertise closer to program delivery. While the Extension agent will continue working with a wide range of problems, he/she also would be expected to become specialized in a particular area (Hutchins, 1990). The agent's specialized knowledge is being shared throughout a multi-county unit known as a cluster. Agents continue to be based in county offices and still spend the majority of their time on county programs and problems, but up to 258 of their work is performed on behalf of the cluster (Hutchins, 1992). Specialization would become a framework for agent's professional development and a criterion for selection of new staff (Hutchins, 1990).

In January 1991, agent specialization was implemented in Ohio. Agents were not expected to develop subject matter specialty to the same level as state specialists. Specialization areas will be broad. Extension agents will provide leadership and teach in their area of expertise inside and outside their county. Most agents are expected to maintain their broad areas of specialization over a long period. However, their areas of emphasis may change periodically. Specialization was designed to improve 
efficiency, since agents will not need to devote teaching preparation to all subject matter areas (OCES, Administrative Cabinet, 1989).

The increased level of specialization in county personnel allows for the development of stronger, more in-depth programs. Specialization also allows for the personal development of county personnel. With a greater level of understanding in a specialty area, county personnel would be able to identify research needs and influence the research efforts of campus faculty (Godke, 1991). Therefore, the traditional concept that county Extension agents can effectively address the wide range of needs of their clientele is no longer valid.

Extension agents in Ohio, in consultation with their district director, select at least one broad area of specialization from the list provided by their state program areas. The area of specialization chosen must be consistent with the agent's own preferences and local needs. A second area of specialization can be selected from any of the four program areas, which are Home Economics, Agriculture, 4-H and Natural Resources Development (OCES Administrative Cabinet, 1989).

Agent specialization implies continuous education for county Extension agents. For that reason, it is 
critical to focus the efforts in the training needs and preferences for training of county Extension agents participating in agent specialization. A needs assessment is a very appropriate way for finding out the Extensionist's needs for training.

As future hiring decisions are being made, consideration will be given to needs for agent specialization on a cluster/multi-county basis (OCES Administrative Cabinet, 1989). However, agent specialization is also being used under the conventional staffing pattern. Specialization also played an important role in performance appraisal beginning in 1992 .

Other states have assigned former county personnel multi-county responsibilities to provide services to the same geographical area with fewer persons. 'Today, the Cooperative Extension Service is being challenged to adapt to a changing world (Taylor-Power, Richarson, 1990).

The availability of new technology and information systems may bring different systems of staffing arrangement and communication methods in the Cooperative Extension System (Warner, Christenson, 1988). While the county has usually been the main focus for Extension programing, budget constraints and 
the need to provide clientele with greater expertise in all program areas will have major implications on staffing arrangements throughout the country (King, 1990).

As early as 1973, suggestions were given regarding the need in Extension for the utilization of specialisto in many areas to bring more in-depth, upto-date information to the public (Moore, 1973). Regarding the need for Extension agents to update their skills under agent specialization, training needs and preferences of training must be addressed.

In the 1980's in Great Britain, it was felt that farmers needs were changing. Many farmers wanted indepth, specific and detailed advice when they needed it. Often, the ADA (Agricultural Development and Advisory Service) could not provide this type of service as they had to "sprinkle" themselves across the whole industry. This situation was already leading to a growth in private agricultural consultants (White, 1991).

Thus, privatization was a response to the specialization of farmers. On the other hand, recent changes in technology have resulted in specialization and intensification of farm production systems, which 
are based on increases in the use of capital, in mechanization and in purchase of inputs.

One of the newest trends in Extension has been the introduction of issues programing. Essentially, issues programing suggests that Extension work with local groups to identify priority needs. The purpose is to let external needs dictate internal response. Another idea was to let the subject matter agenda emerge with changing external needs (Taylor-Power, Richardson, 1990). Issues programing will be very useful in identifying areas of specialization needed within the local communities. Issues programming provides another way to define and execute the unit of planning. Extension staff and administrators are expected to identify an issue, and develop an appropriate action plan. (Dalgaard, 1988).

Issues programming in Extension must seek the involvement of non-traditional clientele, ownership of programs at the county level, and the development of a state-wide plan of work based on locally identified concern and a highly visible marketing goal for Extension (Richarson and Ladewig, 1989). Issues programing is a fundamental tool for implementing agent specialization, since Extension clientele should 
be actively involved in identifying areas of specialization.

In order to provide the best information available to clientele, the Ohio Cooperative Extension Service considered the idea of a clustered staffing pattern to allow agents the opportunity to specialize in areas of interest that are needed within two or more counties (King, 1990). The new trends in Extension are increasingly asking Extensionists to work beyond county lines and across program areas (Hutchins, 1990).

Agent specialization can fit very well within clustered staffing pattern, because each agent will have charge of a program area(s) in a home county and, in addition, identify an area of specialization in a primary and possibly a secondary area. The area(s) of expertise can be used in other counties within the cluster. However, agent specializations also can be used under traditional and multi-county staffing patterns.

Agent specialization, like clustered staffing pattern and issues programming, represents a recent development of Extension in Ohio and nationwide. Therefore, it is essential to know how extensionists are coping with the changes related to agent specialization. By learning how Extensionist's are 
coping with the changes, the agency can gain valuable information for the implementation or improvement of agent specialization procedures.

Organizational change is a complex process. The study of change is further complicated by the lack of a defined theoretical base in educational administration (Vroom, 1983) and the lack of research concerning Cooperative Extension Service administration and leadership behaviors (Boone, 1987).

As ohio and other states move toward instituting an agent specialization system, Extension is obligated to study this new system and offer recommendations for the improvement of agent specialization. When changes of this magnitude are implemented, Extension personnel should be surveyed to determine their attitude to the system and to allow their input into the staffing plan. With little information available on the subject of agent specialization, the need for this study was great.

\section{Purpose of the study}

The purpose of the study was to determine the attitudes of county Extension agents toward agent specialization. Furthermore, this study sought to determine the extent to which attitudes toward agent 
specialization were associated with major personal and organizational characteristics.

Secondly, relationships were explored among attitudes and the variables of importance, knowledge and ability to implement selected agent specialization competencies.

Justification of the Study

Extension agents can identify major concerns regarding agent specialization. Also, by providing Extension agents the opportunity to provide input into a staffing plan through an attitude survey, their understanding of agent specialization will be increased. This increased level of understanding will, hopefully, reduce their resistance to adapt to agent specialization. According to Buford and Bedeian, (1988), attitude surveys can be very revealing and useful as an organizational development technique. The results can be used for analysis and interpretation so staff members can assist in designing the necessary changes.

The study involved the population of Extension agents who represent all areas of specialization within the Ohio State University Extension. The data from this study will contribute to the body of knowledge 
regarding training needs and organizational change in the field.

Data from this study will be of significant value to administrative personnel in The ohio State University Extension, and other states as well. The study will assist Extension Administrators in improving agent specialization. The study also may serve as a model for other state Extension Services to facilitate the implementation of agent specialization.

The data can be used to develop in-service training programs for agent specialization. Extension.

administrators can utilize the study to suggest support and/or training needed to further enhance agent specialization.

The study will provide decision makers within the Ohio State University Extension the necessary tools to decide whether activities within the agent specialization program are being implemented according to plans, what problems need to be resolved and necessary corrections. Furthermore, the results of this study can be used by administrators within the Cooperative Extension Service to focus their efforts on the principal constraints within the specialization system and thereby, make adequate changes in the system as needed for successful operation. The results of the 
study will provide information for improving the components of the training in agent specialization. The study will include the following variables: Independent Variables

1. Personal Characteristics

2. Organizational Characteristics

3. Training Needs

Dependent Variable

1. Attitudes toward agent Specialization Qbjectives of the study

The objectives of the study were to:

1. Describe the agents with regard to selected. personal characteristics including: age, gender, marital status, year's of experience, highest academic degree and major area of study.

2. Describe the agents with regard to selected organizational characteristics including: position, Extension program area, staffing pattern, Extension district and specialization plan.

3. Determine the attitudes of county Extension agents toward agent specialization.

4. Describe the perceptions of county Extension agents about the importance, knowledge and ability to perform selected agent specialization competencies. 
5. Determine the perceptions of training needs of county Extension agents regarding specific concepts of agent specialization.

6. Rank the training preferences of county Extension agents.

7. Determine the extent to which attitudes toward specialization is associated with personal factors, including: age, gender, marital status, length of service, highest academic degree, type of educational degree, organizational factors including: position, County chair, Extension program area, staffing pattern, Extension district and specialization plan, and the perceived training needs of county Extension agents, which include knowledge, and ability to perform.

\section{Assumptions}

For purposes of the study, the researcher assumed that:

1. Specialization has occurred long enough to have had an impact on attitudes among Extensionists who are participating in the program.

2. Specialization is being used under three different staffing patterns (traditional, cluster and multi-county staffing).

3. Extensionist's perceived needs are a reliable source for the development of in-service training programs. 
4. The primary units of adoption of change are the county Extension agents.

Definition of Terms

The following definitions will assist the readers in understanding the study:

In-service Training-- The professional development program offered to Extension Faculty by the OCES organization .

Agent Specialization-- An emphasis in which county Extension personnel direct up to 25 of their time to specific subject matter areas. Agents share expertise via presentations, serving on issues task forces, and developing written materials for use beyond county boundary lines (Ohio State University Extension, Administrative Cabinet, 1989).

Clustered Staffing Pattern-- This staffing pattern involves two or more counties with staff members from each county working together in conducting the Extension programming efforts. Each agent has charge of a program area(s) in a home county and, in addition, identifies an area of specialization in a primary and possible a secondary specialty area. An agent serves as a resource and teacher in his/her specialty area(s) for all counties within the cluster. A county chair is located in each county, with a program coordinator 
identified for the cluster to facilitate programming efforts, particularly issues programming. Multi-County Stafing-- The method of staffing involves sharing an agent's time between two counties. The agent takes primary responsibility for the same major program area (either Agriculture, home economics, 4-H, or Community and Natural Resources Development) in each county.

Conventional staffing-- The staffing pattern generally includes three county agents- one in agriculture, home economics, and 4-H. One agent serves as the county chair with another identified as the community and natural resources development (CNRD) coordinator. Educational programs in a conventionally staffed county are conducted within the borders of that county. Outside agent assistance comes generally from state and district specialists.

Issues Programming-- A program development, implementation and evaluation approach with origins in matters of wide public concern, without regard for traditional Extension subject matter, audiences and methods of program delivery (Dalgaard, 1988). County Extension Agents-- As of January 1, 1993, all county agents are faculty agents or Extension agents. 
Attitudes-- A predisposition to behave in a certain manner.

Personal Characteristics-- Operationally defined in the study with the following variables: age, gender, marital status, highest academic degree, major area of study and year's of experience. Organizational Characteristics.-- Operationally defined in the study with the following variables: position, Extension program area, staffing pattern, Extension district and specialization plan. Training Need-- Is defined as the discrepancy between an educational goal and the individual's performance in relation to the goal (Borish, 1980). 


\section{CHAPTER II \\ REVIEW OF RELATED LITERATURE}

The purpose of this chapter is to present a review of the literature related to the organizational change process, specialization and change in the Cooperative Extension Service and the need of in-service education in organizational change.

\section{Organizational Change}

Organizational change is a process of "organic growth" in which the organization adapts to both, the values of the external society, its source of legitimacy and financial support and to the striving of its internal groups (Wilenky, 1957).

Peters and Waterman (1982) observed that innovative companies are usually good at responding to environmental change of any sort, customer needs, competitor's skills, and government regulations. These companies adjust, transform and adapt. Thus, the entire organization innovates. 
Gray, Long, and Stahlhut (1989) identified four critical elements or dimensions for all organizations that are critical for coping with change. The first dimension is related to organizational goals. This dimension must be agreed upon, written for all to read, and used as a basis for identifying the purpose or mission of the organization. Unless an organization has a set of goals, planning or strategies for the future is unproductive. The second dimension is the changing environment. How an organization interacts with the ever changing forces affecting the organization from the outside is critical to survival. The third dimension, tension and conflict, is managed within the organization. How the organization is managed often determines the morale and energy level of employees. Tension occurs whenever change is apparent. Change implies a move from a negative to a positive, from doing one thing poorly to doing something else better. Finally, every organization has a set of procedures. These procedures must be fair and understood by all employees. On the other hand, procedures can be misunderstood, which causes additional tension. Understood procedures must include decision- making, communication, and the system's hiring, firing and promotion policies. 
Peter and Waterman (1982) identified several tools that help managers focus on a direction and equip the organization to move toward a long term vision. These tools can be divided into "hard" and "soft" implements. The "soft" are flexible and often unused, and include the cultural values within the organization. "Soft" implements are very important because they are based on these values, the leader can identify strategy and long-term vision for the organization. "Hard". implements refer to the structure and system of the organization.

According to Peters and Waterman, "hard" implements have predominantly been used by managers over the last 50 years. Often, managers attempt to change the communication system by rearranging the structure or changing personnel.

Peters and Waterman suggested that part of the reason change failed was the "hard's" are highly influenced by the "soft's". Rather than narrowly focusing only on structure and systems managers must also take into account the less visible "soft's".

Miller and Snow (1978) suggested that organizational change can take two basic directions: prospector or defender. A prospector organization is oriented toward growth, change of clientele and programs, it is prepared 
to take risks and to structure the organization to absorb new ideas and concepts. The defender organization on the other hand, is satisfied with maintaining the status quo.

Greiner (1967) developed a very general model of successful change. Greiner found that successful change invariably focused on one key factor. The factor is concerned with the redistribution of power within an organization so traditional decision making practices move toward greater use of shared power. The occurrence of such procedure involves a series of six momentum building phases:

1) Pressure and arousal

2) Intervention and reorientation

3) Diagnosis and recognition

4) Intervention and commitment

5) Experimentation and search

6) Reinforcement and acceptance

Bennis (1969) forecasted the decline of bureaucracy and the emergence of an organic adaptive system that will dominate the world of scientific and intellectual achievement. Bennings viewed the future of human organizations a leading perpetual change and high frequency of temporary social systems. Bennis predicts that the individuals in new organizations will be 
permitted and encouraged to use their imagination, fantasy, and creativity to an extent unknown at that time.

Boyle (1981) stated that many continuing education programs are designed to help individuals adjust for change. Much less attention has been devoted to preparing individuals or groups to plan for change. Certainly, the latter is more desirable; people should control the environment imposed upon them. However, this control is not always possible, since changes outside the control of a particular social system still may affect that system.

Conner and Patterson (1983) identified the following three phases or degrees of individual support for change:

1) Preparation stage, which involves the stages of contact about the change and awareness of the change. 2) Acceptance phase, which includes individual understanding of the change and positive perceptions about the change.

3) Commitment phase, which involves installment of the change, adoption, institutionalization and internalization. 
Bothen (1955) developed one of he first and still reasonable appropriate models for describing what happens in the individual adoption process. They are: 1)awareness 2 ) interest 3)evaluation 4)trial, and 5) adoption.

Awareness: We learn of the existence of the new idea or practice, but have few if any details about it.

Interest: We develop an interest and curiosity in the innovation, seek more information about it, and consider its general merits.

Evaluation: We turn general interest into personal interest by mentally applying the innovation for our own situation, obtaining more information and deciding whether or not to try it.

Trial: We apply the innovation usually on a small scale to determine its utility in our own situation.

Adoption: We accept and use the innovation continually on a full scale.

Roger and Shoemaker (1971) present an alternative model of the innovation-decision process function. This model seems to overcome some traditional limitations of the traditional adoption process model. The model is consistent with general models of decision making, problem solving, and learning. The model is also very appropriate for optional decisions. 
The model consists of four functions; and they occur in different order. For this reason, it is more useful to think of the functions rather than stages in the process. The functions are:

1) Knowledge: We are exposed to the innovation's existence and gain some understanding of it. 2) Persuasion: We form a favorable or unfavorable attitude toward the innovation.

3) Decisions: We engage in activities that lead to a change to adopt or reject the innovation.

4) Confirmation: We seek reinforcement for the innovation decision made, but may reverse the decision if exposed to conflicting messages about the innovation.

According to Roger and Shoemaker (1971) the innovation decision process consists of four interrelated functions:

1) persuasion and evaluation of the situation by the decision unit 2) decision to accept or reject the innovation by the decision unit 3) communication of the decision to the adopting or implementing unit, and 4 ) action on the decision to adopt or reject by the implementation unit.

Iamble (1984) stated that authority decisions are more common in formal organizations than other types of 
social systems. A formal organization is a social system that has been deliberately established for achieving predetermined goals, such as the Cooperative Extension Service.

Calderon (1982) addressed the evaluation of implementation of bilingual programs. Bilingual programs, unlike many other programs of measuring implementation, does not focus on outcomes. The program focused on answering the following questions: 1) What is the innovation? 2) How is it being used? The system is called the Innovation Configuration Approach. This is a way of measuring what aspects of a staff development training program are actually put into practice. The procedure involves five basic steps: 1) Reading descriptive materials, interviewing the developer or program facilitator, and developing a tentative list of components and variations. 2) Interviewing and observing users to get a concrete image of how they implement, and interweave the components .

3) In new discussions with the developers, clarifying the most important components, verifying variations, and resolving discrepancies between developers and user viewpoints. 
4 ) Collecting data through interviews, observations, and/or self-administered checklists.

5) Analyzing data.

Ayres (1989) compares and contrasts the attitudes toward community change between urban and rural residents. Some communities seem to be better able to deal with changes than others. It is believed that the attitudes of leaders and residents may indicate the amount of community support or opposition to various local actions. Therefore, affect the community ability to deal with change effectively.

In an attempt to understand attitudes toward community change, factors believed to affect such attitudes are examined, leader's and resident's attitudes are then compared. Leaders differed significantly from residents in socio-economic characteristics and were more change oriented. 'The level of psychological attachment to the community and the degree of participation in local affairs had the strongest effect in both leader's and resident's level of interest in affecting community change.

Wriston (1990) describes that the state of American management is changing and will continue to change due to the accelerated pace of knowledge and the global market place. Wriston contends that the role of the 
manager has changed from the traditional manager skilled in finance and marketing to one that focuses on goal setting, leadership, and motivation. The manager's job is supervisor of talent, who allows the employees to do the job.

Organizations today are operating in the information age, with knowledge doubling every 10 to 12 years. However, wriston feels that organizations are still trying to apply the tools of the industrial age. According to Wriston, employees' talent is the number one commodity of any organization.

According to Gordon (1990), the change sequence is the sequence of events that are needed to bring about change in organizations. Whether the intended change is from a less participative to a more participative corporate culture, the process tends to follow a certain pattern. Thus, it is imperative for the manager to recognize a need for change. The sequence is as follow:

1) Unfreezing the status quo 2) Moving to the next condition, and 3) Refreezing to create a new status quo.

Conner and Patterson (1983) identified three phases or degrees of individual support for change:

1) Preparation stage, which involves the stages of contact about the change and awareness of the change. 
2) Acceptance phases, which includes the individual understanding of the change and positive perception about the change.

3) Commitment phase, which involves installment of the change, adoption, institutionalization, and internalization. Specialization and Change in Extension

Changes, prompted by review and renewal, are constant currents within today's Cooperative Extension System. These changes are positive signs of a dynamic organization experiencing transition and rebirth (Johnsrud and Rausckolb, 1989).

Brown and Laughlin (1989) addressed the issue of change in Extension. They stated that change is essential. Extension cannot continue with business as usual. Something has to be fixed. Issues based programming is one way to deal with concerns about relevance, mission, priorities and capabilities. There are others who perceive the problem differently. One of the different points of view holds that Extension is drifting away from a strong basic research into rapid responses to whatever happens to be the latest fad.

The Cooperative Extension Service has from its origins, provided educational programs based on the needs of people (Ecop, 1987). Since Extension programs 
are educational in nature, the organization is placed appropriately as the educational outreach for the Land Grant College and University system. Extension provides informal, non-credit programs for assisting individuals in making their own decisions. Extension programs must meet the needs of the people if they are to be significant. Thus, in order to be effective, the programs must also satisfy the interests of those individuals who need the most assistance (Ohio Cooperative Extension Service, 1987).

According to Warner and Christenson (1984), Extension must provide programs that appeal to local needs to maintain clientele. Due to the technological, economical, and social changes occurring in all phases of society, Extension is continually struggling to define its proper function and purpose. "Issues of defining appropriate target audiences, delivering quality programs in the most efficient manner, projecting a positive organizational image, and maintaining adequate support base are being widely discussed" (Warner and Christenson, 1984). Critics of Extension think that the changes are too slow in coming, the organization is not responsive to the needs of the people, while others feel the organization is too diverse and is straying from its intended purpose. 
The report of the Futures Task Force to the Extension committee on organization and policy (1987), stated that the Extension organization must guard against program content for which it has neither the expertise to adequately cover the subject matter, nor the resources to procure it. Many issues which Extension may address are of importance to people, regardless of demographics. For Extension to become the contemporary and progressive organization that is envisioned, issues must guide the determination of program content.

Dalgaard (1988) indicated that issues for Extension are "matters of wide public concern arising out of complex human problems". Issues programing broadens the field in which Extension personnel can work.

Issues programming goes beyond the existing Extension audiences and problems and creates a more comprehensive source of program priorities. Issuecentered programs are interdisciplinary in nature. This means "individuals from different disciplines work collaborative as a team with significant interaction during the entire process of planning, implementation, analysis, and evaluation," (Lippke, et al., 1987).

According Dalgaard (1989) Issues programming can renew the Extension tradition of being proactive rather 
than reactive. Also, issues programming will create a greater public awareness of Extension programs and foster expectations for positive results However, before issues programming can be utilized as an effective program delivery tool, Extension staff must be prepared to meet these new challenges. One recomendation of the Futures Task Force indicated that one or more Extension staff should remain at the county level; however, "these personnel should have skills in educational facilitations, and at least one technical skill appropriate to the locality", (p.12). County staff should represent a blend of disciplinary skills, and interpersonal skills (ECOP Future Task Force Report, 1987). The idea that county personnel should have the technical expertise to address the range of needs of today's clientele is unrealistic. That's why the proper implementation of agent specialization is so critical.

Specialization, as defined by OCES Administrative Cabinet is:

The staffing arrangement wherein county Extension personnel direct up to 25 percent of their time to specific subject matter areas. Agents share expertise via presentations, serving on issue task forces, and developing written materials for use beyond boundary lines (OCES Administrative Cabinet, 1989). 
One of the recommendations formulated through the public hearings held by the Extension Committee of organization and policy call for a reclarification of the shape of the Cooperative Extension Service staff.

Recommendation 18: Extension should provide clientele access to specialized staff assistance through the effective use of multi-county or area specialists, especially with off-campus research stations. Further, these staff as well as state specialists, must demonstrate greater commitment to applied research (ECOP, 1987, p. 13).

In Extension, financial concerns, early retirements, and a need for specialization have forced ohio and other states to look at new staffing patterns (Bartholomew, Smith, 1990). Traditionally, each county has had three agents; one in agriculture, home economics, and 4-H, with one agent taking the community resource development function. This pattern changed in Ohio on November 1, 1987, when the first agent was appointed to a multi-county position (Bartholomew, Smith, 1990).

New ways of doing things can cause frustration and other concerns. A multi-county agent, along with the staff development office, conducted a study of 23 agents, with the purpose of finding out how agents were adjusting to their new positions. The results of the study shows that agents who have accepted multi-county positions are in general working more hours and more 
effectively. However, Clark (1981) found that agents with increased stress, as is evident in this study, will be subject to a higher level of turnover than single-county agents.

Pittman and Cunninghan (1976) addressed the clientele view on staffing pattern of Extension. The study was part of an Extension Service-USDA funded project to assess the advantages and disadvantages of the following staffing patterns: (1) county/state, (2) multi-county/state and, (3) county/multi-county/state. Three states were selected, each to represent one of the three most common staffing patterns. The results indicated that multi-county staffing is the least satisfying staffing arrangement and is perceived by the clientele as the less effective. These changes over a period could lead to fewer support for Extension on the local level and perhaps reduced county funding.

Bartholomew and Smith (1990) recommend that multicounty staffing should be reconsidered for a system of multi-county clustering that would incorporate district specialists as well as county agents. This system would allow field faculty to be responsible for organizational maintenance in only one county, while allowing for specialization within and perhaps between clusters. 
Agent specialization as a concept of providing expertise closer to program delivery, was introduced by the Minnesota Cooperative Extension Service as a way to improve county agent's ability to work across county lines and across program lines. While the Extension agent was still to be a resident community educator working with a broad range of county problems, he/she also would be expected to become specialized in a knowledge area (Hutching, 1990). The agent's specialized knowledge could then be shared throughout the multi-county unit known as a cluster. The specializations would become a framework for the agent's professional development and a criterion for the selection of new staff.

Minnesota focused on three categories: youth development, educational design, and volunteerism. Youth development would focus on understanding the complex process through which youth grow and develop with special emphasis on adolescence. Educational design agents would become methodology experts. They focus on instructional strategies, learning theory, and program design, with special emphasis on experiential learning methods and models. Volunteerism agents would become specialized in the theory and practice of volunteer development and management. 
The initial challenge in Minnesota has been building the competencies of specialized agents so they feel they really have a special area of expertise to offer. The specialization system expects agents to function as teams, pooling their specialized knowledge to address specific programmatic needs. In Minnesota, agents could only attend training in their own area of specialization. It is not realistic to expect everyone to know everything. This has been somewhat disconcerting for agents who prefer to take part in all training or for those who like to stay up on everything (Hutchins, 1990). One of the goals of the staffing plan is that no agent will have primary responsibilities for more than one program area. However, an agent may choose to specialize in community and natural resources development (Minnesota Extension Service, 1987).

Hutchins (1992) reviewed the performance of county clustering in Minnesota. Clustering has been in existence in Minnesota since 1987. It was introduced as a way to improve the Minnesota Extension Service capacity to do issues-based programming. Clustering has been accompanied by the implementation of agent Specialization. Specialization increases the expertise of individual agents, and county clustering brings 
these agents together in multi-county teams to apply their collective expertise to regional problems. Agents continue to be based in county offices and still spend the majority of their time on county programs and problems, but up to 258 of their work is done for the cluster.

The introduction of clustering was received in different ways by the Minnesota staff. Feelings ranged from excitement to anxiety and apathy. Agents found specialization an attractive component of clustering. Agents liked being able to focus more of their energy in a single area and to be viewed throughout the cluster as a teacher and a resource in a specialized field. However, other agents were anxious about the plan. They saw increased demands on their time. Agents would spend up to 258 of their time working on cluster programs, yet there was no indication of a corresponding reduction in county work. Some staff believed local priorities were of primary concern, and the distraction of clustering would keep them from addressing these priorities. Overall, agents have enjoyed the specialized staff development they have received and feel they are better trained today as a result. 
In the state of Indiana, the trend is also toward more specialization. In phase $I$, of the Purdue University Cooperative Extension Service (1991) it was proposed that agricultural extension agents become more specialized and less of an agricultural generalist. The rational is based on the fast pace of developments in modern-day agriculture, which may very well prevent generalists from keeping current in all fields. Miller and Rockwell (1987) examined the changing Extension pattern in Nebraska. The Nebraska Cooperative Extension Service developed a reorganization plan that included multi-county clusters in order to meet clientele needs through more specialized agents assistance. A budget shortfall in 1986 also contributed to the development of the plan.

Once the clusters were in place, a second effort was launched in the identification of priority initiatives for the University of Nebraska. Eight Task Forces were established that eventually resulted in six priority initiatives with 20 sub-components identified under the six priority initiatives. That led to an increase in agent specialization with 608 of agents time spent in issues programming.

In South Dakota, a clustered staffing plan went into effect on July 1, 1986. A total of 21 clusters of two 
to four counties each, plus three one county units were established. Cluster counties were asked to meet to formally develop the clustering concept. Once the program priority needs were identified, the Extension agents were asked to specialize in one primary and one secondary area. State specialist's roles focused on training agents and preparing teaching materials with a reduction in county and area teaching assignments. A unique outcome of the South Dakota clustered staffing project was the appropriation of over $\$ 8$ millions from the state legislature to purchase new equipment to facilitate the implementation of the cluster plan. Microcomputers were installed in each county Extension office and were provided for every specialist and administrative staff members. Video cassette recorder units, monitors and production equipment were also placed in each county (South Dakota Extension Service, $1985)$.

In the $1980^{\prime} \mathrm{s}$ Great Britain, felt that farmer's needs were changing. Many farmers wanted in-depth, specific and detailed advice when they needed it. Often, ADAS (Agricultural Development and Advisory service) could not provide this type of service as they had to "sprinkle" themselves across the whole industry. This was already leading to a growth in private 
agricultural consultants (White, 1991). Thus, privatization was a response to the specialization of farmers. Additionally, recent changes in technology have resulted in specialization and intensification of farm production systems. These systems are based in the use of capital, increase mechanization, and, purchase of inputs.

Gelber (1985) highlights the impact of a specialist's changing role in Extension in the U.S.A. For that purpose; a national survey was conducted to document perceived changes in the role of the Extension Horticulture in 1983.

The instrument was mailed to 501 individuals who had either a full or partial appointment as state Cooperative Extension Horticulture specialist. A total of 301 questionnaires were returned and 288 were usable. As state specialists become more active in research programs and reduced their clientele visits, county staff may need more than ever to increase their specialization level so they can be more effectively dealing with individual growers and related agribusiness.

The question then arises about the ability of county staff in general to satisfy the needs of specialized industries such as commercial horticultural crop 
production. Some county staff are perceived as being fully qualified to serve specialized industries. Most specialists ( 738 ) indicated that the number of qualified county staff was inadequate to fulfill the needs of specialized industries.

Further, while 688 reported that an active training program for county staff exists, 638 indicated that the training was not adequate. More well trained county or multi-county Extension workers are needed in most states if Extension is going to continue to solve the needs of horticulture industries.

If neither specialists nor county staff are available for individualized problem solving, paid consultants may become a major resource for growers who can afford the service. Therefore, in order for Extension to remain relevant to the needs of their clientele, training in the subject matter area needs to be improved. Due to the rising demand of the clientele, specialization of the Extension agent needs to be sought.

Fitzsimmons (1989) provides a discussion of the future of Extension. She visualizes the local specialization scenario as very feasible. Under that system, state staff work within program area boundaries and may work on more than one priority at a time. 
Frequently, county staff carry responsibilities for more than one program area and are being hired with a narrow area of specialization that intersects two program areas. At the local level, county staff share their expertise across county lines and become specialized.

Thompson and Gwynn (1989) found that about 328 of the agricultural Deans expressed the need for more specialization and fewer generalists, in order to upgrade subject matter competency. This feeling was consistent in each of the four agricultural regions in the U.S.A. The opinion of a Dean at a large north region may very well reflects a general trend among the agricultural Deans in the U.S.A.

"We have already carried out major restructuring and refocusing of the Cooperative Extension. We have clustered counties together so agents can be more specialized. We are putting more people out as area specialists with Ph.D. We found that regular county Extension agents can no longer cope with the high technological nature of farm problems." This view clearly supports the concept of agent specialization. Some Deans also expressed concern with the valuable time University researchers were spending providing 
technical advice to farmers that generalists were not able to provide.

Issues programming may aggravate the problem of Extension's already weak link to campus based research. A solution must include balance between rapid-response, relevance and a strong research foundation in Extension programming.

Krueger (1989) identified several features about the dynamic nature of issues:

1) Some people are able to identify the issue earlier than others.

2) The problem may not show up in needs assessment instruments until peak or past peak.

3) Administrators of organizations and elected officials may not provide support until the concern reaches the peak.

Boyle (1989) provides a discussion of the change in the Extension System. He states that due to the unprecedented changes that our society is facing nowadays, CES should respond to that change. Boyle said addressing issues changed the Extension approach to programing because it is based on external needs assessment rather than beginning with the limitations of existing program areas. Thus, issues programing 
will enable Extension to demonstrate that the Cooperative Extension System has indeed changed.

Web (1989) stated that Extension will continue to focus on agriculture and natural resource issues with vigor. However, it is imperative to look beyond agriculture to social and human issues that concern a larger proportion of the clientele. New human and capital resources will be required to meet this expanded commitment. According to Web, society will not change until Extension is able to meet its needs. If Extension does not change to meet emerging needs, then society will look elsewhere to get those needs met. Therefore, the Cooperative Extension Service cannot be bound by tradition.

Decker, Noble, and Call (1989) stated that Extension staff need to become better evaluators of program impacts on people, starting with critical analysis of theoretical framework, including assessment of implementation, appropriateness, and ultimately measuring impact. Thus, it is possible to learn a great deal about what should be changed and how to change. However, Decker, Noble and Call pointed out that some aspects of CES are not broken, so they do not need fixing. They state that most of the needed change in Extension is not in the philosophy, but in the 
operational aspect. One example could be manifested in the involvement of local people in identifying Extension and Research priorities, and also if educational programming should be based on research of the Land-Grant Universities and U.S.D.A

Hutchins (1990) addressed the issue of change in the Minnesota Extension Service. Hutchins describes the implementation process in three clusters over a threeyear period. For data collection, Hutchins interviewed 15 county agents who had actively participated in the implementation efforts. Cross-case analysis showed the importance of leadership to implementation. Progress depended on whether or not there was an Extension manager actively involved with the staff providing information, clarifying expectations, helping the group interpret the organizational vision, and providing feedback to them. The agent's willingness to try out the innovation even in limited ways was also found to contribute to the implementation. The study presents three cases, 1) the value of on-site management, 2) monitoring a support for the staff engaged in implementation, and 3) the importance of individual workers steeping forward and being engaged in innovation are illustrated. 
Dalgaard (1987) examined the involvement of local citizens in organizational change and program planning and also the way learners are empowered through shared leadership. Dalgaard found that the leadership training provided by the Minnesota Extension Service has had a significant effect on the state's Extension program. The program provided training in needed knowledge and skills, opportunities for significant leadership roles, and reinforcement and recognition for assuming leadership. The objective of the program was to educate adults for Extension education and leadership.

In some counties, the comunity members who have joined county committees were urging the professional staff to accept the concept of clustering county committees into groups and to take a more cooperative approach. It was also believed that citizen participation has been an important factor in the Extension's program movement from University subject matter emphasis to an issue emphasis. The leadership training, although designed to make adults assume a more active role within Extension, has also appeared to encourage many program participants to become more involved in other community activities as well.' 
Conklin (1990) addressed the issue of perspectives on issues programming in the Ohio Cooperative Extension Service. Faculty attitude, knowledge, importance to professional role, and ability to implement were examined in relation to six characteristic variables: 1) tenure, 2) program area assignment, 3) prior training, 4) prior employment in an educational field, 5) professional role, and 6) academic major of highest degree attained.

Using stepwise regression, training and program area assignment were found to have low, positive associations with attitude towards issues programming. The overall attitude of Extension faculty toward issues programming was neutral. Though the area was perceived as important, knowledge and ability to implement issues programming were not rated very high. Training needs identified included resource identification, evaluation, and audience identification. The findings supported the need for additional research to measure knowledge about issues programming and to study effectiveness of in-service training methods dealing with issues programming.

King (1990) examined the attitudes of Extension faculty and staff regarding the clustered staffing pattern in Ohio. The study also examined the 
association between the perceptions of population members regarding three staffing pattern options and their attitudes toward clustering. strong correlation was found between agent specialization success and clustering success, which indicates that the OCES faculty and staff perceive these staffing patterns in a similar fashion. The major concern of OCES personnel was the negative effects that clustered staffing might produce between Extension and county funding sources.

King recommends that OCES personnel who have had favorable experiences with agent specialization should be utilized to promote clustered staffing throughout the organization because of the perceived similarities between the two concepts. Thus, the OCES faculty and staff perceived these concepts in a similar fashion.

Godke (1991) examined the attitudes of county Extension advisory committee members regarding the clustered staffing pattern in Ohio. The findings indicates that the majority of the county Extension advisory committee members participating in the study felt that a negative effect on funding would result with the clustered staffing pattern. No difference in the funding was seen with clustered staffing by 63 of the committee members. Questions were raised by 55 committee members without indicating a positive or 
negative effect of clustered staffing on funding from local sources. Another finding was that committee members have requested further information regarding the formation of clusters.

The major repercussion of these findings were the major categories of concern. Personnel, funding, and perceived loss of program quality must be addressed by Extension administration at all levels within the organization if clustered staffing is to be successfully conducted in Extension. Thus, the audiences of professional staff at all levels, county Extension advisory committee members, and county commissioners must be the primary focus of information regarding the philosophical and logistical features of new staffing patterns.

Osborne (1991) conducted a study to investigate the perception of advisory committee members regarding the delivery of quality programs for two staffing patterns of the OCES. He found that advisory committee members level of satisfaction with the staffing pattern in their county was basically unaffected by the type of staffing pattern present in their county. Osborne recommends that the agent's and advisory committee members'level of satisfaction should be investigated 
further. This can be accomplished with additional statistical manipulation of the current data set.

Little (1992) addressed the issue of "Perspectives on cluster units in the Ohio Cooperative Extension Service". For the study, Little conducted separate focus interviews of agents and associate agents, done in two $11 / 2$ hour sessions on the same day with participants being from the same cluster unit. Faculty and staff working in 10 clusters functioning throughout the state were interviewed.

Some of the findings were:

1) To provide cluster agents access to specialized inservice training.

2) Administrators should reevaluate the usefulness of the multi-county staffing positions, particularly when these agents are involved in clustering.

3) Involve and sell the clustering concept to county Extension support staff and secretaries. The clustering concept will experience great difficulties if staff do not support and understand clustering. 4) Form cluster advisory committees to help agents determine programming priorities.

5) Be conscious of county financial support and demonstrate the fulfillment of county clientele needs. 
6) Provide assistance to clusters so that they may develop inter-disciplinary issues programming.

Tondl (1991) investigated the climate for change, through the following four factors of change, in Nebraska: 1) need for change, 2) openness to change, 3) potential for change 4) participation in change. Tondl found that administrators were more positive toward change than board members. The board members were concerned about the changes occurring in the Nebraska Extension Service because the move toward multi-county program units might decrease the county's control.

Krueger (1989) conducted a study to evaluate changes in the Minnesota Extension Service regarding the perceptions of commissioners, Extension committee members and agents. The purpose of the study was to gather opinions regarding program and staff quality, clustering, agent specialization, and issues programing development of the Minnesota Extension Service. To collect the data, a time series survey was mailed to 131 people representing the subjects of the study. The survey was sent out three times at six month intervals, starting in February 1988 and ending in February 1989. The results indicated that perceptions of program and staff quality increased over the course 
of the study. The improvement can be attributed in part to staffing changes that occurred during that time.

All respondents indicated that they were familiar with the concept of clustering. The respondents cited travel as the greatest weakness of clustering, and the sharing of expertise as its greatest strength. Agent specialization was thought to be a somewhat to very important development within Extension. All groups of respondents felt agents were competent in their area of specialization, and that their competency levels had remained the same or improved during the study. Respondents were favorable toward issues programming. During the course of the study, the commissioners became more favorable. Agents and Extension committee members changed very little. Written comments indicated that both issues programming and the traditional programs were very well regarded because they related to local needs.

In a research study conducted by Tondl (1989) the issue of the perception of climate for change in the work place was addressed. The study included the opinion of Extension agents, administrators, and board members. The climate for change survey, developed by the researcher, was used to measure climate for change. A 63 statement survey was mailed and returned by 153 
agents, 12 administrators and 237 board members. The statistical analysis used to interpret the data was a multivariate. Tondl recommends a replication of this study in another state where Extension staff is going through organizational change.

Buford (1988) provides a discussion of the nature of organizational change. Buford stated that change is a universal aspect of all organizations. To be effective, an Extension Service must apply the knowledge gained from its experiences to future conditions. While change often present threats to the future, it does frequently offer an unprecedented opportunity for growth.

It is ultimately the responsibility of the Extension manager to create a structure capable of remaining current and viable, and to introduce change in a manner consistent with objectives.

Brown (1989) addressed the issue of the mission of Extension. According to Brown, Extension must either relocate its present resources or face extinction. Some formerly supportive clientele have been criticizing Extension for becoming unresponsive and even irrelevant, failing to change and adapt to a rapidly changing world. Brown stated that Extension 
must serve in some new areas. The objective is" to provide adequate services to many potential audiences.

The Futures Task Force recommendations are examined in an article by Geasler (1989). According to Geasler, each state and local office must move proactively toward the future. Geasler stated that the system of Extension has moved toward issues programing quite effectively. However, progress in flexibility of staffing and funding is more difficult. If issues truly drive the system, then staffing flexibility is a must.

Another concern about staffing is the availability of the resources of the total University to address the issues identified by Extension programming. Deshler (1989) visualizes Extension as a catalyst in bringing together critical elements to address major social, economic, and political issues. Back in 1966, York anticipated that for Extension to deal with the broad problems of agriculture and rural America, the agency will require more resources in addition to those found in the colleges of Agriculture and Home Economics. Specialized assistance will be needed from business management, political science, law, industrial. management, various fields of engineering, the social and behavioral sciences, and many other areas. This is 
in addition to the subject-matter competencies normally found in Colleges of Agriculture and Home Economics. The need for assistance from these other disciplines is a reflection of the tremendous complex and interdependent nature of society. If an organization such as the Cooperative Extension Service is concerned with the problems and forces at play in any given area, it must have available extremely broad resources as knowledge base.

Need of In-service Education in Organizational Change

Kaufman (1985) defines needs as "gaps in results, not gaps in wants." Needs assessment involves "identifying and justifying gaps in results, and prioritizing the gaps for attention." The National Task force on In-service training identified nine major areas in which Extension agents needed competencies (1957). These major areas were 1)program planning and development, 2) effective thinking, 3) communication, 4) technical knowledge, 5) human development, 6) research and evaluation, 7) the educational process, 8) understanding social systems, and 9) Extension organization and administration.

Although most researchers based their studies on the nine areas identified by the task force in 1957, survey 
instruments and items under the major categories varied according to the objectives of the researchers.

McCormick (1959) developed a questionnaire based on the above nine areas of competencies and analyzed the needs of county Extension agents in Ohio. He concluded that most agents had bachelor's degree in home economics education and agricultural education. The majority (80\%) perceived their role as an educator. The rank order of the nine areas of competencies for which Ohio agents indicated they needed training were: 1) program planning and development, 2) effective thinking, 3) communication, 4) technical knowledge, 5) human development, 6) research and evaluation 7) the educational process, 8) understanding social systems, and 9) Extension organization and administration. A low correlation was found between areas in which agents indicated a need for training and the areas in which they indicated they planned to pursue graduate work or request in-service training.

As an effective way to improve training and to keep current in subject matter (Bjorklund, Fremeyer 1985) consider Teleconferencing. This educational approach was successfully used with Missouri Extension Home Economics. County-based home economics have received subject matter updates and food and nutrition 
specialists have been able to keep current through Teleconferencing. The follow-up evaluations and costs analysis have indicated that using Teleconferencing is both efficient and effective.

Smith (1983) examined the value of in-service training on Extension agents. The beliefs were that in-service training makes a difference or that there was a significant change in the Extension agents after in-service training. In order to test this belief, cognitive changes were examined (Knowledge acquisition) of agents attending an evaluation workshop compared to those who did not attend. The conclusion was that in at least the cognitive (knowledge) area, a significant change had taken place. Agents who attended the evaluation workshop had significantly greater knowledge in the area of evaluation than did agents who did not attend.

Agnew and Foster (1991) examined the trends in delivering Extension programs and the staffing of field-based positions throughout the United States. The objective was to achieve a more effective inservice education to address the needs. The subjects of the study were the 50 State Extension Directors. Data analysis included the use of descriptive statistics. Agnew and Foster found that 
Telecommunications as a mode of delivering information will continue to increase in importance as the related technologies are made available.

Some respondents expect county agents to specialize in one or more areas and others will assist with areas they are lacking. Some respondents are expecting a move toward hiring temporary personnel for specific issues related, short term programs, projects, to increase flexibility in staffing.

The most common degrees held among Agricultural agents were animal science and agronomy, with agricultural education following a close third. The most important criteria used to evaluate field-based faculty for employment in order of importance were: level of degree, human relation skills, knowledge of subject matter, area in which degree is earned, and personal references.

Brooks (1983) assessed the in-service needs of Florida County agents as perceived by the agent and the state Extension administrator and specialists. He found a moderate (.58) correlation between Florida County agent's perception and state staff perception of the degree of importance for the nine major areas of training. A high correlation (.83) was found between county and state staff perception of the degree of 
competence for the nine major areas. An analysis of variance showed that technical knowledge in program areas differed with area of employment, academic level, academic major in the last degree earned and rank.

The needs assessment model (Borish, 1980) was used in follow-up studies in education by designing a survey instrument to obtain from the users, the type and quality of data to collect. The questionnaire is designed so that respondents provide data in a form that can be weighed and prioritized, responses are then used for program improvement. In order to increase the validity of the studies, Walter and Haskell (1988) use a modified Borish needs assessment model. The rankings of perceived training needs have been substantively different from that obtained using more traditional needs assessment methods. The Borish Model was used by Shiban (1983), Bowen (1988), Nieto (1989) Rodriguez, (1989) Conklin (1990) and Rach (1992). The Borish model increases the validity of a needs assessment study by gathering three times as much data as the traditional methods. The traditional needs assessment method ask "what skills the individual needs," while the Borish approach follows up this question with "what skills do you possess?, and "how important are the competencies to you?". The validity 
of an instrument is increased by increasing the number of questions and the Borish method actuallys triples the number of questions asked.

\section{Summary of Iiterature Review}

Agent specialization was implemented in Ohio on January 1991. This new system allows county Extension agents to select at least one broad area of specialization, which must be consistence with agent's own preferences and local needs. After approximately two years since agent specialization was first implemented in Ohio, now is the right moment to get input from county Extension agents who are participating in the new approach, regarding their attitudes toward agent specialization. Several studies addressed the trend toward agent specialization. Agent specialization is compatible with other staffing patterns (traditional, clustered, multi-county) because county Extension agents will provide leadership and teach in their area of expertise inside and outside their counties. However, the trend is to increase agent specialization under the clustered system, since this staffing pattern allows agents the opportunity to specialize in areas of interest that are needed within two or more counties. Several recent studies addressed the variable attitudes regarding clustered staffing 
pattern. King, (1991) found a strong correlation between agent specialization success and clustering success. Other studies compared the variable attitudes toward different staffing patterns. Some studies have found different levels of correlation between attitudes toward a given issue, and some demographic characteristics of the population under study. Another related concept to agent specialization is Issues Programming, which has been addressed in several studies. The knowledge of issue programming is essential for understanding agent specialization, since it is suggested that Extension work with local groups to identify priority needs. Therefore, issue programming will be very useful in identifying areas of specialization needed for a changing population.

Agent specialization is a new concept for Extension in Ohio. For that reason, the literature review included several studies where the major objective was helping organizations and individuals adjust to change. The present study is also intended to increase the level of understanding of county Extension agents toward agent specialization, which according to several studies, will be very helpful in coping with change.

In agent specialization, continuous training is fundamental for the county Extension agents to keep 
up-to-date in the chosen specialty area. Several studies on in-service training were based on McCormick's (1959) study in which nine areas were identified:1) Program planning and development, 2 ) effective thinking, 3) communication, 4) technical knowledge, 5) human development, 6) research and evaluation, 7) the educational process, 8) understanding social systems, and 9) Extension organization and administration. Several studies focus on training needs of specific groups of agents. In order to identify needs, knowledge of needs assessment is essential. Need assessment involves "identifying and justifying gaps in results and prioritizing the gaps for attention." Therefore, need for training, as well as training preferences of county Extension agents participating in agent specialization, are critical for improvement of agent specialization. Several studies addressed the educational needs of different populations. The Borish model increased the validity of the study and was used by several researchers for the purpose mentioned. 
CHAPTER III

METHODOLOGY

The purpose of this study was to determine the attitudes of Extension agents toward agent specialization in Ohio. Population

The target population for this study was county agents in the Ohio State University Extension who are participating in agent specialization. The population included all county Extension agents in ohio participating in agent specialization, so sampling was not necessary. An accessible population of 285 county Extension agents was included in the study. A list of agent names, addresses and position description prepared by the State Extension office was used to identify the population of county Extension agents in Ohio. A cross check of the mailing list was conducted using the February 1992 issue of the Personnel Directory of Ohio State University Extension. 
Discrepancies between the mailing list and the directory were clarified by clerical personnel in the office of the Associate Director of Extension. All county Extension agents in ohio with at least six months of experience in agent specialization were chosen to participate in the study.

The researcher used a census, which according to Isaac and Michael (1990) involves no sampling error, greater reliability, and eliminates the use of. inferential statistics or statistical tests applied to the data in order to make inferences beyond the population studied. Isaac and Michael also said that whenever practical, especially if a survey touches on controversial matters or will lead to an important decision or conclusion, it is well to include all possible respondents. For this particular study, the results were very important and the conclusions were critical for Ohio State University Extension. Additionally, the target population was easily accessible. Therefore, the researcher decided to use a census of all county Extension agents who were participating in agent specialization in Ohio. 
Regearch Design

A descriptive-correlational design was used to accomplish the objectives of this study. Non-Respondents

Comparisons of early to late respondents was carried out to control for non-response. According to Miller and Smith (1983), comparing early to late respondents is one way to estimate the nature of the replies of non-respondents through late respondents, since research has shown that late respondents are often similar to non-respondents. Late respondents are statistically compared to early respondents using the evaluation data to justify generalizing from the respondents to the sample. If data on the characteristics are unavailable, available evaluation data can be used with this technique. Respondents can be dichotomized into those that respond early and those that respond late. These two groups can be compared statistically to determine differences between the groups. With late respondents assumed typical of nonrespondents, if no differences are found, then respondents are generalized to the sample. If differences are present, data are weighted proportionately for determining the statistics to describe the sample. 


\section{Instrumentation}

A questionnaire was designed by the investigator through a literature review for the purpose of collecting the necessary data from the respondents. The instrument consisted of 52 items on the content and objectives of agent specialization. The instrument had fixed questions, sequence, and wording. The length of time to complete each questionnaire was estimated to be approximately 20 minutes.

The questionnaire contained four parts:

Part I: Attitudes toward agent specialization. The attitudinal section of the instrument utilized a 4point Iikert scale for rating attitude from (1) strongly negative to (4) strongly positive. The rating scale for attitudes ranged from a low of 1 to a high of 4: 1-Strongly Disagree; 2;-Disagree; 3-Agree; and 4Strongly Agree. Participants ratings were summated and averaged to determine an individual attitudinal rating. Findings were reported as mean attitudinal ratings. Mean ratings of 1 to 1.5 were described as strongly Disagree, 1.5 to 2.5 as Disagree, 2.5 to 3.5 as Agree, and 3.5 to 4 as Strongly Agree. This section contained six negative worded items, which were reversed coded in order to accurately reflect the attitudes of respondents. Three open-ended questions were also 
included in this section. The open-ended questions were grouped according to the greatest amount of time respondents spent in the Extension program area of 4-H, agriculture, home economics, community and natural resources development, or other. Responses to the open-ended questions were sumarized and analyzed by the researcher.

Part II: Contained a variety of educational needs for the county agents as they pursue agent specialization. This part consisted of three scales, which were designed to measure the agents' perception of the importance of selected agent specialization competencies, the knowledge they possess, and their abilities to perform on selected agent specialization competencies. The format used in this section of the questionnaire was based on the Borish Model of Needs Assessment (Borish, 1980). 
Part III: measured preferences of respondents regarding types of training for agent specialization. A ranking scale from 1-10 was provided, with 1 being the most preferred training, and 10 being the least preferred. Two additional suggestions for types of training were also included. Questions on the personal and organizational characteristics of the respondents were in Part IV.

\section{Conceptual Schema}

Upon completing the review of literature, the variables set of personal characteristics, organizational characteristics, and training were identified as factors affecting the attitudes toward change within an organization. As shown in Figure 1 on page 70," attitudes toward agent specialization was conceptualized as being dependent upon personal characteristics, organizational characteristics, and training. 
Independent Variables

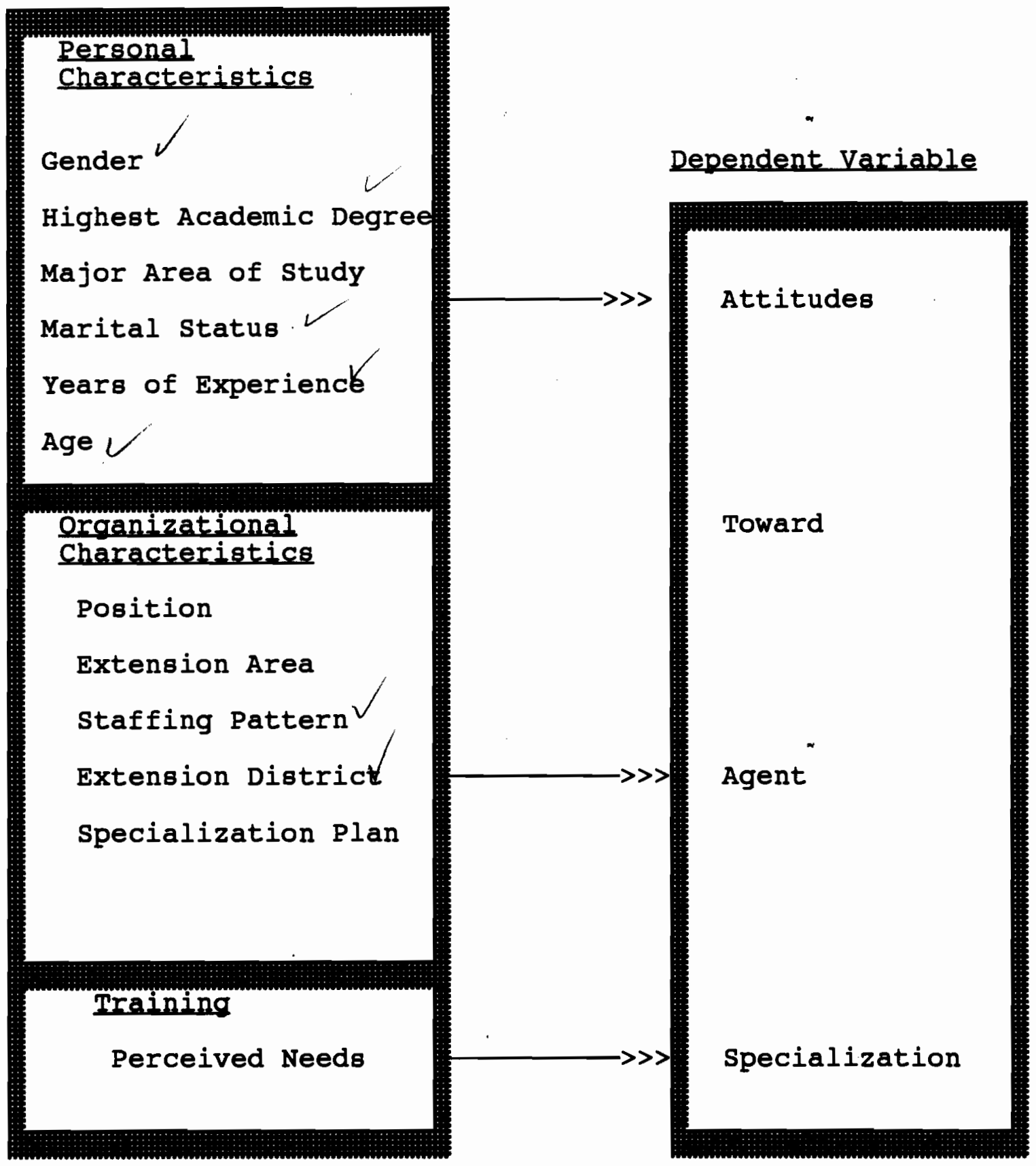

Figure 1

CONCEPTUAI SCHEMA Showing the Relationship Between selected Variables and the Dependent Variable 


\section{External Validity}

A major concern in the outcome measures of survey research refers to the degree to which results of a study can be generalized beyond the sample. Frame error was controlled in this study because a complete up-to-date listing of all county agents in ohio was obtained.

Sampling Error. Threat to external validity that can result when inappropriate sampling procedures are utilized in selecting a sample. Sampling error was controlled in the study with a census.

Selection Error. Selection error takes place in survey research when some members of the population have a greater chance of being selected into the sample than other members of the population. Selection error was controlled in the study by checking the list of county Extension agents against any possible duplication.

Non-Response-Error. This Involves subjects selected from the sample who do not cooperate or who cannot be located. Non-respondents can vary significantly from respondents on major variables of interest to the researcher. Non-response error was controlled in the study by comparing the early respondents to those of late respondents (Miller and Smith, 1983). The initial 
deadline of January 22, 1993 was utilized to divide respondents into two (early and late) groups. Differences between early and late respondents on the dependent variable selected for the study were examined through the use of a T-test. An alpha level of .05 was established the level of significance.

Data Collection. Data were collected by a mail questionnaire which were sent to all the county agents who were participating in agent specialization in ohio ( $N=285)$. A questionnaire was mailed on January 7, 1992 to each agent in the population selected for inclusion in the study. A cover letter signed by Dr. Keith Smith, Extension Director in Ohio, explaining the study was also included. A small incentive (a pen and a logo) was included with each questionnaire to encourage response, and, a stamped- self addressed envelope was enclosed for return of the survey. Additionally, a memo from the Extension Director was sent to all agents by the Electronic Mail Network two days before the mailing of the instrument. A tentative deadline of January 22, 1993 was established as the termination date for the return of all questionnaires. Ten days after the original mailing, 182 out of the 285 agents had responded with usable questionnaires. Two weeks after the original mailing date, a reminder 
postcard was sent to the non-respondents asking them to return the questionnaires. Those who had not responded by February 3, 1993 received a second complete packet with a new cover letter. A final established deadline date of February 17, 1993 was set and by then, a total of 268 agents had responded, representing a 94.8 rate of return. No additional contacts were made at that time since several surveys had been sent to the same population by other researchers. Data collection ended February 17, 1993. Two surveys were returned with notes that agents did not know anything about agent specialization; three additional surveys did not contain Part III, making statistical analysis of some of the data meaningless. Two surveys were returned with notes that the Extensionists had left Extension prior to the study. Two hundred sixty- one surveys were considered valid responses, representing 91.68 of the surveys mailed. Two questionnaires were received after the close of the data collection period, and were not included in the data analysis.

Permission to collect data from Extension faculty was obtained from the following sources:

1) Ohio State University Extension Administrative review. The Ohio State University Extension Director and the Acting Associate Director reserve the right to 
review any proposed research involving Extension personnel. Their permission was sought and signatures obtained on the letter accompanying the survey instrument. Modifications were made in the research proposals as recommended by these reviews.

2) Approval from Human Subjects Review Committee was not required in this study, since the population studied was composed exclusively of Extension personnel, and therefore, participants were assured of the confidentiality of the information they shared. When participants perceive that their responses will remain confidential, it decreases the threat to validity associated with socially desirable responses (Mueller, 1986).

Content validity of the instrument was determined by a panel of experts. The panel was composed of agricultural education faculty at The ohio State University, Extension administrators in the state of Ohio, and selected graduate students at The Ohio State University. The panel of experts were asked to evaluate the instrument by checking the content, structure, clarity, length, format, and wording of the instrument in order to make the instrument free from irrelevant factors to the purpose of the study. 
The panel was asked to evaluate the instrument by making comments and/or suggestions as to its simplicity, clarity, content, relevance, and appropriateness. A decision was made a priori to delete or modify any item identified as inappropriate or unclear by two or more members of the panel. Panel members also suggested items for addition and deletion. Based on faculty review and suggestions from the panel of experts, items that did not have a direct bearing on the study, were removed from the instrument.

A pilot test was Iun for determining the reliability of the instrument. The pilot test involved 25 county agents in the state of Minnesota. The cover letter for the pilot test told respondents they were part of a study examining the perceptions toward agent specialization. To determine the internal consistency coefficients of the different areas of the instrument, Cronbach's alpha model was used for both the attitude scale and training needs scales. Nunally (1967) indicated that reliability of .50 to .60 would suffice for predictor tests in early stages of research: The Cronbach's alpha reliability coefficient for the attitudinal section of the instrument was .75 and for the scales of perceived needs for training were .83, .84 and .80 for importance, knowledge and ability, 
respectively. The data on instrument reliability are summarized in Table 1 . An overall reliability coefficient of .90 was calculated for the instrument (Table 1). Each section of the questionnaire and the overall questionnaire were judged to be reliable.

Table 1

Summary of Internal Realiability of Instrument

Summary of Internal Reliability of Instrument

\begin{tabular}{|c|c|c|c|}
\hline $\begin{array}{l}\text { Number } \\
\text { Items }\end{array}$ & r of & $\begin{array}{l}\text { Number of } \\
\text { Cases }\end{array}$ & $\begin{array}{l}\text { Cronbach's } \\
\text { Alpha } \\
\text { Reliability } \\
\text { Coefficient }\end{array}$ \\
\hline $\begin{array}{l}\text { Attitude toward } \\
\text { Agent Specialization }\end{array}$ & 12 & 25 & .75 \\
\hline $\begin{array}{l}\text { Perceived Needs } \\
\text { For Training } \\
\text { (Importance) }\end{array}$ & 14 & 25 & .83 \\
\hline $\begin{array}{l}\text { Perceived Needs } \\
\text { For training } \\
\text { (Knowledge) }\end{array}$ & 14 & 25 & .84 \\
\hline $\begin{array}{l}\text { Perceived Needs } \\
\text { For training } \\
\text { (Ability) }\end{array}$ & 14 & 25 & .80 \\
\hline
\end{tabular}


Table I (continued)

Overall Reliability

$\begin{array}{ccc}\text { Number of } & \text { Number of } & \text { Cronbach's } \\ \text { Items } & \text { Cases } & \text { Alpha } \\ & & \text { Reliability } \\ & & \text { Coefficient }\end{array}$

Overall

54

25

90

Reliability

\section{Data Analysis}

All variables were defined and coded in order to analyze the data generated for the study. Data were coded onto floppy disk using the Microsoft Word word processing program as the questionnaires were received. The Minitab computer package was used to analyze the data. Descriptive statistics and correlational techniques were used to satisfy the objectives of the study. The techniques that were used to analyze each objective follow:

1. Describe the agents with regard to selected personal characteristics including: age, gender, marital status, years of experience, highest academic degree and major area of study.

* frequencies

* mean, media,

* standard deviation 
2. Describe the agents with regard to selected organizational characteristics including: position, Extension program area, staffing pattern, Extension district and specialization plan.

* frequencies

* percents

3. Determine the attitude of county Extension agents toward agent specialization.

* mean, media,

* standard deviation

* qualitative analysis- 3 open ended questions * $t$ test and analysis of variance

4. To describe the perceptions of county Extension agents about the importance, knowledge, and ability to perform on selected agent specialization competencies. * rank order of areas according to mean scores * Standard deviations

5. To determine the perceptions of training needs of county Extension agents regarding specific concepts of agent specialization.

* Rank order of areas according to mean scores

* Standard deviations 
6. To rank the training preferences of county Extension agents.

* Rank order of areas according to mean scores

* Standard deviations

7. To determine the extent to which attitudes toward specialization is associated with personal factors, including: age, gender, marital status, length of service, highest academic degree, type of educational degree, organizational factors including: position, county chair, Extension program area, staffing pattern, Extension district and specialization plan, and the perceived training needs of county Extension agents, which include knowledge, and ability to perform.

* Correlational statistics

Cronbach's alpha was used for estimating the reliability coefficient for the Likert-type scale of the instrument, which was established at 0.90 .

Needs assessment studies in the past have used the direct or traditional approach to measure people's perceptions about the importance of educational program needs. The direct approach asks respondents to rate an 
item based upon their perception of its importance. Borish (1980) developed an indirect approach to measure people's perceptions of their educational needs. The indirect approach asks the respondents to rate an item based upon their perceptions of its importance and in addition asks the respondents about their current knowledge on the item. Additionally, the Borish model also provides the option to add a third component, ability to produce Extensionists learning.

The Borish model provides a systematic way to collect, analyze, and interpret survey data. The data collected can be used to assess program effectiveness or to develop an in-service training program.

A training need is defined as the discrepancy between an educational goal and the individual's performance in relation to the goal (Borish, 1980). A training need is identified as the discrepancy between "what is and what should be." The discrepancies can be ranked for priority by statistical techniques for weighing relative importance of values assigned to survey responses. Priority ranking also can be determined by a panel of trainers with expertise in the area of concern. A framework for program revisions is provided by the ranking of the discrepancies of competencies in descending order. The researcher 
utilized the following steps of the Borish model to develop the survey instrument:

Iist competencies. Competency statements related to agent specialization were based upon literature in that area, program objectives of trainers and administrators, in-service teachers/trainers and administrators, research studies and program materials. These competencies were used to construct the survey.

Survey Trainees. The population of trainees was asked to rate the competencies on a) the relevance of each competency to their current job role (or perceived future job function), b) perceived knowledge level of competence, and c) perceived skill in implementing the competence. The format appears as follows in example 1.

\section{EXAMPLE 1}

Competency Item 1

\begin{tabular}{|c|c|c|c|c|c|c|}
\hline \multirow[t]{2}{*}{ Case } & \multicolumn{2}{|c|}{$\begin{array}{l}\text { Perceived } \\
\text { Importance }\end{array}$} & \multicolumn{2}{|c|}{$\begin{array}{l}\text { Know ledge } \\
\text { Competence }\end{array}$} & \multicolumn{2}{|c|}{$\begin{array}{l}\text { Ability to } \\
\text { Perform }\end{array}$} \\
\hline & Low & High & Low & High & Low & High \\
\hline 1 & 123 & 4 & 123 & 4 & 123 & 4 \\
\hline 2 & 123 & 4 & 123 & 4 & 123 & 4 \\
\hline 3 & 123 & 4 & 123 & 4 & 123 & 4 \\
\hline
\end{tabular}

Each competency yields two discrepancy scores for each respondent. The discrepancy scores were used as 
indicators of the effectiveness of a training program in producing training knowledge or trainee performance. A third component, ability to perform the competence, was added. The discrepancy scores were then ranked to provide guidance for in-service education. The researcher utilized the discrepancy scores for knowledge and ability because the shift to agent specialization is a recent development of ohio state University Extension. The Borish model provides a discrepancy score for both importance and ability to perform. Differences were:

1) calculated between the perceived importance and perceived level of knowledge, and

2 ) the perceived importance and perceived ability in implementation. The difference was multiplied by the group mean perceived importance score. The group mean reflected scores of all respondents. Example 2 presents the scoring of the instrument. Example 2 Competency 1

Respondent Importance

Low High

$$
1
$$

2

3
Knowledge

Low High

$\begin{array}{llll}1 & 2 & 3 & 4\end{array}$

$\begin{array}{llll}1 & 2 & 3 & 4\end{array}$

$\begin{array}{llll}1 & 2 & 3 & 4\end{array}$
Ability

Low High

$\begin{array}{llll}1 & 2 & 3 & 4\end{array}$

$\begin{array}{llll}1 & 2 & 3 & 4\end{array}$

$\begin{array}{llll}1 & 2 & 3 & 4\end{array}$

Group importance Mean for competence $1=3.0$ 
Calculation of Knowledge Discrepancy Score

4 (Perceived Importance rating for respondent 1)

-3 (Perceived knowledge rating for respondent 1)

1 (Importance Score for Competency 1)

x3(Mean Importance for group for Competency 1)

3 Knowledge discrepancy score for respondent 1

Calculation of Ability to perform Discrepancy Score

4 (Perceived Importance rating for respondent 1 )

-4 (Perceived Skill for respondent 1)

O(Importance Score for Competency 1)

x3 (mean Importance Score for group for Competency 1)

0(Skill discrepancy score for respondent 1

\section{Rank Competencies.}

Competencies were ranked according to discrepancy scores. Highly positive scores had highest priority for identification of in-service education needs.

Compare In-service program content and high priority competencies.

The ranked competencies were used to suggest the inservice education program content. 
CHAPTER IV

Findings

This chapter includes the presentation and discussion of the findings. Within each section, the findings and discussion are organized according to the objectives of the study. Data pertaining to the characteristics of the population are presented first, followed by. information specific to the objectives in which differences related to those characteristics are examined.

1. Describe the agents with regard to selected personal characteristics including: age, gender, marital status, years of experience, highest academic degree, and major area of study.

\section{Age of Respondents}

Table 2 reports data on the age of the county Extension agents. The mean age of the county Extension agents was 38.61 years with a range from 22 years to 63 years. As Table 2 shows, 24.58 or almost one fourth of the county Extension agents were between 42 and 46 years of age. over four percent were fifty-two years and older, and 8.4\% were between 22 and 26 years old. 
Table 2

Age of County Extension Agents ( $N=261$ )

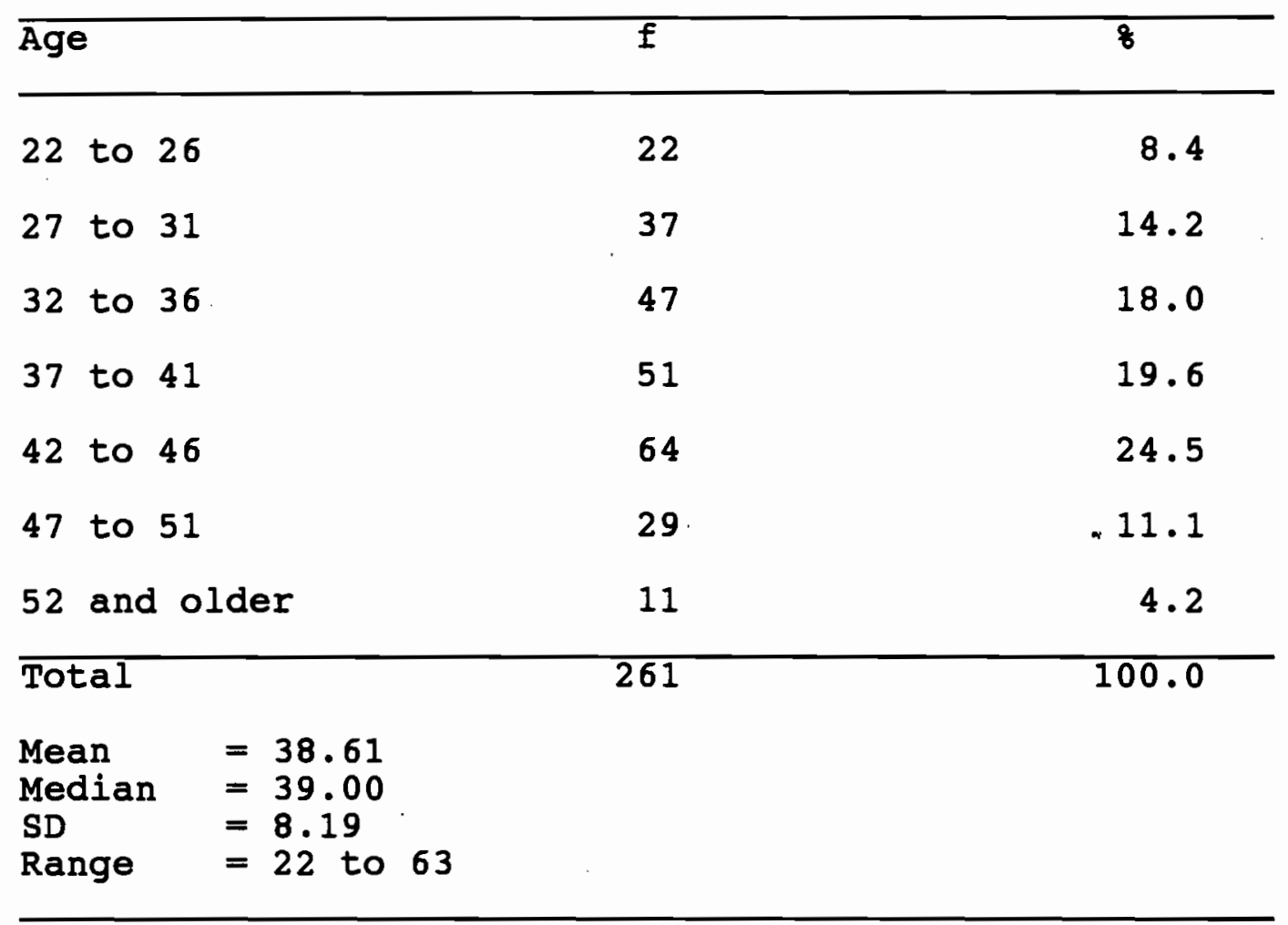

Gender of County Extension Agents.

Table 3 represents findings on the gender of the county Extension agents. As illustrated in this table, 53.78 of the county Extension agents were female and 46.38 were male. 
Table 3

Gender of Respondents

\begin{tabular}{lcc}
\hline Gender & $f$ & 8 \\
\hline Female & 140 & 53.7 \\
Male & 121 & 46.4 \\
\hline Total & 261 & 100.0
\end{tabular}

\section{Marital Status}

Table 4 indicates the marital status of the respondents. The majority or 77.88 of the respondents were married.

Table 4

Marital Status of respondents

\begin{tabular}{lrc}
\hline Marital Status & $f$ & 8 \\
\hline Single & 44 & 16.9 \\
Married & 203 & 77.8 \\
Widowed & 1 & 0.4 \\
Divorced & 13 & 5.0 \\
Total & 261 & 100.0 \\
\hline
\end{tabular}


Years Tenure with ohio state Extension

Table 5 reports data on the years of experience of the county Extension agents. The mean years of tenure with Ohio State Extension was 9.8 years. Respondents were nearly equally distributed among four of seven categories of tenure. The mentioned categories represented employment between 6 and 25 years. Tenure between 1-5 years represented 41,88 of the respondents, whereas tenure of 26 years or more was 1.98 . For coding purposes, county Extension agents with a tenure between 6 months and 1 year, were considered with 1 year of experience and within the group of 1-5 years. Table 5

Tenure with Ohio state Extension

\begin{tabular}{lrc}
\hline Years & $f$ & 8 \\
\hline$x_{1-5}-109$ & 41.8 \\
$6-10$ & 39 & 14.9 \\
$11-15$ & 48 & 18.4 \\
$16-20$ & 42 & 16.1 \\
21 to 25 & 36 & 13.8 \\
26 and more & 5 & 1.9 \\
\hline Total & 261 & 100.0
\end{tabular}
Note. information from top of page 88 
Mean $\quad=9.82$

Median $=7.00$

SD $\quad=7.32$

Range $\quad=0.5$ to 27

NOTE. X Xgents with a tenure between 6 months and 1 year are included in the $1-5$ years category

Highest Academic Degree

Table 6 shows that the majority (72.48) of county

Extension agents held a Master's degree, 25.38 held a Bachelor's degree, and 2.38 had a Doctoral degree.

Table 6

Highest Academic Degree of County Extension Agents

\begin{tabular}{lcc}
\hline Highest Academic Degree & $f$ & 8 \\
\hline Bachelor Degree & 66 & 25.3 \\
Master's Degree & 189 & 72.4 \\
Doctoral Degree & 6 & 2.3 \\
Total & 261 & 100.0 \\
\hline
\end{tabular}

Major Area of Highest Degree Attained

Table 7 reports data concerning the major area of the highest degree attained. A high percentage (44.48) of the county Extension agents held their highest degree in education. The next most prevalent groups held majors in agriculture (21.8\%) and home economics $(20.38)$. 
Table 7

Major Area of Highest Degree Attained by Extension Agents

\begin{tabular}{llll}
\hline Academic Major & $f$ & $*$
\end{tabular}

Administration/Management

Agriculture

21.8

Education

116

44.4

Home Economics

Natural Resources

Social Sciences

Other

2. Describe the agents on selected organizational characteristics including: position, Extension program area, staffing pattern, Extension district and specialization plan.

\section{Position of County Extension Agents}

Table 8 reveals that 29.18 of the respondents were county chairs. The rest, or 70.98 of county Extension agents were non-county chairs. 
Table 8

Position of Respondents ( $N=261$ )

Position

f

8

County Chair

76

29.1

Non-County Chair

185

70.9

Total

261

100.0

Extension Program Area

Findings in Table 9 reveal that 36.48 of the respondents spend the greatest amount of time in the 4-H Extension program. Agriculture and home economics were second and third with 30.38 and 25.78 respectively, and 4.68 percent of the county Extension agents spend the greatest amount of time in Community and Natural Resources Development (CNRD). 
Table 9

Extension Program Area ( $N=261)$

\begin{tabular}{lcc}
\hline Extension Program Area & $f$ & f \\
\hline $4-\mathrm{H}$ & 95 & 36.4 \\
Agriculture & 79 & 30.3 \\
Home Economics & 67 & 25.7 \\
CNRD & 12 & 4.6 \\
Other & 8 & 3.1 \\
Total & 261 & 100.0
\end{tabular}

Other was identified by the respondents as a combination of different program areas

\section{Staffing Pattern}

Table 10 illustrates that conventional staffing

(468) is the most prevalent county staffing pattern in

Ohio, followed by multi-county staffing pattern

$(36.48)$. Only 8.1 of the respondents were working under clustering staffing patterns. 
Table 10

County Staffing Pattern ( $N=261)$

Staffing Pattern

f 8

Clustered Staffing 21

8.1

Conventional staffing

120

46.0

Multi-county staffing

95

36.4

Other

25

9.6

NOTE Other was identified by the respondents as a combination of different Extension Staffing Patterns

\section{Extension District}

Data in Table 11 demonstrate that approximately one fourth of the respondents $(24.9 \%)$ belong to the Southwest Extension district. The Northeast (21.88) and Northwest district (20.7\%) were nearly evenly distributed. The East district (16.58) and the" South district (16.18) were also nearly equal in number of county Extension agents. 
Table 11

Extension District $(\mathrm{N}=261)$

Extension District

f

8

East

43

16.5

Northeast

57

.21 .8

Northwest

54

20.7

Southwest

65

24.9

South

42

16.1

Total

261

100.0

Specialization Plan.

Approximately seventy- three percent of the county Extension agents reported that they had a plan for specialization (see table 12).

Table 12

Specialization Plan ( $N=261)$

\begin{tabular}{lcc}
\hline Specialization Plan & $f$ & 8 \\
\hline Yes & 190 & 72.8 \\
No & 71 & 27.2 \\
\hline Total & 261 & 100.0
\end{tabular}


3. Determine the attitudes of county Extension agents toward agent specialization.

\section{Attitudes of county Extension agents Toward Agent}

Specialization.

Part I of the survey instrument included 12 LikertType scale and three open-ended questions. The rating scale ranged from $1=$ Low to $4=$ High. Questions \# 2, 4, 6, 7,9 , and 11 were negatively worded. The negatively worded questions were reverse coded. The overall mean score for the attitudinal scale was 2.85 , which implies that attitudes toward agent specialization were favorable among county Extension agents in Ohio. Table 13 shows the responses to individual items on the Attitude Scale by the county Extension agents in Ohio. Individual items showing a more positive attitude by the respondents were, in descending order, items 1, 8, and 5 respectively, whereas the items showing a less positive attitude by respondents were beginning with the less favorable 11,9 , and 4. 
Table 13

$(n=261)$

Response to Individual Items on Attitudes Scale by Respondents

Item

mean sd

1. A shift to agent apecialization is

a progressive change for Extension.

$3.08 \quad 0.60$

2. Agent specialization does not enable

Extension educatorg to facilitate

significant community change.

$2.94 \quad 0.59$

3. I am confident about how my

professional role contributes

toward agent specialization.

$2.77 \quad 0.65$

4. Agent specialization limits the

scope of Extension agents.

$2.68 \quad 0.72$

5. Agent specialization allows agents to respond to the more specialized needs of our clientele.

$2.97 \quad 0.63$

6. Agent specialization decreases county funding oupport for Extension.

$2.81 \quad 0.62$

7. Agent specialization alienates traditional Extension audiences.

$2.74 \quad 0.65$

8. Agent specialization is enhancing the available expertise of county

Extension agents

$3.07 \quad 0.63$

9. When I have questions about agent specialization I do not know who to go to for help

$2.66 \quad 0.73$

10. Agent specialization facilitates coalition to support Extension.

$2.84 \quad 0.64$

11. An emphasis on agent specialization

alienates more experienced

Extension personnel

$2.64 \quad 0.64$

12. Overall, I am satisfied with the

concept of agent specialization. $\quad 2.93 \quad 0.62$

$\begin{array}{lll}\text { Overall } & 2.85 & 0.40\end{array}$


Attitudes Toward Agent Specialization and Early and Late Respondents.

Each survey was coded as to the date of return. The return dates were analyzed by the week the survey was returned.

The initial deadline of January 22, 1993 was utilized to divide respondents into two (early and late) groups). Differences between early and late respondents on the dependent variable of attitudes toward agent specialization were examined through use of a T test. An alpha level of 0.5 was established the level of significance. Over sixty nine percent of the respondents replied within the first and second weeks, whereas 30.78 of the respondents had replied within the third and forth weeks. The mean attitude (2.85), was slightly higher for the early respondents, but it was not statistically significant different than the mean of late respondents (2.84). In Table 14 mean attitude ratings of early and late respondents are summarized.

No significant differences were found between early and late respondents in the dependent variable, thus respondents are generalized to the population in the attitudes of county Extension agents toward agent specialization. 
Table 14

Attitude Toward Agent Specialization and Early and Iate Respondents ( $N=261$ )

\begin{tabular}{lllllll}
\hline Group & o & mean & sd & $t$ & $d f$ & $t$
\end{tabular}

\begin{tabular}{lllllll}
\hline Early $(n=181)$ & 69.3 & 2.85 & 0.38 & .26 & 259 & .79 \\
Late $(n=80)$ & 30.7 & 2.84 & 0.42 & & & \\
& & & & & & \\
Total 261 & 100.0 & 2.85 & 0.40 & & &
\end{tabular}

$1-1.5=$ Low

$1 \cdot 5-2 \cdot 5=$ Med Low

$2 \cdot 5-3.5=$ Med High

$3.5-4.00=\mathrm{High}$

\section{Position and Attitude}

The mean score was slightly higher for non-county chairs ( 2.86$)$ whereas county chairs obtained a mean of 2.82 on attitudes toward agent specialization. Differences between county agents and non-county agents were examined on the dependent variable of attitudes toward agent specialization through use of a $t$ test. An alpha level of 0.5 was established the level of significance. 
There was not a statistically significant difference between the means of county chairs and non-county chairs and attitudes toward agent specialization. Table 15

Position and Attitudes Toward Agent Specialization

\begin{tabular}{llllllll}
\hline & mean & sd & $t$ & df & $p$ \\
\hline County Chairs $(n=76)$ & 2.82 & 0.44 & 1.57 & 259 & .12
\end{tabular}

Non-County Chairs $(n=185) \quad 2.86 \quad 0.38$

NOTE $1-1.5=$ LOW

1.5-2.5 = Med Low

2.5-3.5 = Med High

$3.5-4.00=\mathrm{High}$

Extension Program and Attitude Toward Specialization

Among the three traditional programs of Extension, home economic agents reported the largest mean (2.90) followed by agents in agriculture (2.86). On the other hand, 4-H agents were the least satisfied (2.80) regarding attitudes toward agent specialization". The biggest mean was for the community and natural 
resources development agents. Differences between the means of Extension program areas were examined on the dependent variable of attitudes toward agent specialization through use of analysis of variance. An alpha level of 0.5 was established as the level of significance. There were not statistically significant differences between the means of Extension program areas and attitudes toward agent specialization.

Table 16

Extension Program and Attitude Toward Specialization

\begin{tabular}{|c|c|c|c|c|}
\hline Program & $\mathbf{f}$ & mean & md & $\mathbf{s d}$ \\
\hline $4-\mathrm{H}$ & 95 & 2.80 & 2.83 & 0.37 \\
\hline Agriculture & 79 & 2.86 & 2.92 & 0.39 \\
\hline Home economics & 67 & 2.90 & 2.92 & 0.43 \\
\hline CNRD & 12 & 2.94 & 2.83 & 0.40 \\
\hline Other & 8 & 2.65 & 2.63 & 0.35 \\
\hline \multicolumn{5}{|c|}{$\begin{array}{l}\text { CNRD = Community and natural resources development } \\
1-1.5=\text { Low } \\
1.5-2.5=\text { Moderately Low } \\
2 \cdot 5-3.5=\text { Moderately High } \\
3.5-4.00=\text { High } \\
\text { NOTE Anova Table on top of page } 100\end{array}$} \\
\hline
\end{tabular}




\begin{tabular}{lrrrrl}
\hline Source & df & \multicolumn{1}{c}{ SS } & \multicolumn{1}{l}{ MS } & \multicolumn{1}{l}{ F } & \multicolumn{1}{l}{ P } \\
\hline Between Groups & 6 & .8555 & .2139 & 1.3779 & .2420 \\
Within Groups & 254 & 39.7365 & .1522 & & \\
Total & 260 & 40.5920 &. & &
\end{tabular}

Highest Academic Degree and Attitude

Table 17 shows that agents holding a Master's Degree (2.85) had a higher mean for attitude than agents holding a Bachelor's Degree (2.83) and agents holding a Doctorate Degree (2.82). Differences between means in highest academic degree were examined on the dependent variable of attitudes toward agent specialization through use of analysis of variance. An alpha level of 0.5 was established the level of significance. There were no statistically significant differences among means of highest academic degrees and attitudes toward agent specialization. 
Table 17

Highest Academic Degree and Attitude

\begin{tabular}{lrrl}
\hline Degree & $f$ & mean & sd \\
\hline Bachelor's & 66 & 2.83 & 0.35 \\
Master's & 189 & 2.85 & 0.41 \\
Doctorate & 6 & 2.82 & 0.58 \\
\hline $\begin{array}{l}1-1.5=\text { Low } \\
1.5-2.5=\text { Moderately Low }\end{array}$ & & & \\
$2.5-3.5=$ Moderately High & & & \\
$3.5-4.00=$ High & & & \\
\hline
\end{tabular}

\begin{tabular}{lllllll}
\hline Source & df & SS & MS & F & p
\end{tabular}

\begin{tabular}{lrrrrr}
\hline Between Groups & 2 & .0462 & .0231 & .1471 & .8633 \\
Within Groups & 258 & 40.5457 & .1572 & & \\
Total & 260 & 40.5920 & & \\
\hline
\end{tabular}

\section{Area of Study and Attitude}

Table 18 demonstrates that natural resource majors (3.12) had the highest mean for attitude toward agent specialization, followed by social science majors, with a mean of 2.96. Education and agriculture majors obtained the lowest mean for attitude toward agent specialization which were 2.81 and 2.82 respectively. 
Differences between means in areas of study were examined on the dependent variable of attitudes toward agent specialization through use of analysis of variance. An alpha level of 0.5 was established a priori as the level of significance. There were not statistically significant differences among means of areas of studies and attitudes toward agent specialization.

Table 18

Area of Study and Attitude Toward Agent Specialization $(\mathrm{N}=261)$

\begin{tabular}{lccc}
\hline Area of Study & $f$ & mean & sd \\
\hline Administration/Management & 10 & 2.88 & 0.41 \\
Agriculture & 57 & 2.82 & 0.42 \\
Education & 116 & 2.81 & 0.37 \\
Home Economics & 53 & 2.89 & 0.43 \\
Natural Resources & 5 & 3.12 & 0.44 \\
Social Sciences & 9 & 2.96 & 0.29 \\
Other & 11 & 2.92 & 0.39 \\
\hline $\begin{array}{l}1-1.5=\text { Low } \\
\begin{array}{l}1.5-2.5=\text { Moderately Low } \\
\text { 3.5-3.5 = Moderately High }\end{array}\end{array}$ & & & \\
Note Anova Table on top of page 103 & & \\
\end{tabular}




\begin{tabular}{llllll}
\hline Source & df & SS & MS & F & p
\end{tabular}

\begin{tabular}{lrrrrr}
\hline Between Groups & 6 & .8911 & .1485 & .9502 & .4597 \\
Within Groups & 254 & 39.7009 & .1563 & & \\
Total & 260 & 40.5920 & &
\end{tabular}

\section{Extension Stafing Pattern and Attitude}

Table 19 shows that county Extension agents working under a clustered staffing pattern had obtained a mean of 3.07 in regard to attitudes toward agent specialization, which is higher than those for conventional staffing pattern with a mean of 2.85, multi-county staffing pattern with a mean of 2.81 and a combination of staffing patterns under the category of "other", which had a mean of 2.73. Only only 88 of respondents, however, were under the clustering staffing pattern. Differences between means in county staffing patterns were examined on the dependent variable of attitudes toward agent specialization through use of analysis of variance. An alpha level of 0.05 was established the level of significance. There was a statistically significant difference between the means of county staffing patterns and attitudes. A Sheffee post hoc analysis was utilized to investigate 
differences between staffing patterns at an alpha level of 05. There was a statistically significant

difference between the means of clustering staffing pattern and the other staffing patterns in attitudes toward agent specialization. There were not a statistically significant difference among the means of the other staffing patterns.

Table 19

Extension Staffing Pattern and Attitude

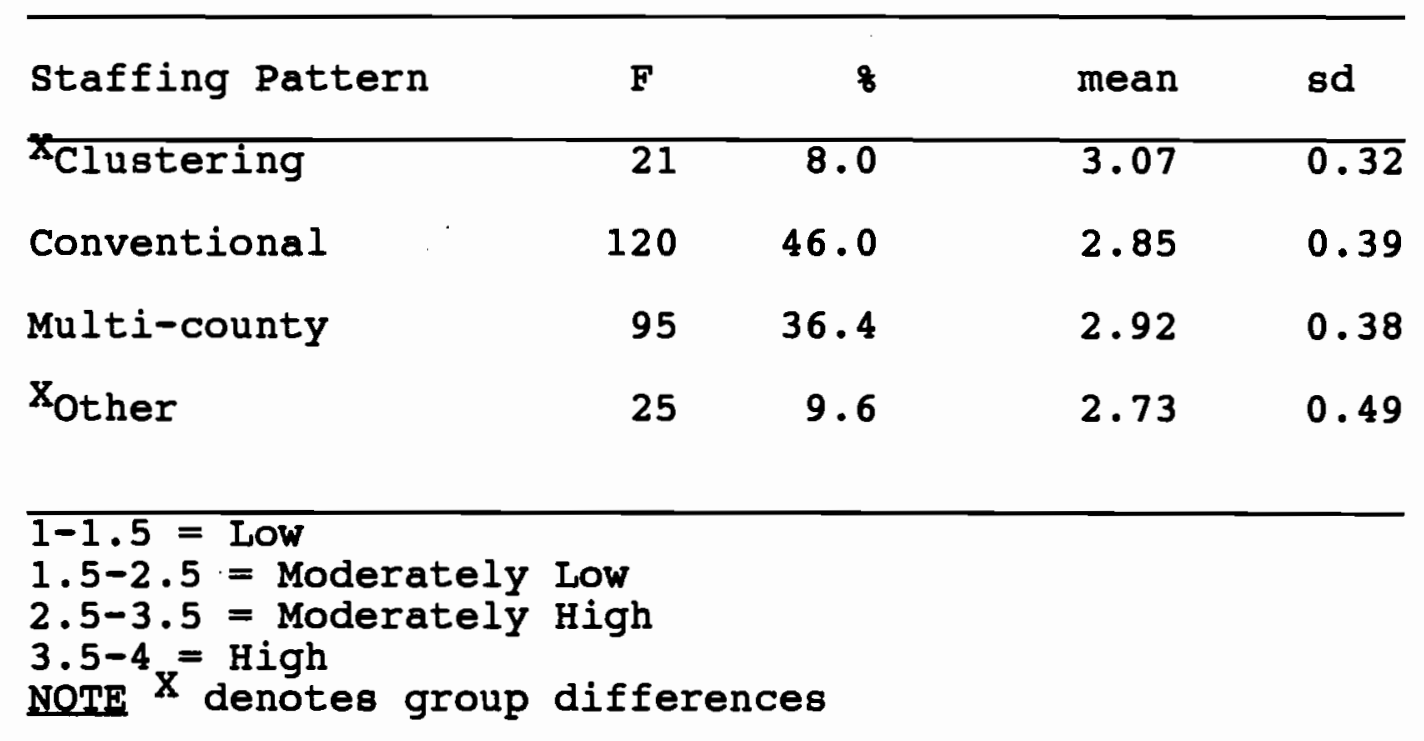

\begin{tabular}{llllllll}
\hline Source & df & SS & MS & F & & \\
\hline
\end{tabular}

\begin{tabular}{lrrrrr}
\hline Between Groups & 3 & 1.5021 & .3755 & 2.46 & .0460 \\
Within Groups & 257 & 39.0899 & .1527 & & \\
Total & 260 & 40.5920 & & &
\end{tabular}


Extension District and Attitude

Table 20 demonstrates that county agents working in the Northwest district had the highest mean scores for districts of Extension (2.96). The Northeast district obtained the second highest mean (2.88). South, East and Southwest districts follow with means of $2.87,2.77$ and 2.76 , respectively. Differences between means in Extension districts were examined on the dependent variable of attitudes toward agent specialization through use of analysis of variance. An alpha level of 0.5 was established a priori as the level of significance. There were no statistically significant differences among the means in Extension districts and attitudes toward agent specialization.

Table 20

Extension District and Attitude

\begin{tabular}{llllll}
\hline District & F & 8 & mean & md & sd \\
\hline East & 43 & 16.5 & 2.78 & 2.75 & 0.50 \\
Northeast & 57 & 21.8 & 2.88 & 2.83 & 0.34 \\
Northwest & 54 & 20.7 & 2.96 & 3.00 & 0.32 \\
Southwest & 65 & 24.9 & 2.76 & 2.75 & 0.41 \\
South & 42 & 16.1 & 2.87 & 2.83 & 0.37 \\
\hline
\end{tabular}

NOTE more information on top of page 106 
$1-1.5=$ Low

1.5-2.5 $=$ Moderately Low

2.5-3.5 = Moderately High

3.5-4 = High

Source

$d f$

SS

MS

F

$\mathrm{p}$

Between Groups

4

1.4677

.36692 .4008

.0515

Within Groups

256

$39.1243 \quad .1258$

Total

260

$40.5920 \quad .1258$

Gender and Attitude

Table 21 shows that females had a slightly higher mean score for attitude toward agent specialization (2.85) than males with a mean of 2.84. Differences between means in gender were examined on the dependent variable of attitudes toward agent specialization through use of a $t$ test. An alpha level of 0.5 was established a priori as the level of significance. There were no statistically significant differences between gender and attitudes toward agent specialization. 
Table 21

Gender and Attitude

\begin{tabular}{llllll}
\hline Gender & 8 & mean & sd & $t$ & df \\
\hline Female $(\mathrm{n}=140)$ & 53.7 & 2.85 & 0.38 & .32 & 259 \\
Male $(\mathrm{n}=121)$ & 46.4 & 2.84 & 0.41 & & \\
\hline $\begin{array}{l}1-1.5=\text { Low } \\
1.5-2.5=\text { Moderately Low }\end{array}$ & & & \\
$2.5-3.5=$ Moderately High \\
$3.5-4=$ High
\end{tabular}

\section{Marital Status and Attitude}

Table 22 shows that the only respondent identified as widowed had the highest mean score for attitudes toward agent specialization. The majority of the respondents (788) were married, with a mean score for attitude of 2.83. Single people, with a mean of 2.88, obtained a higher mean than married people, but less than divorced respondents (2.92). Differences between means in marital status were examined on the dependent variable of attitudes toward agent specialization through use of analysis of variance. An alpha level of 0.5 was established a priori as the level of significance. There were no statistically significant differences among the means of marital status, and attitudes toward agent specialization. 
Table 22

Marital Status and Attitude ( $N=261)$

\begin{tabular}{lrrll}
\hline Marital Status & \multicolumn{1}{l}{ m } & \multicolumn{1}{l}{ s } & mean & \multicolumn{1}{l}{ sd } \\
\hline Single & 44 & 16.9 & 2.88 & 0.36 \\
Married & 203 & 77.8 & 2.83 & 0.40 \\
Widowed & 1 & 0.4 & 3.75 & -- \\
Divorced & 13 & 5.0 & 2.92 & 0.33
\end{tabular}

$1-1.5=$ Low

1.5-2.5 = Moderately Low

$2.5-3.5=$ Moderately High

3.5-4= High

\begin{tabular}{lrrrrr}
\hline Source & df & sS & MS & F & p \\
\hline Between Groups & 3 & .9680 & .3227 & 2.09 & .1016 \\
Within Groups & 257 & 39.6240 & .1542 & & \\
Total & 260 & 40.5920 & & \\
\hline
\end{tabular}

\section{Plan for Specialization and Attitude}

Table 23 demonstrates that county Extension agents with a specialization plan have a higher mean score for attitude toward specialization (2.87) than county Extension agents without a specialization plan (2.78). The majority of county Extension agents (73\%) reported that they had a specialization plan. Differences 
between means in plan for specialization were examined on the dependent variable of attitudes toward agent specialization through use of a $t$ test. An alpha level of 0.5 was established a priori as the level of significance. There were no statistically significant differences between the mean scores of plan for specialization and attitudes toward agent specialization.

Table 23

Plan for specialization and attitude ( $N=261)$

Specialization

Plan 8 mean sd $t$ df $\quad p$

$\begin{array}{lllllll}\text { Have } P \operatorname{lan}(n=190) & 72.8 & 2.87 & 0.41 & 1.57 & 259 & .12 \\ \text { No } P \operatorname{lan}(n=71) & 27.2 & 2.78 & 0.33 & & & \end{array}$

$1-1.5=$ Low

1.5-2.5 = Moderately Low

2.5-3.5 = Moderately High

$3 \cdot 5-4=\mathrm{High}$ 


\section{Age and Attitude}

Table 24 shows that respondents 52 years old or older had the highest mean scores (2.97) for their attitude toward agent specialization. The second highest mean scores (2.93) came from the second youngest group of respondents: with an age range between 27 and 31 years. Groups in the age ranges of 37-41 and 47-51 obtained mean scores for attitudes of 2.91 and 2.89 respectively. Two groups had lower mean scores for attitude although the mean is still moderately high: 32-36, and 42-46 years of age, with mean scores for attitude of 2.77 and 2.74 , respectively.

Table 24

Age and Attitude ( $N=261)$

Age Range

f

8 mean

sd

$22-26$

$27-31$

$32-36$

$37-41$

$42-46$

47-51

52 and older
22

8.4

2.90

0.28

37

14.2

2.93

0.27

47

18.0

2.77

0.36

51

19.5

2.91

0.43

64

24.5

2.74

0.43

29

11.1

2.89

0.40

11

2.97

0.41 
$1-1.5=$ Low

1.5-2.5 = Moderately Low

2.5-3.5 = Moderately High

$3 \cdot 5-4=\mathrm{High}$

Tenure and Attitude

Table 25 demonstrates that respondents with a tenure of 26 years or more in the Ohio State Extension, had the highest mean for attitude toward agent specialization (2.98). The less experienced group, with a tenure range between 1-5 years, obtained a mean score of 2.88 . The Group of respondents in the range of 6-20 years of experience obtained a nearly equal mean, which fell between 2.82 and 2.85 . The group with a tenure between 21 and 25 years obtained the lowest mean score $(2.72)$.

Table 25

Tenure and Attitude ( $N=261$ )

\begin{tabular}{lrrll}
\hline Tenure Range & \multicolumn{1}{l}{ f } & \multicolumn{1}{l}{ mean } & sd \\
\hline $1-5$ years & 109 & 41.8 & 2.88 & 0.35 \\
$6-10$ Years & 39 & 14.9 & 2.83 & 0.37 \\
$11-15$ Years & 48 & 18.4 & 2.85 & 0.43 \\
$16-20$ Years & 42 & 16.1 & 2.82 & 0.47 \\
$21-25$ Years & 18 & 6.9 & 2.72 & 0.42 \\
26 and More & 5 & 1.9 & 2.98 & 0.42
\end{tabular}


$1-1.5=$ Low

1.5-2.5 = Moderately Low

2.5-3.5 = Moderately High

3.5-4 $=\mathrm{High}$

\section{Qpen-Ended Questions}

The first open-ended question asked the respondents to identify what they liked best about agent specialization. One hundred percent of the extensionists in the program area labeled as "other" responded to this question.

Extensionists spending the greatest amount of time in community and natural resource development (CNRD), agriculture, 4-H and home economics had response rates of $838,858,788$ and 898 , respectively.

All agents, regardless of area of emphasis, experienced a similar positive attitude toward agent specialization, which can be classified into three major categories: expertise, professional growth, and recognition. In general, extensionists expressed the following comments in favor of agent specialization: a) focus and develop specific areas of expertise to better help clientele,

b) share specialization in neighboring counties'c) being recognized as an expert in one particular area d) better inservice training, and e) opportunity to specialize in an area of interest. Examples of extensionists's comments include the following:

"Agent specialization offers an opportunity to gain respectability within Extension." 
"Under agent specialization extensionists are becoming well versed in selected areas instead of know a little about a lot."

"Agent specialization reduces dependance on state specialists."

"We feel worthy when someone seeks out our specialized skills, especially from a distant geographical area."

The second open-ended question asked the respondents to identify what extensionists like least about agent specialization. One hundred percent of the agents under the area of "other" responded to this question. Agents spending the greatest amount of time in the areas of agriculture, $4-\mathrm{H}$ home economics and CNRD had response rates of $868,818,848$ and 838 , respectively.

The major problems encountered by the agricultural agents can be classified into three major categories: time consuming, local expectations and a narrow spectrum. In general, agricultural agents experienced the following problems: a) lack of time and money b) lack of interest and support at the state level and most departments, and c) most of the local support coming from generalist activities. Examples of agricultural extensionists' comments include the following:

"An agent should not declare themselves a specialist in a certain area and then receive training to make them a specialist."

"The fact that you still have to have a broad knowledge of everything."

"Make the 258 time commitment a mandatory item." 
"There is less time for other areas of my work."

"County responsibilities detract from agent specialization and county support."

The major problems encountered by $4-\mathrm{H}$ agents can be classified into two major areas: time consuming, and lack of suitability for specialization by 4-H agents. In general, 4-H agents experienced the following problems: a) lack of local support for specialization b) more work, less time, c) specialization occurring at the expenses of local programs. Examples of $4-\mathrm{H}$ agent's comments regarding what they liked the least regarding agent specialization include: "4-H specialties are not as suitable to specialjzation as other areas."

"4-H specializations are unclear. Exactly, what is agent "A" specializing in education design able to do to help my county program? Categories are vague."

"Not enough help or training coming from the state." "The amount of time it takes from a very full schedule." The major problems expressed by the home economic agents can be classified into the following three major categories: time consuming, need for generalization, and lack of directions. Home economics agents, in general experienced the following problems: a) specialization is threatening the traditional audience, b) missing training in other areas of interest, and c) clientele's expectations. Some of the comments of home economics agents regarding the problems faced with agent specialization include: 
"Having to specialize in one area yet still covering a wide variety of subject matter in order to answer clients' questions, concerns."

"There is not enough time to get regular work done, let alone time to specialize"

"You can pick up the title "specialist" by writing it down on a form somewhere, since there is not special training or written information."

"There is really no meaning to the title of "specialist" you are still required to give programs on a wide range of topics and must appear to be a "specialist" on each topic taught to the general public. Whats the point?

The major problems encountered by the agents under the area of "other" can be classified into the following three major categories: time consuming, need for generalization, and lack of local support. Agents under the classification of "other" generally experienced the following problems: a) time is taken away from local activities, b)" no funds for extra secretarial work, and c) diversified requests for help. Some of the comments made by the extensionists under the area of "other" regarding what they liked least about agent specialization included:

"In my county the requests for help are very diverse." "Specialization forces me to drop a few areas I handled in the past. Also deciding on an area of specialization was difficult because I like several areas."

"Taking away county activities without county compensation for time away from the main job which provides county support."

The major problems encountered by the extensionists spending the greatest amount of time in natural" resources and community development can be classified into two major 
categories: time consuming and need for generalization. Some of the comments made by CNRC agents include: "Specialization reduces confidence in broad based information plus audience assistance."

"I do not have enough time to commit to specialization as I would like."

The third open-ended question asked the respondents to provide suggestions for improving agent specialization for the future.

Ninety-two percent of the agents under the category of "other" responded to this question. Extensionists spending the greatest amount of time in the areas of agriculture, home economics, 4-H and NRCD obtained response rates of $688,648,628$ and 678 , respectively. Agricultural extensionists focused their suggestions in three major areas: More guidelines and financial support from the state level, more flexibility in the amount of time spent in specialization, and more interaction between agents and state specialists. In general, agricultural extensionists felt that additional people should be hired in order to carry out office work. Some respondents felt that the state level needed to provide more support for in-service training. Other respondents recommended that agent specialization should provide more opportunities for 
publishing with faculty on campus. Examples of agricultural extensionists' suggestions are as follows:

"Develop a system whereby agents submit credentials supporting their claims to an area of specialization and state specialists should be involved in judging credibility of the claims."

"More cooperation from all areas of specialization i.e agricultural economics and agronomy, and support of agent specialization."

"More involvement in research between agents and state specialists."

The 4-H agents focus their suggestions in three major areas: make specialization optional, allow more flexible specialization areas for $4-\mathrm{H}$ agents, and more help in developing a plan for specialization. Examples of suggestions made by 4-H agents are as follow:

"We should be relieved of many 4-H traditional responsibilities."

"More opportunities to share information with ofher agents with similar specializations."

"Less time commitment to agent specialization. More directions, future goals."

Home economics agents focused their suggestions in three major areas: offer a criteria for areas of emphasis on specialization, better coordination of specialization talents, and to provide more flexibility for agent specialization. Several respondents suggested that Extension must arrange a state wide network by areas of specialization and a nationwide listing of the training 
offered by areas of specialization. Some respondents suggested that areas of specializations should be matched with clientele needs. Other respondents said that more help from district specialists is needed. One home economics agent suggested that new agents should not specialize; They need to develop an area where they are not experts. Examples of home economics agents suggestions are as follow: "Have established cluster groups that include agents who specialize in many different subject areas."

Make it optional or else; do not set a time to be spent on it.

"CNRD agents focused their suggestions in two major areas: better organization of specialization and more support from Ohio State University Extension. Some examples of CNRD agents' suggestions included:

"More cooperation among agents to utilize specialization." "Strengthen funding, support and counseling about specialization. I feel that I am on my own."

"Agents need more training in their specialization from sources that go beyond Ohio State University Extension resources. Agents need more time to pursue their specialization and do research in it, networking with state Extension specialists and researchers."

Extensionists under the category of "other" focused their suggestions in two major areas: more information and support about agent specialization and more interaction with professors on campus. Examples of suggestions of agents under the classification of "other" included: 
"Funding for course work should come from state or federal monies, not county funds."

"District supervisor support must be there, especially for new Extension employees."

"allow us to drop some traditional roles to move forward. Open the opportunity to attend quarter or semester classes to improve our knowledge base."

4. Describe the perceptions of county Extension agents about the importance, knowledge and ability to perform selected agent specialization competencies. Perceptions on Importance, Knowledge and Ability

Part II of the survey instrument includes 14 items. Respondents rated each statement using three scales: importance to professional role, perceived knowledge about the concept, and perceived ability to implement the concept. The rating scale ranged from $1=$ Low to $4=$ High. Mean ratings for the scales measuring importance, knowledge, and ability to implement were calculated for each competence.

As shown in Table 26, the mean importance rating for the respondents was 3.53 with a range of 2.29 to 4.00 ,. The mean knowledge rating was 3.02 with a range of 1.64 to 4.00 . The mean ability to implement was 3.03 with a range of 2.14 to 4 . Table 27 shows the ranking of perceptions of county Extension agents regarding the importance of selected agent specialization competences. Table 28 show the ranking of perceptions 
of respondents regarding the knowledge on selected agent specialization competences. Table 29 presents the ranking of perceptions of respondents regarding the ability to implement selected agent specialization competences.

Throughout Extension, faculty rated mean importance of agent specialization as high, they perceived their level of knowledge and ability to implement agent specialization at a lower level, although it is still moderately high. In the individual areas, the same pattern was observed. Mean importance ratings were slightly higher than mean knowledge ratings. Mean knowledge and ability to implement were nearly equals as illustrated in Table 27. In all areas, importance, knowledge, and ability to implement agent specialization, the group means represented ratings in the moderate high to high range. 
Table 26

Mean scores for Perception of Importance, Knowledge and Ability to Implement Selected Competences, ( $N=261$ )

\begin{tabular}{|c|c|c|c|c|c|c|}
\hline \multirow[b]{2}{*}{ Competence } & \multicolumn{2}{|c|}{ mportance } & Knowledge & \multicolumn{2}{|c|}{ Ability } & \multirow[b]{2}{*}{ gd } \\
\hline & mean & sd & mean & sd & mean & \\
\hline Information giving & 3.82 & 0.41 & 3.31 & 0.61 & 3.39 & 0.57 \\
\hline Group facilitation & 3.48 & 0.62 & 3.05 & 0.67 & 3.15 & 0.66 \\
\hline $\begin{array}{l}\text { Information } \\
\text { Collecting }\end{array}$ & 3.42 & 0.64 & 3.10 & 0.68 & 3.15 & 0.6 \\
\hline $\begin{array}{l}\text { Leading group } \\
\text { discussion }\end{array}$ & 3.47 & 3.52 & 3.21 & 0.63 & 3.22 & 0.69 \\
\hline $\begin{array}{l}\text { Choosing effective } \\
\text { teaching techniques }\end{array}$ & 3.71 & 0.51 & 3.21 & 0.69 & 3.29 & 0.64 \\
\hline $\begin{array}{l}\text { Identifying how } \\
\text { participantg learn }\end{array}$ & 3.37 & 0.69 & 2.81 & 0.68 & 2.81 & 0.68 \\
\hline $\begin{array}{l}\text { Making content } \\
\text { meaningful }\end{array}$ & 3.85 & 0.39 & 3.28 & 0.62 & 3.33 & 0.62 \\
\hline Interpreting trends & 3.33 & 0.64 & 2.76 & 0.75 & 2.76 & 0.74 \\
\hline $\begin{array}{l}\text { Using effective } \\
\text { evaluation techniques }\end{array}$ & 3.24 & 0.75 & 2.68 & 0.72 & 2.60 & 0.72 \\
\hline $\begin{array}{l}\text { Networking in the } \\
\text { community }\end{array}$ & 3.70 & 0.52 & 3.23 & 0.73 & 3.28 & 0.72 \\
\hline $\begin{array}{l}\text { Networking in the } \\
\text { Ohio state } \\
\text { University Extension }\end{array}$ & 3.44 & 0.64 & 2.93 & 0.70 & 2.92 & 0.73 \\
\hline Managing conflict & 3.48 & 0.64 & 2.99 & 0.64 & 2.98 & 0.74 \\
\hline
\end{tabular}


Table 26 (continued)

\begin{tabular}{lllllllll}
\hline Importance & Rnowledge & Ability \\
Competence & mean & mean & mean & sd & mean & sd \\
\hline
\end{tabular}

Balancing agent

specialization

with other program

responsibilities

$\begin{array}{llllll}3.56 & 0.71 & 2.70 & 0.80 & 2.56 & 0.88\end{array}$

Acquiring in-depth

$\begin{array}{lllllll}\text { subject matter } & 3.53 & 0.62 & 2.97 & 0.70 & 2.98 & 0.74 \\ \text { skills } & & & \end{array}$

skills

$\begin{array}{llllll}3.53 & 0.32 & 3.02 & 0.40 & 3.03 & 0.39\end{array}$

Overall

$2.29-4.00 \quad 1.64-4.00$

$2.14-4.00$

$1-1.5=$ Low,

$1 \cdot 5-2 \cdot 5=$ Moderately Low

2.5-3.5 = Moderately High

3.5-4 = High

Ranking of Perceptions of County Extension Agents

Regarding the Importance of Selected Agent

Specialization Competencies

Table 27 shows the ranking of areas according to mean scores on perceptions of respondents regarding the importance of selected agent specialization competencies. Mean and standard deviations for the 
individual competencies are also provided. Making content meaningful and information giving were the areas with highest perception of importance among the respondents. Using effective evaluation techniques was the area with the lowest perception of importance among Extensionists.

Table 27

Perceptions of Importance of Selected Agent Specialization Competences $(N=261)$

\begin{tabular}{|c|c|c|c|}
\hline Rank & & mean & $\mathbf{s d}$ \\
\hline 1. & Making content meaningful & 3.85 & 0.39 \\
\hline 2 . & Information Giving & 3.82 & 0.41 \\
\hline 3 & $\begin{array}{l}\text { Choosing effective } \\
\text { teaching techniques }\end{array}$ & 3.71 & 0.51 \\
\hline 4. & $\begin{array}{l}\text { Networking in the } \\
\text { community }\end{array}$ & 3.70 & 0.52 \\
\hline 5. & $\begin{array}{l}\text { Balancing agent specialization } \\
\text { with other } \\
\text { responsibilities }\end{array}$ & 3.56 & 0.71 \\
\hline 6. & $\begin{array}{l}\text { Acquiring in-depth } \\
\text { subject matter skills }\end{array}$ & 3.53 & 0.62 \\
\hline 7. & Group facilitation & 3.48 & 0.62 \\
\hline 8 & Managing conflict & 3.48 & 0.64 \\
\hline 9 & Leading group discussion & 3.47 & 3.52 \\
\hline
\end{tabular}


Table 27 (continued)

\begin{tabular}{llll} 
Rank & mean & sd \\
\hline 10. $\begin{array}{l}\text { Networking in the Ohio } \\
\text { State University Extension }\end{array}$ & 3.44 & 0.64 \\
$\begin{array}{l}\text { Information } \\
\text { collecting }\end{array}$ & 3.42 & 0.64 \\
12. $\begin{array}{l}\text { Identifying how } \\
\text { participants learn }\end{array}$ & 3.37 & 0.69 \\
13. $\quad \begin{array}{l}\text { Interpreting trends } \\
\text { 14. } \begin{array}{l}\text { Using effective } \\
\text { evaluation techniques }\end{array}\end{array}$ & 3.33 & 0.64 \\
\hline & $\quad 3.24$ & 0.75 \\
\hline
\end{tabular}

Ranking of Perceptions of County Fxtension Agents Regarding the knowledge on Selected Agent Specialization Competencies

Table 28 shows the ranking of areas according to mean scores on perceptions of County Extension Agents regarding the knowledge on selected agent specialization competencies. Mean and standard deviations for the individual competencies are also provided. Information giving and making content meaningful were the areas with highest perceptions of knowledge among the respondents. Balancing agent specialization with other responsibilities and $\mu$ sing 
effective evaluation techniques were the areas with the lowest perception of knowledge among Extensionists. Table 28

Perceptions of Knowledge on Selected Agent

Specialization competences

\begin{tabular}{|c|c|c|c|}
\hline$\overline{\text { Rank }}$ & . & mean & $\overline{8 d}$ \\
\hline 1. & Information giving & 3.31 & 0.61 \\
\hline 2 . & $\begin{array}{l}\text { Making content } \\
\text { meaningful }\end{array}$ & 3.28 & 0.62 \\
\hline 3. & $\begin{array}{l}\text { Networking in the } \\
\text { community }\end{array}$ & 3.23 & 0.73 \\
\hline 4 . & $\begin{array}{l}\text { Leading group } \\
\text { discussions }\end{array}$ & 3.21 & 0.63 \\
\hline 5 . & $\begin{array}{l}\text { Choosing effective } \\
\text { teaching techniques }\end{array}$ & 3.21 & 0.69 \\
\hline 6. & Information collecting & 3.10 & 0.68 \\
\hline 7. & Group facilitation & 3.05 & 0.67 \\
\hline 8. & Managing conflict & 2.99 & 0.64 \\
\hline 9. & $\begin{array}{l}\text { Acquiring in-depth subject } \\
\text { matter skills }\end{array}$ & 2.97 & 0.70 \\
\hline 10 . & $\begin{array}{l}\text { Networking in the ohio state } \\
\text { University Extension }\end{array}$ & 2.93 & 0.70 \\
\hline 11. & $\begin{array}{l}\text { Identifying how } \\
\text { participants learn }\end{array}$ & 2.81 & 0.68 \\
\hline 12 . & Interpreting trends & 2.76 & 0.75 \\
\hline 13. & $\begin{array}{l}\text { Balancing agent specialization } \\
\text { with other responsibilities }\end{array}$ & 2.70 & 0.80 \\
\hline 14 . & $\begin{array}{l}\text { Using effective evaluation } \\
\text { techniques }\end{array}$ & 2.68 & 0.72 \\
\hline
\end{tabular}


Table 28 (continued)

Overall

mean sd

$3.02 * 0.40$

Ranking of Perceptions of County Extension Agents Regarding the Ability to Implement Selected Agent Specialization Competences

Table 29 shows the ranking of areas according to mean scores on perceptions of respondents regarding the ability to implement selected agent specialization competencies. Mean and standard deviations for the individual competencies are also provided. Information giving and making content meaningful were the areas with the highest perception on ability to implement selected agent specialization competencies among county Extension agents. Using effective evaluation techniques and balancing agent specialization with other responsibilities were the areas with the lowest perception on ability to implement selected agent specialization competencies among the respondents. 
Table 29

Perceptions on Ability to Implement Selected Agent Specialization Competencies

Rank

1. Information giving

2. Making content meaningful

Choosing effective

3. teaching techniques

4. Networking in the community

5. Leading group discussions

6. Group facilitation

7. Information collecting

Acquiring in-depth subject

8. matter skills

9. Managing conflicts

Networking in the Ohio state

10 University Extension

Identifying how

11. participants learn

12. Interpreting trends

Using effective

13. evaluation techniques

Balancing agent specialization

14. with other responsibilities mean sd

$3.39 \quad 0.57$

$3.33 \quad 0.62$

$3.29 \quad 0.64$

$3.28 \quad 0.72$

$3.22 \quad 0.69$

$3.15 \quad 0.66$

$3.15 \quad 0.67$

$2.98 \quad 0.74$

$2.98 \quad 0.75$

$2.92 \quad 0.73$

$2.81 " 0.68$

$2.76 \quad 0.74$

$2.60 \quad 0.72$

$2.56 \quad 0.88$

$3.03 \quad 0.39$ 
5. Determine the perceptions of Training Needs of County Extension Agents Regarding Specific Concepts of Agent Specialization

Perceptions of Training Needs

The knowledge and ability to implement discrepancy scores regarding specific concepts of agent specialization are listed in Table 30. The ranking for both knowledge and ability to implement are also provided. Balancing agent specialization with other program responsibilities obtained the highest priority need among respondents on both, knowledge and ability to implement discrepancy scores. 
Table 30

Knowledge and ability to Implement Discrepancy Score and ranking for Items

\begin{tabular}{|c|c|c|c|c|c|c|}
\hline \multirow[b]{2}{*}{ Items } & \multicolumn{3}{|c|}{$\begin{array}{l}\text { Know ledge } \\
\text { Discrepancy }\end{array}$} & \multicolumn{3}{|c|}{$\begin{array}{l}\text { Ability } \\
\text { Discrepancy }\end{array}$} \\
\hline & $\mathrm{R}^{*}$ & mean & $\mathbf{s d}$ & $\mathrm{R}^{*}$ & mean & sd \\
\hline Information giving & 4 & 1.96 & 2.50 & 9 & 1.64 & 2.42 \\
\hline $\begin{array}{l}\text { Group } \\
\text { facilitation }\end{array}$ & 12 & 1.48 & 2.88 & 12 & 1.13 & 2.76 \\
\hline $\begin{array}{l}\text { Information } \\
\text { Collecting }\end{array}$ & 13 & 1.11 & 2.61 & 13 & 0.92 & 2.68 \\
\hline $\begin{array}{l}\text { Leading group } \\
\text { Discussion }\end{array}$ & 14 & 0.90 & 2.51 & 14 & 0.87 & 2.80 \\
\hline $\begin{array}{l}\text { Choosing } \\
\text { effective } \\
\text { teaching techniques }\end{array}$ & 7 & 1.83 & 2.83 & 10 & 1.54 & 2.68 \\
\hline $\begin{array}{l}\text { Identifying how } \\
\text { participants learn }\end{array}$ & 5 & 1.90 & 2.80 & 6 & 1.87 & 2.82 \\
\hline $\begin{array}{l}\text { Making content } \\
\text { meaningful }\end{array}$ & 2 & 2.20 & 2.57 & 3 & 2.01 & 2.65 \\
\hline $\begin{array}{l}\text { Interpreting } \\
\text { trends }\end{array}$ & 6 & 1.89 & 2.85 & 5 & 1.90 & 2.79 \\
\hline $\begin{array}{l}\text { Using effective } \\
\text { evaluation techniques }\end{array}$ & $8^{8}$ & 1.81 & 3.04 & 2 & 2.09 & 3.12 \\
\hline $\begin{array}{l}\text { Networking in the } \\
\text { community }\end{array}$ & 10 & 1.74 & 2.65 & 11 & 1.53 & 2.61 \\
\hline $\begin{array}{l}\text { Networking } \\
\text { in the Ohio State } \\
\text { University Extension }\end{array}$ & 9 & 1.77 & 2.94 & 7 & 1.81 & 2.96 \\
\hline Mànaging conflict & 11 & 1.69 & 2.82 & 8 & 1.75 & 3.18 \\
\hline
\end{tabular}


Table 30 (continued)

Knowledge and ability to implement discrepancy score and ranking for items

\begin{tabular}{|c|c|c|c|c|c|c|}
\hline \multirow[b]{2}{*}{ Items } & \multirow[b]{2}{*}{$R^{*}$} & \multicolumn{2}{|c|}{$\begin{array}{l}\text { Knowledge } \\
\text { Discrepancy }\end{array}$} & \multirow[b]{2}{*}{$R^{*}$} & \multicolumn{2}{|c|}{$\begin{array}{l}\text { Ability } \\
\text { Discrepancy }\end{array}$} \\
\hline & & mean & sd & & mean & $\mathbf{s d}$ \\
\hline $\begin{array}{l}\text { Balancing agent } \\
\text { specialization } \\
\text { with other } \\
\text { programs } \\
\text { responsibilities }\end{array}$ & 1 & 3.06 & 3.84 & 1 & 3.57 & 4.10 \\
\hline $\begin{array}{l}\text { Acquiring } \\
\text { in-depth } \\
\text { subject matter } \\
\text { skills }\end{array}$ & 3 & 1.99 & 2.91 & 4 & 1.94 & 2.95 \\
\hline $\begin{array}{l}\mathrm{R}^{*}=\text { Ranking } \\
1=\text { Highest } \\
14=\text { Lowest } \\
\text { Sd = Standard dev }\end{array}$ & $\alpha$ & ion & & & & \\
\hline
\end{tabular}

Selecting items with the highest discrepancy scores is one way to begin organizing a training program for county Extension agents. The 14 items on the questionnaire were ranked in descending order according to knowledge and ability to implement discrepancy scores. Seven items with knowledge discrepancy scores above the median were selected as high priority items for organizing a training program. The same process was utilized for ability to implement discrepancy scores. 
Priority items for training based upon the knowledge discrepancy scores are presented in table 32 and those based upon ability to implement discrepancy scores are in table 32 .

Table 31

High Priority Items for Training Based on Knowledge Discrepancy Scores

Rank Item \#

1 13. Balancing agent specialization with other program responsibilities

27 . Making content meaningful

3 14. Acquiring in-depth subject matter skills

4 1. Information giving

56 . Identifying how participants learn

68 . Interpreting trends

7 5. Choosing effective teaching techniques

Table 32

High Priority Items for Training Based on Ability to Implement Discrepancy Scores

Rank Item \#

1 13. Balancing agent specialization with other program responsibilities 
Table 32 (continued)

Rank Item \#

29 . Using effective evaluation techniques

3 7. Making content meaningful

4 14. Acquiring in-depth subject matter skills

58 . Interpreting trends

66 6. Identifying how participants learn

7 11. Networking in Ohio State University Extension

6. Determine the Ranking of Training Preferences of County Extension Agents

\section{Ranking of Training Preferences}

Table 33 presents the ranking of training preferences of county Extension agents. For ranking considerations, the means were coded in ascending order and ranged from 1 to 10 . Overall, the most preferred type of training for the respondents was state-Wide Conference, with a mean of 3.66. District conference was the second most preferred type of training with a mean of 4.04, followed by formal classes, working with a district specialists and video cassette, with means of $4.27,4,76$ and 4.82 , respectively. Audio cassette 
and telephone conference calls were the least preferred type of training, with a mean of 7.52

Table 33

Ranking of the training preferences of county Extension agents for agent specialization ( $N=261)$

Ranking Type of training mean sd

\begin{tabular}{llll}
\hline 1. & State wide conference & 3.66 & 2.50 \\
2. & District Conference & 4.04 & 2.50 \\
3. & Formal Classes & 4.27 & 2.58 \\
4. & $\begin{array}{l}\text { Working with a State } \\
\text { Specialist }\end{array}$ & 4.76 & 3.19 \\
5. & Video Cassette & 4.82 & 2.50 \\
6. & Internships with a & & \\
7. State Specialist & Satellite & 5.56 & 3.19 \\
8. & Letter Studies & 6.01 & 2.58 \\
9. & Audio Cassette & 6.62 & 2.33 \\
10. & Telephone conference call & 7.52 & 2.35 \\
& & & 2.38 \\
\hline
\end{tabular}

Ranking 1 = most preferred

Ranking 10 = least preferred 
other Suggestions for Training Made by the Respondents

The following types of training were mentioned at least five times by the respondents:

national association training, Training conferences outside Extension, team study, using computers to share information, being observed by specialists plus feedback, work with research specialists on research project, seminars to enhance teaching skills, and out of state sharing.

7. Determine the relationships between attitudes toward agent specialization and personal, organizational characteristics, and training needs. Relationships between Variables

Objective \#7 was to determine the relationships between the dependent variable attitude toward agent specialization and organizational characteristics (position, Extension area, staffing pattern, Extension district and specialization plan); personal factors (age, gender, marital status, length of service, highest academic degree and type of educational degree); and perceived training needs (knowledge and ability to implement). These relationships were determined by using Pearson's product moment correlations, Eta, Cramer's V, $\oslash$ phi, and point biserial. The level of measurement of four of the independent variables, namely age, length of service, knowledge and 
ability to implement were interval while that of position, Extension program area, staffing pattern, Extension district, specialization plan, gender, marital status, highest academic degree and type of educational degree were nominal. The magnitude of the relationships that existed between the variables listed above is described in the figure 2: (Davis, 1971).

$$
\begin{aligned}
& \text { Coefficient } \\
& .70 \text { or higher } \\
& .50 \text { or } .69 \\
& .30 \text { to } .49 \\
& .10 \text { to } .29 \\
& .01 \text { to } .09
\end{aligned}
$$

Description

Very strong relationship

Substantial relationship

Moderate relationship

Low relationship

Negligible relationship

Figure 2.

Davis's Convention

\section{Dummy Coding of Variables}

According to Cohen and Cohen (1983) dummy-variable coding renders information into dichotomized variables "with the group membership thus rendered in quantitative form, the data can be fully and meaningfully exploited by multiple regressions/correlations, and discriminant analysis." The values obtained can be used for descriptive purposes as well as tested for statistical significance (Cohen, Cohen, 1983). 
For statistical purposes of this study, the following variables were dummy coded: Highest academic degree, marital status, Extension program area, Extension staffing pattern, and major area of study. The component groups which comprised the variable highest academic degree were dummycoded and assigned to three mutually exclusive and exhaustive categories: Highest academic degree (Bachelor), highest academic degree (Master), and highest academic degree (Ph.D.) table (table 34). The component groups of marital status were dummy-coded and assigned to four mutually exclusive and exhaustive categories: marital status (single), marital status (married), marital status (widowed), and marital status (divorced) (Table 35). The component group of Extension program area was dummy-coded and assigned to five mutually exclusive and exhaustive categories: Extension program area (4-H), Extension program area (agriculture), Extension program area (home economics), Extension program area (community and natural resources), and Extension program (other area) (Table 36). The component groups of Extension staffing pattern were dummy-coded and assigned to four mutually exclusive and exhaustive categories: Extension staffing pattern (clustered), Extension staffing pattern (conventional), Extension staffing pattern (multi-county), and Extension staffing pattern (other staffing pattern) (Table 37). The component 
groups which comprised the variable of major area of study were dummy-coded and assigned to five to seven mutually exclusive and exhaustive categories: major area of study (administration/management), major area of study (agriculture), major area of study (education), major area of study (home economics), major area of study (natural resources), major area of study (social sciences), and (other area of study) (Table 38 ).

Table 34

Dummy-Variable Coding of Highest Academic Degree

$G=3$ Groups

Highest Academic Degree

$\mathrm{x}_{1} \quad \mathrm{x}_{2}$

$\mathrm{G}_{1}$ Bachelor

1

0

$\mathrm{G}_{2}$ Master

0

1

$\mathrm{G}_{3} \mathrm{Ph} \cdot \mathrm{d}$.

0

0 
Table 35

Dummy Variable of Marital status

G= 4 Groups

Marital status

$\begin{array}{lll}x_{1} & x_{2} & x_{3}\end{array}$

$\mathrm{G}_{1}$ single

100

$\mathrm{G}_{2}$ Married

010

$\mathrm{G}_{3}$ Widowed

$0 \quad 0 \quad 1$

$\mathrm{G}_{4}$ Divorced

$0 \quad 0 \quad 0$

Table 36

Dummy-Variable coding of Extension Program Area

$G=5$ Groups

Extension Program Area

$x_{1} \quad x_{2} \quad x_{3} \quad x_{4}$

$\mathrm{G}_{1 \quad 4-\mathrm{H}}$

1

$\mathrm{G}_{2}$ Agriculture

0

$\mathrm{G}_{3}$ Home Economics

$\begin{array}{llll}0 & 0 & 1 & 0\end{array}$

$\mathrm{G}_{4}$ Community and Natural Resources

$\begin{array}{llll}0 & 0 & 0 & 1\end{array}$

$\mathbf{G}_{5}$ Other Program Area

$\begin{array}{lll}0 & 0 & 0\end{array}$


Table 37

Dummy Variable Coding of Extension Staffing Pattern

$G=4$ Groups

Extension Stafing Pattern

$\begin{array}{lll}\mathrm{x}_{1} & \mathrm{x}_{2} & \mathrm{x}_{3}\end{array}$

$\mathrm{G}_{1}$ Clustered Stafing Pattern

100

$\mathrm{G}_{2}$ Conventional Staffing Pattern

$0 \quad 1 \quad 0$

$\mathrm{G}_{3}$ Multi-County Staffing Pattern

$0 \quad 0 \quad 1$

$\mathrm{G}_{4}$ Other Staffing Pattern

$0 \quad 0 \quad 0$

Table 38

Dummy Variable coding of Major Area of Study

$G=7$ Groups

$\mathbf{G}_{1}$ Major Area of Study

$\begin{array}{llllll}x_{1} & x_{2} & x_{3} & x_{4} & x_{5} & x_{6}\end{array}$

$\mathbf{G}_{1}$ Administration/Manag 1

1

$\mathrm{G}_{2}$ Agriculture

0

$\mathbf{G}_{3}$ Education

0

0

0

0

0

0

$\mathrm{G}_{5}$ Natural Resources

0

$\mathrm{G}_{6}$ Social Sciences

0

$\mathbf{G}_{7}$ Other Area of Study

0

0

0

0

$1-0$

0

0

$\mathrm{G}_{4}$ Home Economics

1

0

0

0

G Other Area of study


Relationships Between Dependent Variable and Independent Variables

A negligible association was found between the dependent variable (attitudes toward agent specialization) and the independent variables: degree (eta=.03), position $\left(r_{p b}=.04\right)$, specialization plan $\left(\mathrm{r}_{\mathrm{pb}}=-.02\right)$, age $(\mathrm{r}=-.02)$, years of experience $(r=-.07)$, and ability to implement $(r=.05)$.

Low correlations were found between the dependent variable (attitudes toward agent specialization) and the independent variables: marital (eta=.15), study (eta=.15), program (eta=.15), pattern $($ eta $=.19)$, district $\left(r_{p b}=.19\right)$, specialization plan $\left(r_{p b}=.10\right)$, and knowledge $(r=.10)$. (table 39).

Table 39

Correlation Between Independent Variables and Attitudes Toward Agent Specialization

Marital

eta $=.15$

Study

eta $=.15$

Degree

eta $=.03$

Program

eta $=.15$

Pattern

eta $=.19$

District

$r_{\mathrm{pb}}=.19$ 
Table 39 (continued)

Independent Variable

Position

$$
\begin{aligned}
& r_{\mathrm{pb}}=-.04 \\
& r_{\mathrm{pb}}=.02 \\
& r_{\mathrm{pb}}=-.10 \\
& r \quad=-.02 \\
& r=-.07 \\
& r=.10 \\
& r \quad=.05
\end{aligned}
$$

Gender

Specialization plan

Age

Years of experience

Knowledge

Ability

\section{InterCorrelations Among Variables}

Table 40 shows the results of correlation analysis for attitude toward agent specialization among all variables included in the study. Based on the Davis's convention scale, the magnitude of the relationships ranged from negligible to very strong association. The relationships between training needs in knowledge and training needs in ability to implement was very strong (Pearson's ' $r=.82$ ). This correlation indicated that the ability to implement selected agent specialization competencies increase as knowledge increases.

The combination of the following variables show a substantial association between them: Program and gender 
(Cramer's V=.69); this indicated that female agents tended to be in the home economics program more than in other Extension programs. Age and tenure in Ohio state Extension (Pearson'r $=.61$ ); this indicated that older people tended to have more experience working for Ohio State Extension than younger people. Gender and area of study (Cramer's $\mathrm{V}=.53$ ). This indicated that females tended to chose home economics as an area of study more than any other area.

The combinations of variables showing a moderate association were: tenure with Ohio State Extension and degree $(E$ ta $=.45)$; this indicated that the higher the academic degree, the longer is the tenure with Ohio State Extension.

Area of study and program area : (Cramer's V =.40); this indicated that county Extension agents tended to work in a program area related to their area of study. Position and tenure with Ohio State Extension : (Eta $=-.40)$; this indicated that county chairs tended to have more experience working for Ohio state Extension than non-county chairs. Position and degree: (Cramer's $\mathrm{V}=.38$ ); this indicated that county chairs tended to have higher degrees than non-county chairs. Area of study and tenure with Ohio state Extension (Eta $=.31)$; this indicated that extensionists with an educational background in the area of natural resources (average tenure $=14.6$ years) tended to have longer tenure 
with Ohio State Extension than extensionists in different area of studies. The rest of the combination of variables show either low association or negligible assocjation. 


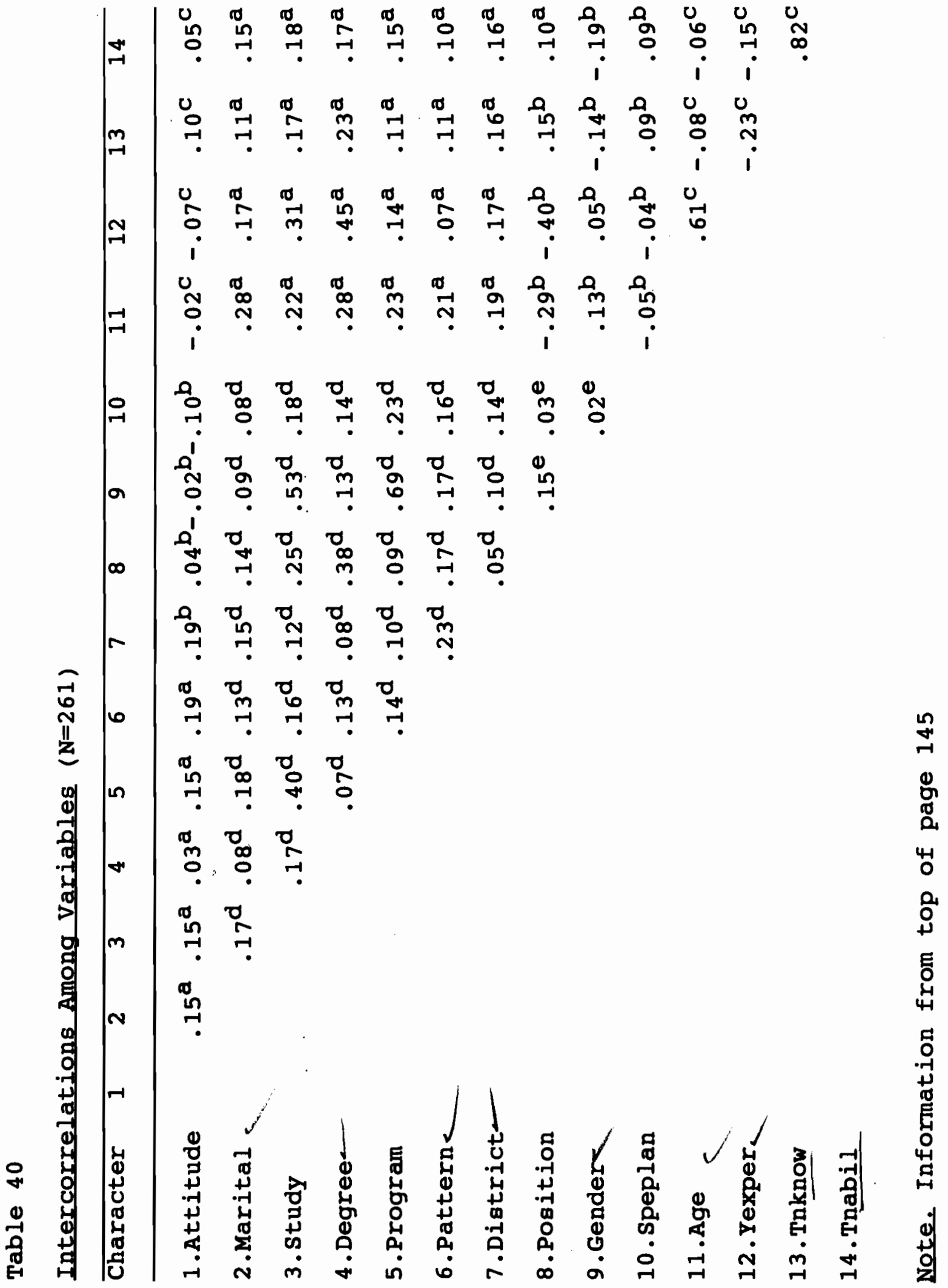


Table 41 (Continued)

a--denotes Eta (Interval vs Nominal with more than two levels)

b--denotes Point biserial (Interval vs Nominal-Dichotomous)

C--denotes Pearson's r (Interval vs Interval)

d--denotes Cramer's V (Nominal vs Nominal but is not a $2 \times 2$ )

e--denotes $\varnothing \mathrm{Phi}$ (Nominal vs Nominal $2 \times 2$ ) 


\section{CHAPTER V}

SUMMARY, IMPLICATIONS, AND RECOMMENDATIONS

Summary of Procedure

The study was conducted to examine the associations between attitudes toward agent specialization and personal characteristics (age, gender, highest academic degree, major area of study, marital status, and years of experience), organizational characteristics (position, Extension program area, Extension staffing pattern, Extension district, and specialization plan), and the variable of perceived training needs (knowledge discrepancy scores, and ability to implement discrepancy scores). The major objectives of the study were:

1. To describe the agents with regard to selected personal characteristics including: age, gender, marital status, years of experience, highest academic degree and major area of study. 
2. To describe the agents with regard to selected organizational characteristics including: position, Extension program area, staffing pattern, Extension district, and specialization plan.

3. To determine the attitudes of county Extension agents toward agent specialization.

4. To describe the perceptions of county Extension agents about the importance, knowledge, and ability to perform on selected agent specialization competencies.

5. To determine the perceptions of training needs of county Extension agents regarding specific concepts of agent specialization.

6. To rank the training preferences of county Extension agents.

7. To determine the extent to which attitudes toward specialization is associated with personal factors, including: age, gender, marital status, length of service, highest academic degree, type of educational degree, organizational factors inclüding: position, County chair, Extension program area, staffing pattern, Extension district and specialization plan, and the perceived training needs of county Extension agents, which include knowledge, and ability to perform. 
Subject Selection

The target population to which results were to be generalized included all county agents who were participating in agent specialization in ohio. To obtain the most accurate results possible a census was utilized in gathering the information from the target population, which consisted of 285 county Extension agents. A list of agent's names, addresses and position description prepared by the State Extension Office was used to identify the population of county Extension agents in Ohio. A cross check of the mailing list was conducted using the February 1992 issue of the Personnel Directory of Ohio State University Extension. Discrepancies between the mailing list and the Directory were clarified by clerical personnel in the office of the Associate Director of Extension. All county Extension agents in Ohio with at least six months of experience in agent specialization were chosen to participate" in the study. An accessible population of 285 county Extension agents was included in the study.

Two hundred eighty five surveys were mailed during January, 1993. Two hundred sixty eight of the original surveys mailed were returned, representing a 948 rate of return. After eliminating incomplete questionnaires, two hundred and sixty one were considered valid for the analysis, representing 91.68 of the surveys mailed. 


\section{Instrumentation}

Section I contained 15 items, which were designed to collect information pertaining to the attitude of subjects toward agent specialization. In the first 12 items, subjects were instructed to circle the number which best represented their feelings related to a series of statements pertaining to agent specialization. A Likert-type scale was used with the following values:

$$
\begin{aligned}
& 1=\text { Strongly Disagree } \\
& 2=\text { Disagree } \\
& 3=\text { Agree } \\
& 4=\text { Strongly Agree }
\end{aligned}
$$

This section contained six negatively worded items, which were reversed coded in order to accurately reflect the attitudes of respondents. Three open-ended questions were included in this section in order to allow respondents to express the positive and negative aspects of agent specialization in addition to recommendations for improving the system. Responses to the open-ended questions were summarized and analyzed by the researcher.

Part II had 14 items, where respondents rated selected agent specialization competencies based on the importance, knowledge and ability to implement. A Likert-type scale was used with the following values: 


$$
\begin{aligned}
& 1=\text { Strongly Disagree } \\
& 2=\text { Disagree } \\
& 3=\text { Agree } \\
& 4=\text { Strongly Agree }
\end{aligned}
$$

The Borich Model for Needs Assessment (Borish, 1980) was used to collect, analyze, and report the data in this section.

Part III measured preferences of respondents* regarding types of training for agent specialization. A ranking scale from 1-10 was provided, with 1 being the most preferred training, and 10 being the least preferred. Two additional suggestions for types of training were also included. Questions on the personal and organizational characteristics of the respondents were in part IV.

To control for measurement error, the questionnaire was presented to a panel of experts, which consisted of the Director and Acting Associate Director of Ohio State University Extension, selected graduate students and professors in the Department of Agricultural education at The Ohio State University, and district directors and district specialists in Ohio State University Extension (Appendix A). The questionnaire, with appropriate revisions, was distributed in draft form to a sample of 25 county Extension agents in the state of Minnesota for pilot testing. 
Cronbach's alpha coefficients were calculated from the data collected in the pilot tests for the attitudinal scale, and for the scales of perceived needs for training on importance, knowledge, and abilities, which were .75, .83, .84 , and, .80 respectively.

Data Collections Procedures

Questionnaires were mailed to all 285 members of the target population of county Extension agents working under agent specialization on January 7, 1993. On January 23, 1993, a reminder postcard was sent to the non-respondents. Those who had not responded by February 3, 1993 received a second complete packet with new a cover letter. A final established deadline date of February 17, 1993 was set and by then, a total of 268 agents had responded, representing a 948 rate of return. The initial deadline of January 22, 1993 was utilized to divide respondents into two (early and late) groups. Differences between early and late respondents on the dependent variables selected for the study were examined through use of a t-test. An alpha level of .05 was established a priori as the level of significance. The t-tests yielded no significant differences between the early and late respondents on the dependent variables selected for the study. 


\section{Data Analysis}

Descriptive statistics were used first to summarize and organize the data. A t test was performed to see whether a difference between the means of two groups was significant. Analysis of variance was used to find out if there were significant differences between the means of more than two groups. Measures of association were utilized to determine the extent to which attitudes toward specialization were associated with personal factors, organizational factors, and training needs. Intercorrelations were used to determine the correlation of attitudes toward agent specialization and all variables included in the study. Training needs were determined by calculating knowledge and ability to implement discrepancy scores for competency items in agent specialization.

Summary of Findings

A summary of the results of this study, are presented in the following section: .

\section{Personal Factors}

The average age of county Extension agents was 39 years. The majority of the respondents (55\%) were females. Most of the county Extension agents (78\%) were married. The average tenure of respondents was 10 years. Tenure between 1-5 years of experience represented 428 of respondents, whereas respondents with 26 years or more of experience were 28. 
There was a fairly even distribution of respondents with tenure in the following groups: 6-10 years (158), 11-15 years (188), 16-20 years (168), and 21 to 25 years (148). The majority (72\%) of county Extension agents held a Master's degree, 258 held a Bachelor's degree and 28 had a Doctoral degree. A high percentage of the respondents held their degree in education (448), followed by agriculture (228), and home economics (208).

\section{Organizational Factors}

Almost thirty percent ( 298) of the agents were county chairs. Respondents spent the greatest amount of time in the 4-H Extension program(36\%), followed by agriculture and home economics, with 308 and 258 respectively. Conventional staffing (468) was the most prevalent county staffing pattern in Ohio, followed by the multi-county staffing pattern (368). One fourth of the respondents (258) belong to the Southwest Extension district. The Northeast (228) and Northwest district (218) were nearly evenly distributed. The East district $(16 \%)$ and the South district (168) were equally distributed in number of county Extension agents. Seventy three percent of the county Extension agents had a plan for specialization.

\section{Attitudes Toward Agent Specialization}

Part II of the instrument consisted of 12 Likert-type scale items to measure attitudes, with half of them 
negatively worded. The negatively coded items were reversed coded in order to obtain a consistent measure. "The overall mean score for the attitudinal scale was 2.85 , which implies that attitudes toward agent specialization were favorable among county Extension agents in Ohio.

Non-county chairs (2.86), had a slightly higher attitude toward agent specialization than county chairs (2.82). The difference was not statistically significant as demonstrated through use of a t-test.

Community and natural resources development agents reported the highest mean for attitudes toward agent specialization (2.94), followed by home economics agents (2.90) and agriculture agents, (2.86), whereas 4-H agents were the least satisfied $(2.80)$. However, there were no statistically significant differences among the groups through use of analysis of variance.

Master's degree holders (2.85) reported the highest attitude score among the academic degrees, followed by Bachelor(2.83) and Doctoral degrees (2.82). However, no significant differences between the groups were found through use of analysis of variance.

Natural resource majors (3.12), had the highest attitude scores when area of study was examined. Education and agriculture majors reported the lowest attitudes, which were 
2.81 and 2.82 , respectively. The reported group differences were not statistically significant.

Agents working under a clustered staffing pattern (3.07), reported the highest mean for attitude toward agent specialization, followed by conventional staffing patterns (2.85), and multi-county staffing pattern (2.81). The category "other", which consisted of a combination of the mentioned staffing patterns, reported the lowest mean for attitude (2.73). Significant differences were found between clustering staffing pattern and the "other" staffing pattern in the attitudes toward agent specialization. A Scheffe post hoc analysis was utilized to investigate differences between staffing patterns at an alpha level of .05. There was a statistically significant difference between mean scores of clustered staffing pattern and the "other" staffing pattern in attitudes toward agent specialization. Respondents working in the Northwest district (2.96) had the highest mean for attitude among the Extension districts in Ohio, followed by the Northeast district (2.88). East and Southwest obtained the lowest means for attitude, which were 2.77 , and 2.76 respectively. No significant differences were found among the districts through use of analysis of variance.

Females (2.85), had a slightly higher mean for attitude toward agent specialization, whereas males had an attitude 
mean of 2.84. This difference was not statistically significant through use of a t-test.

Married respondents, which comprised 788 of the population, reported the lowest mean for attitudes (2.83). No statistically significant differences were found among the marital groups through use of analysis of variance.

County Extension agents with a specialization plan had a higher mean score (2.87) for attitude toward specialization than county Extension agents without a specialization plan (2.78). The reported group differences were not statistically significant through use of a t-test.

Respondents 57 years old or older had the highest mean (2.98) for attitude. The second highest mean for attitude (2.93), was obtained by the second youngest group of respondents, with an age range between 27-31 years. Groups between the ages of 32-36 and 42-46 years reported the lowest means, which were 2.77 and 2.74 , respectively.

Respondents with a tenure of 26 and more years with Ohio State University Extension, had the highest mean for attitude toward agent specialization (2.98). The more experienced group was followed by the least experienced group regarding attitude, with a mean of 2.88 for respondents and a tenure range between 1-5 years. The group with a tenure between 21 and 25 years had the lowest mean $(2.72)$. 


\section{open-Ended Ouestions}

In general, respondents expressed what they liked best about agent specialization in the following manner:

a) focus and develop specific areas of expertise to better help clientele, b) share specialization in neighboring counties c) be recognized as an expert in one particular area d) better in-service training, and e) an opportunity to specialize in an area of interest.

The major problems of agent specialization encountered by the respondents can be classified into the following major categories: time consuming, lack of local support, and need for more generalization. Eleven agricultural agents expressed that specialization implies a narrow spectrum. Twelve 4-H agents said that agent specialization is not as suitable for $4-\mathrm{H}$ as it is for other Extension programs. Ten home economics agents said that agent specialization lacks direction.

In general, county Extension agents expressed the following suggestions for improving agent specialization: a) more flexibility in the amount of time in specialization, b) more coordination among local agents, state specialists and University professors, and c) more guidelines and formal support from the state level. Seven agriculture agents said that there should be more involvement in research among agents, state specialists, and college professors. Six 4-H 
agents said that $4-\mathrm{H}$ specialization should be optional. Eight 4-H agents thought that more flexibility must be allowed for specialization areas related to 4-H agents. Nine home economics agents said that standard criteria for areas of specialization should be developed. Two agents under the category of "other" said that more information should be made available about agent specialization. Perceptions of Extensionists about the importance, knowledge, and ability to perform on selected agent specialization competencies.

Though Extension faculty rated mean importance of agent specialization as high, their perceived level of knowledge and ability to implement agent specialization was at a lower level, although it was still moderately high. Learning styles and personal motivation for pursuing agent specialization may have an impact, besides the area of specialization, educational background, and type of training received. Overall, Making the content meaningful and information giving were the areas with the highest perceptions of importance, knowledge, and ability to implement selected agent specialization competencies. On the other hand, using effective evaluation techniques was the area with the lowest perceptions of importance, knowledge, and ability to implement selected agent specialization competencies. 
Determine the perceptions of training needs of county Extension agents regarding specific concepts of agent specialization

Based on the knowledge discrepancy scores, the areas regarding perceived training needs were ranked in the following descending order:

1. Balancing agent specialization with other program responsibilities

2. Making content meaningful

3. Acquiring in-depth subject matter skills

4. Information giving

5. Identifying how participants learn

6. Interpreting trends

7. Choosing effective teaching techniques

Based on the ability to implement discrepancy scores, the areas regarding training needs were ranked in the following descending order:

1. Balancing agent specialization with other program responsibilities

2. Using effective evaluation techniques

3. Making content meaningful

4. Acquiring in-depth subject matter skills

5. Interpreting trends

6. Identifying how participants learn

7. Networking in Ohio State University Extension. 
These findings suggest that future training efforts should be focused on areas such as balancing agent specialization with other program responsibilities, making content meaningful, and acquiring in-depth subject matter skills.

\section{Rank the training preferences of Extensionists}

Based on the mean scores, 10 types of training were ranked in the following descending order:

1. State-wide conference

2. District conference

3. Formal classes

4. Working with a state specialist

5. Video cassette

6. Internships with a state specialist

7. Satellite

8. Letter studies

9. Audio cassette

10. Telephone conference call

This finding suggests that future training in agent specialization should give priority to the format of state wide conferences, district conferences, and formal classes. 
Intercorrelations Among Variables

The magnitude of the relationships ranged from negligible to very strong. The relationships between training needs in knowledge and training needs in ability to implement was very strong : (Pearsons'r $=.82$ ); this correlation indicated that the ability to implement selected agent specialization competencies increases as knowledge increases.

Among the moderate associations found were: Program and gender (Cramer's V=.69); this indicated that female respondents tended to be in the home economics program more than in other Extension programs. Age and tenure in Ohio State Extension (Pearsons'r $=.61$ ); this indicated that older people tended to have more experience working for ohio State Extension than younger people. Gender and area of study (Cramer's V=.53); this indicated that females tended to choose home economics as an area of study more than any other area.

Conclusions/Implications

1. Attitudes toward agent specialization were moderately positive. The attitudes have not been affected by gender, highest academic degree, major area of study, marital status, position, Extension program area, Extension district, and specialization plan. 
Thus, county Extension agents visualized agent specialization as a positive step, regardless of personal and organizational characteristics.

2. Respondents working under the clustering staffing pattern achieved a more significant positive attitude toward agent specialization than the "other" category. However, no group differences were found between clustering, traditional, and multi-county staffing patterns. Only 88 of the respondents were working under the clustering staffing pattern.

This finding indicated that the clustering staffing pattern, where agents work in two or more counties, and identify an area of specialization, is very suitable for agent specialization. This finding coincides with those of Bartholomew and Smith (1990), when they recommended that multi-county staffing should be reconsidered for a system of multi-county clustering that would incorporate district specialists as well as county agents. Additionally, in the State of Minnesota, clustering has been accompanied by the implementation of agent specialization (Hutchins,1992). This finding was also supported by King (1990), who found a strong correlation between agent specialization success and clustering success.

3. In general, county agents liked the concept of specializing in a area of interest, getting recognition, and 
the access to more specialized training. However, county Extension agents still spend $75 \%$ of their time in a general area. Additionally, areas of specialization may change periodically.

This finding suggests that training in general areas may need to be included in agent specialization training, so a well balanced program is not neglected.

4. Overall, respondents expressed the following problems regarding agent specialization: time consuming, lack of local support, and need for more generalization.

This finding indicates that some generalists activities might need to be dropped in order to prevent county Extension agents from being overworked, and alsó to allow agents to work more in specialized areas. One solution could be to hire additional helping hands to do office work, so agents can dedicate more time to focus on specialization. The lack of local support can be alleviated by providing clear and concise information to the local clientele and county commissioners about agent specialization. One solution could be that the cost of training and traveling for agent specialization comes from state and federal monies, not from local funds.

5. In general, the county Extensions agents expressed the following recommendations: More guidelines* and formal support at the state level, more coordination among local, 
state specialists, and college professors, and more flexibility in the amount of time spent in agent specialization.

This finding indicates that more support from the state level is necessary regarding funding and criteria for specialization. Better coordination between the different levels of specialization must be sought. The coordination problem could be resolved by requiring University professors to work on research at the county level, so agents can gain invaluable expertise, and the professors can acquire experiences from the real world. On the other hand, allowing specialized agents to teach classes at the OSU campus could bring insight from the real world. A more structured network for utilization of specialization across county lines should be provided. One solution could be to arrange a state wide network by areas of specialization, and a nationwide listing of the training offered by area of specialization.

6. Overall, agents were moderately satisfied with agent specialization. This finding supports the opinion of Fitzsimmons (1989), who visualized the Extension local specialization scenario as very feasible.

7. County Extension agents preferred to receive training through state wide conferences, district conferences, and formal classes. 
This finding indicates that the mentioned types of training should be utilized when possible for agent specialization

8. Future training efforts should be focused on areas such as balancing agent specialization with other program responsibilities, insuring meaningful content, and providing in-depth subject matter skills.

These were the competency areas in which agents needs were the greatest. Lack of time for working in agent specialization is only part of the problem in agent specialization. Learning how to balance agent specialization with other program responsibilities is essential.

9. The ability to implement selected agent specialization competencies increases as knowledge increases.

This finding indicates that for county Extension agents, training that focuses in the cognitive areas should suffice for mastering the ability to implement the competencies. Smith (1983) found that in-service training makes a difference at least in the cognitive area. The perceptions of respondents are that increases in knowledge, increases the abilities to implement the competencies as well. 
Recommendations for Ohio State University Extension

1. A longitudinal study should be developed to examine the degree to which agent specialization is implemented in Ohio. Extension is changing rapidly and so do the people. Therefore, it is critical for. Extension to follow-up on agent specialization.

2. This study should be replicated in Ohio after inservice training has been provided in the areas of balancing agent specialization with other program responsibilities, insuring content meaningful, and, providing in-depth subject matter skills. These were the high priority areas for training county Extension agents in agent specialization.

3. In agent specialization, training in general areas need to be expanded, so a well balanced program is not neglected. In Ohio, county Extension agents still spend 758 of their time as generalists. Reeping an overall balanced program should not be neglected.

4. The number of county Extension agents working under the clustering staffing pattern need to be increased. Only 88 of county Extension agents were working under clustering, which was the only staffing pattern to show significant differences with other staffing patterns. 
5. University Professors should be encouraged to work on research in coordination with Extensionists at the county level. Specialized agents need to be offered the opportunity to teach at the college level.

6. More coordination among specialized agents and districts specialists, state specialists, and college professors should be encouraged. The possibility of joint publications among specialized agents, district specialists, state specialists, and college professors should be promoted.

7. A state-wide network by areas of specialization, and a listing of training available outside the system should be provided.

8. Hiring additional individuals to do day-to-day coordination and facilitation of activities. Specialized agents can then dedicate more time to work on agent specialization.

9. The program area of $4-\mathrm{H}$ needs to be given more flexibility in the amount of time spent in agent specialization, and their areas of specialization need to be redefined and targeted for training.

10. Increase support in terms of guidelines, criteria for specialization and funding should be provided by the districts and state level. 


\section{Recommendations for Future Research}

The following recommendations are based upon the findings of the study:

1. As Extension explores new staffing patterns and new specialization areas, further research is needed to investigate the effectiveness of agent specialization under different staffing patterns and areas of specialization. It is essential to investigate the attitudes of county Extension agents under different conditions, and additionally, how the system can be improved while keeping pace with changes.

2. The study should be replicated in other states where agent specialization is in a similar stage of development, after minor revisions are made in the instrument. Other states could benefit from the present study, in addition to examining agent specialization under different conditions.

3. A similar study should be conducted in other states where agent specialization is under consideration. This would enable county Extension agents and Extension administrators to plan for change rather than adjust for change.

4. A need to study the attitudes of Extension audiences toward agent specialization is critical. After all, the Extension audience is the real beneficiary of Extension, and the primary reason Extension was created. Therefore, the 
Extension clientele should have an opinion regarding agent specialization.

5. A study that addresses the attitudes of district specialists, state specialists and, college professors, regarding agent specialization needs to be considered. If they are expected to be a part of the specialization system, then their inputs should be sought.

6. A qualitative aspect such as a focus group interview (FGI) should be added to the study. The focus group interview is a very suitable method for uncovering information about human perceptions, feelings, opinions and thoughts. Questions regarding new programs and proposals can be investigated fast and relatively cheap (Krueger, 1985). Additionally, the FGI assists the researcher in generating hypotheses when little is known about the topic being researched (Higgenbotham, 1979). 
APPENDIX A

Mailing Procedures, and Panel of Experts 
September 9, 1992

To: $\quad$ Selected Panel of Experts

$\begin{array}{ll}\text { Nikki Conklin } & \text { Larry Ault } \\ \text { Emmalou Norland } & \text { Richard Martin } \\ \text { Louis Fourman } & \text { Robert Fleming } \\ \text { Charles Bell } & \text { Betty Reese } \\ \text { Barbara Ludwig } & \text { Janet Henderson } \\ \text { Keith Smith } & \text { Jo Jones } \\ \text { Richard Clark } & \text { Dale Safrit } \\ \text { David Gerber } & \text { Bill Haynes } \\ \text { Joe Heilinch } & \text { Tom Rach } \\ \text { Mike Cote } & \text { Ruben Nieto }\end{array}$

FROM: Jose M. Huerta

Graduate Student, Agricultural Education * The Ohio State University

Room 3, 2120 Fyffe Road

Columbus, Ohio 43210

RE: Content and Face Validity of Dissertation Instruments

I have purposefully selected a small group of Extension educators and administrators to serve as a panel of experts to assist me in determining the content and face validity of my dissertation instrument. I would like to request that you serve on this panel.

The instrument titled Attitudes of County Extension Agents toward Agent Specialization in Ohio will be completed by county agents who are participating in agent specialization. These instruments will be used to measure the level of satisfaction toward agent specialization and need of training as perceived by county agents.

Please review the instrument and letter for content validity (Are the items representative of the concept being measured?); clarity (Is each item clear? Do you understand the directions? Are you confused in what I am asking?); and format (Suggestions for improvement). Please write suggestions you may have directly on the instrument. Return them to the address listed above by Monday, september 21, 1992 .

I thank you in advance for your expertise and suggestions. Should you have any questions, please contact me at 614-488-3324. If I am not in, please leave a message. 
November 3, 1992

Dear Pat

Agent specialization is a new focus of the Ohio Cooperative Extension Service since January, 1991. The Ohio Cooperative Extension System has made a commitment to allocate resources of faculty time and financial support to agent specialization.

In order to assist faculty in the evaluation of agent specialization, José $M$. Huerta, doctoral candidate, department of agricultural education, is conducting a census study to identify and describe the attitudes of county Extension agents toward agent specialization. $\mathrm{Dr}$ Jo Jones, associate Director of Extension is the principal investigator and graduate Co Advisor, and I am serving as graduate advisor for the study.

The state of Minnesota has been the pioneer in agent specialization. For that reason, we are asking for your assistance in the present study. First of all, we need your permission to use a random sample of 25 county agents in your state to conduct the pilot project. If your permission is granted, we would like to get a copy of the current Personnel Directory of the Minnesota Extension Service or any listing of agents who are specializing as soon as you can.

Your cooperation in this critical study will be greatly appreciated. The deadline will be given as soon as I have your approval for the conduction of this pilot project. The commitment will require no longer than 20 minutes of the agents' time. For your convenience, I am including a copy of the instrument. I would be happy to answer any questions or concerns that you may have about the study and how the information will be utilized. Please feel free to call me at 614-292-1889.

Hoping to hear from you soon.

sincerely yours

Reith L. Smith

Extension Director

Ohio Cooperative Extension Service 
November 18,1992

Dear Extension professional:

Agent specialization is a new focus of the Ohio Cooperative Extension Service since January, 1991. The Ohio Cooperative Extension Service has made a commitment to allocate resources of faculty time and financial support to agent specialization.

In order to provide assistance in the evaluation of agent specialization in Ohio, it is important to get the inputs of a similar population of county Extension agents in

Minnesota. Jose $M$. Huerta, doctoral candidate, department of agricultural education, is conducting a census study to identify the attitudes of county Extension agents toward agent specialization in Ohio. Dr Jo Jones, Acting Extension Associate Director is the principal investigator and graduate Co-Advisor, and I am serving as graduate Advisor for the study.

The state of Minnesota has been the pioneer in agent specialization. For that reason, you have been identified to offer input for the pilot project in this critical study for Extension in Ohio. Your identity will remain confidential. The commitment will require no longer than 20 minutes of your time. Permission letter for conducting this pilot project in Minnesota is included. If you have questions concerning the study, please contact Jose $M$. Huerta at 614442-8058. Please complete the survey and return it by December 2,1992. Thank you in advance for your cooperation.

Sincerely yours

Reith I. Smith

Director 
January 7, 1993

Dear Extension Agents,

Ohio State University Extension has made a commitment to allocate resources of agents' time as well as financial support to agent specialization. As we gathered information related to staffing it was evident that many of you supported maintaining agent specialization. This support though does not indicate that agent specialization is "perfect". We know some changes need to be made to increase it's effectiveness.

To provide assistance in the evaluation of agent specialization we want and need your input. Jose M. Huerta, doctoral candidate, Department of Agricultural Education, is working with us in conducting a study to identify the attitudes of county Extension agents toward agent specialization and to determine changes that need to take place to make agent specialization more effective. We are serving as co-advisors for Jose's study.

We are asking you to spend approximately 20 minutes of your time during the next week to complete the enclosed survey. Your code number on the instrument will be used only to follow up with non-respondents. Your identity will remain confidential. If you have questions concerning the survey, please contact Jose directly at 614-442-8058. Jose has enclosed a couple items to show his appreciation for your assistance.

Please complete the survey and return it in the envelope provided by January 22, 1993. Thanks for your cooperation. It will result in us obtaining information that we can use to improve the effectiveness of our agent specialization efforts.

Sincerely,

Reith L. Smith Director
Jo Jones

Acting Associate Director 
February 3, 1993

Dear Extension Professional:

A few weeks ago you received a packet from me containing a survey about "Attitudes of County Extension Agents Toward Agent specialization in Ohio". If you have already completed and returned the survey, please disregard this request. If you have not returned the survey, please read on.

The mentioned study is critical for ohio state Extension and for all county agents working under agent

specialization, since my goal in this census study is to provide all county Extension agents in Ohio an opportunity to offer input for the improvement of agent specialization.

This is the first study of this nature since agent specialization was implemented in Ohio two years ago. Therefore, the usefulness of the study depends on how accurately we are able to describe the attitudes of county Extension agents.

I am asking you to spend approximately 20 minutes of your time during the next week to complete the enclosed survey. Your code number on the instrument will be used only to follow-up with non-respondents. Your identity will remain confidential. If you have questions concerning the study, please feel free to contact me directly at 614/442-8058. I have enclosed a couple of items to show my appreciation for your assistance.

Please complete the survey and return it in the envelope provided by Fobruary 17, 1993. Since the outcome of this research study is so important for all of you, I will be happy to send you a copy of results if you want one. Simply write on the back of the return envelope "copy of results requested". I expect to have them ready to send early next summer.

Your contribution to the success of this study will be greatly appreciated.

Most Sincerely, Jose M. Huerta Doctoral Candidate 
Panel of Experts

Panel Member

Dr Nikki Conklin

Assistant Professor Department of Agr Education The Ohio State University

Dr Joe Heilinch

Assistant Professor Department of Agr Education The Ohio State University

Dr Jo Jones

Acting Associate Director Ohio State University Extension

Barbara Ludwig

District Director

Northeast District

Ohio State University Extension

Keith Smith

Director

Ohio State University Extension

Dr Janet Henderson

Associate Professor

Department of Agr Education

The Ohio State University

Louis Fourman

District Director

East District

Ohio State University Extension

Larry Ault

District Specialist, CNRD

Northeast District

Ohio State University Extension

Richard Martin

District Director Northeast District Ohio State University Extension

Mike Coté

Graduate student

Department of Agr Education

The Ohio State University

Tom Rach

Graduate student

Department of Agr Education

The Ohio State University 
Panel of Experts (continued)

\begin{tabular}{|c|c|}
\hline Emalou Norland & $\begin{array}{l}\text { Associate Professor } \\
\text { Department of Agr Education } \\
\text { The Ohio State University }\end{array}$ \\
\hline Charles Bell & $\begin{array}{l}\text { District Specialist, } 4-\mathrm{H} \\
\text { East District. } \\
\text { Ohio State University Extension }\end{array}$ \\
\hline Robert Fleming & $\begin{array}{l}\text { District Specialist, Farm Mgt } \\
\text { Northest District } \\
\text { Ohio State University Extension }\end{array}$ \\
\hline Betty Reese & $\begin{array}{l}\text { District Director } \\
\text { South District } \\
\text { Ohio State University Extension }\end{array}$ \\
\hline Ruben Nieto & $\begin{array}{l}\text { Graduate Student } \\
\text { Department of Agr Education } \\
\text { The Ohio State University }\end{array}$ \\
\hline
\end{tabular}


APPENDIX B

Instrument for the study 
ATTITUDES OF COUNTY EXTENSION AGENTS TOWARD AGENT SPECIALIZATION IN OHIO

Code \#

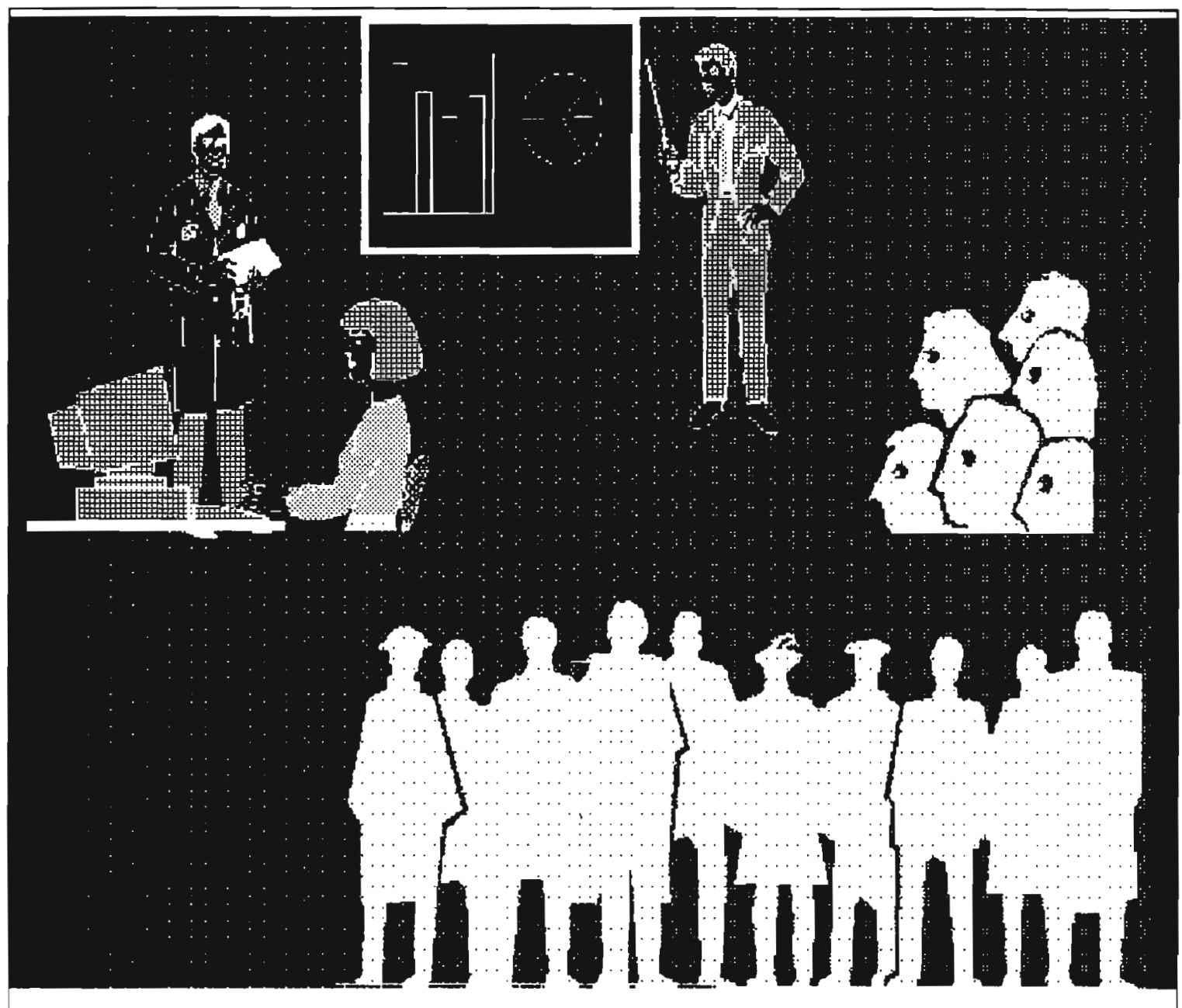

BY: JOSE M. HUERTA, DOCTORAL CANDIDATE

Department of Agricultural Education.

The Ohio State University Columbus, Ohio 


\section{INTRODUCTEOI}

Please respond honestly and accurately following the instructions provided for each section. It is extremely important that you answer all of the questions in this instrument. Your responses are very important and will be kept confidential. The questionnaire should take about 20 minutes to complete. Please return the questionnaire in the enclosed, self-addressed stamped envelope. The mailing address is listed at the end of the questionnaire.

PART I

Instructions- On the following pages are listed 12 statements that describe possible attitudes of Extension Professionals about Agent Specialization.

(In part I, the following scale is to measure ATTITUDE).

\begin{tabular}{lccc}
\hline $\begin{array}{l}\text { Strongly } \\
\text { Disagree }\end{array}$ & Disagree & Agree & $\begin{array}{l}\text { Strongly } \\
\text { Agree }\end{array}$ \\
\hline SD & D & A & SA $^{*}$ \\
\hline
\end{tabular}

Briefly reflect on what you think and how you feel about Agent Specialization, and then respond to the following general statements about yourself, your work setting, and the Cooperative Extension Service.

Please indicate the degree to which you agree or disagree with each statement by circling one response following each statement.

Example

I am satisfied with my job
Strongly Strongly

Disagree Agree

\begin{tabular}{llll}
\hline SD & D & A & SD
\end{tabular}

In this case, the circled response indicates Agreement with the statement.

Three open ended questions are also included in this section in order to address other concerns county Extension agents may have about agent specialization 


$$
\begin{array}{ll}
\text { Strongly } & \text { Strongly } \\
\text { Disagree } & \text { Agree }
\end{array}
$$

1. A shift to agent specialization SD

(CIRCLE ONE)

D A

SA is a progressive change for

Extension.

2. Agent specialization does not SD enable Extension educators to facilitate significant community change.

3. I am confident about how my professional role contributes

SD toward agent specialization.

4. Agent specialization limits the scope of county Extension agents

5. Agent specialization allows agents to respond to the more SD

D

A

SA specialized needs of our clientele.

6. Agent specialization decreases SD county funding support for Extension.

7. Agent specialization alienates SD traditional Extension audiences.

8. Agent specialization is enhancing the available expertise of county Extension agents

9. When I have questions about agent specialization I do not know who to go to for help.

10. Agent specialization facilitates coalition to support Extension.

11. An emphasis on agent specialization alienates more SD

SD

D

A

SA experienced Extension personnel.

12. Overall, I am satisfied with SD the concept of specialization.
SD

SD

D

A

SA 
Please, complete the following open ended questions:

13. What I like best about agent specialization is:

14. What I like least about agent specialization is:

15: Suggestions I have for improving agent specialization include: 
Part II

Each of us has a variety of educational needs to improve our effectiveness as Extension educators. Often our jobs demand skills related to working with people, organizations and within systems or process skills besides subject matter. The following is a list of competencies that may benefit you and your clientele as you pursue agent specialization.

You are asked to rate each competence according to three areas:

IMPORTARCE- How important is this competence to you in your present professional role?

KWOWLEDE- At what level would you rate your knowledge in the competency described?

ABILITY TO PERFORM- At what level would you rate your ability to perform the described competence in your present professional role?

Please respond to the three areas for every item. Rate your perception of importance, knowledge, and ability to perform by circling the number that corresponds to the appropriate level.

Example:

\section{Importance} Low High

Networking in my community.
Rnowledge

Low High

$\overline{1234}$
Ability

Low High

By circling 4 on importance, I am saying I think networking in my community is very important to the success of my job. The circle 1 on knowledge means I need substantial help in exactly how to network in my community.

The circle 4 on ability means my ability to perform

networking in my community is very high.

1 No: importance, knowledge or ability

2 Little: importance, knowledge ability

3 Some: importance, knowledge or ability

4 Very: important, knowledgeable or skilful 
Competence
Importance Low High
Rnowledge

Low High
Ability

Low High

1. Information giving $\begin{array}{llll}1 & 2 & 3 & 4\end{array}$

$\begin{array}{llll}1 & 2 & 3 & 4\end{array}$

$\begin{array}{llll}1 & 2 & 3 & 4\end{array}$

2. Group facilitation $\begin{array}{llll}1 & 2 & 3 & 4\end{array}$

$123 \quad 34$

$\begin{array}{llll}1 & 2 & 3 & 4\end{array}$

3. Information

$\begin{array}{llll}1 & 2 & 3 & 4\end{array}$

$\begin{array}{llll}1 & 2 & 3 & 4\end{array}$

$\begin{array}{llll}1 & 2 & 3 & 4\end{array}$ collecting

4. Leading Group discussion

$\begin{array}{llll}1 & 2 & 3 & 4\end{array}$

$\begin{array}{llll}1 & 2 & 3 & 4\end{array}$

$\begin{array}{llll}1 & 2 & 3 & 4\end{array}$

5. Choosing effective $\begin{array}{llll}1 & 2 & 3 & 4\end{array}$ teaching techniques

$\begin{array}{llll}1 & 2 & 3 & 4\end{array}$

$\begin{array}{llll}1 & 2 & 3 & 4\end{array}$

6. Identifying how $123 \quad 3 \quad 4$ participants learn

7. Making content $\begin{array}{llll}1 & 2 & 3 & 4\end{array}$ meaningful

8. Interpreting trends $1 \begin{array}{llll}1 & 2 & 3 & 4\end{array}$

$\begin{array}{llll}1 & 2 & 3 & 4\end{array}$

$\begin{array}{llll}1 & 2 & 3 & 4\end{array}$

9. Using effective

$\begin{array}{llll}1 & 2 & 3 & 4\end{array}$

$\begin{array}{llll}1 & 2 & 3 & 4\end{array}$

$\begin{array}{llll}1 & 2 & 3 & 4\end{array}$ evaluation techniques.

10. Networking in the community.

11. Networking in OSU 12334 Extension

12. Managing conflict 1234

$\begin{array}{llll}1 & 2 & 3 & 4\end{array}$

$\begin{array}{llll}1 & 2 & 3 & 4\end{array}$

13. Balancing agent specialization with

$\begin{array}{llll}1 & 2 & 3 & 4\end{array}$

$\begin{array}{llll}1 & 2 & 3 & 4\end{array}$

$\begin{array}{llll}1 & 2 & 3 & 4\end{array}$ other program responsibilities

14. Acquiring in-depth $1223 \quad 3$ subject matter skills.

$\begin{array}{llll}1 & 2 & 3 & 4\end{array}$

$\begin{array}{llll}1 & 2 & 3 & 4\end{array}$ 


\section{PART III}

Training is a very important aspect of agent specialization. For that reason, it is essential to get the inputs of the participants on preferred methods for receiving training.

Please rank the following items 1-10, with 1 being your most preferred method, and 10 being your least preferred method. Two additional suggestions for training are also included.

\section{Example :}

A. Formal classes

B. Satellite

C. Letter Studies

Satellite is the type of training preferred by respondent, followed by letter studies. Formal classes is the least preferred method of this respondent.

this

A. State wide conference

B. Formal classes

C. Video Cassette

D. Audio Cassette

E. District conference

F. Working with a district specialist

G. Satellite

H. Letter studies

I. Internships with a state specialist

J. Telephone conference calls

Other suggestions for training

1.

2 . 
PART IV. General information

Instructions- Please answer the following questions by circling the letter corresponding to the most appropriate answer for each, or by filling the corresponding blank.

1. Your present age

\section{YEARS}

2. Your gender
A. FEMALE
B. MALE

3. Your marital status
A. SINGLE
B. MARRIED

4. Your years of experience in the Ohio Cooperative Extension Service as of January 1, 1992 YEARS

5. What is your highest academic degree? (circle 1)
A. BACHELOR DEGREE
B MASTER DEGREE
C. DOCTORAL DEGREE

6. What is your professional position? (circle 1)
A. EXTENSION AGENT
B. ASSOCIATE AGENT
C. OTHER (PLEASE SPECIFY) 
7. What was the major area of study in your highest academic degree? (circle 1)

A. ADKINISTRATION/MAMAGEMENT

(INCLUDING THE AREAS OF: FINANCE, MANAGEMENT AND HUMAN RESOURCES, MANAGEMENT SCIENCES, OR MARKETING)

B. AGRICULTURE

(INCLUDING THE AREAS OF: AGRICULTURAL ECONOMICS,

AGR ICULTURAL ENGINEERING, AGRONOMY, ANIMAL SCIENCE, DAIRY

SCIENCE, HORTICULTURE, OR POULTRY SCIENCE)

C. EDUCATIOA

(INCLUDING THE AREAS OF: ADULT AND CONTINUING EDUCATION, AGRICULTURAL EDUCATION, EDUCATION ADMINISTRATION, ENVIRONMENTAL ADMINISTRATION, EXTENSION EDUCATION, GENERAL EDUCATION OR HOME ECONOMICS EDUCATION

D. HOME ECONOMICS

(INCLUDING THE AREAS OF: CHILD DEVELOPMENT, CLOTHING

AND TEXTILES, DESIGN, FAMILY LIFE, HOME

FURNISHING, HOME MANAGEMENT, OR NUTRITION)

E. MATURAT RESOURCES

(INCLUDING THE AREA OF: CHILD DEVELOPMENT, -

ECOLOGY, ENTOMOLOGY, FORESTRY, PLANT PATHOLOGY,

OR WILDLIFE BIOLOGY)

F. SOCIAI SCIEHCE

(INCLUDING THE AREAS OF: COMMUNITY DEVELOPMENT,

PSYCHOLOGY, RURAL SOCIOLOGY, OR SOCIOLOGY)

G. OTHER (Please specify)

8. Are you a county chair?

A. YES

B. NO

9. In what Extension program area do you spend the greatest portion of your time? (circle I)
A. 4-H
B. AGRICULTURE
C. HOME ECONOMICS
D. COMMUNITY AND NATURAL RESOURCES DEVELOPMENT
E. OTHER (Please Specify)

10. What is the current staffing pattern in your county? (circle 1)
A.
CLUSTERED STAFFING PATTERN
B.
CONVENTIONAL STAFFING
C. MULTI-COUNTY STAFFING
D.
OTHER (Please Specify) 
11. Which Extension District are you in? (circlè 1)
A. EAST
B. NORTHEAST
C. NORTHWEST
D. SOUTHWEST
E. SOUTH

12. Do you have a plan for specialization?
A. YES
B. NO

PLEASE FEEL PREE TO ADD AMT ADDITIONAT COMMENTS YOU MAT HAVE ABOUT AGEAT SPECIALIZATIOA IN THE SPACB PROVIDED BEION.

PLEASE RETURN THIS QUESTIONNAIRE IN THE STAMPED, SELFADDRESSED ENVELOPE PROVIDED. RETURN TO: JOSE M. HUERTA

Agricultural Education, 2120 FYFFE ROAD, COLUMBUS, OHIO 43210

THANR YOU! 


\section{REFERENCES}

Agnew, D. M. \& Foster, R. (1991). National Trends in Programming Preparation and Staffing of County Level Cooperative Extension Service Offices as Identified by State Extension Directors. Journal of Extension, 32(1), 47-53.

Ayres, J. S. (1989). Attitudes toward community change. A Comparison between rural leaders and residents. CommunityDev-Soc Superior. University of Wisconsin, 20(1), 1-18.

Bartholomew. H. M. Smith, \& K. L. (1990). Stresses of Multicounty agent positions. A new Staffing Pattern for Extension. Journal of Extension, 28, 10-12.

Bennis, W. G. (1969) The Planning of Change. Holt, Renehart and Winston, INC. New York, New York.

Bjorklund J. \& Fredmeyer J. (1985). Journal of Extension, $23,-3-4$.

Blackburn, D. J. (1984). Extension Handbook. Canada . University of Guelph.

Bohlem, J. M. et al (1955). How farm people accept new ideas. Iowa State College, Ames.

Boone, E. J. (1985). Developing program in adult education. Englewood Cliffs: Prentice-Hall, INC.

Boyle P. (1989). Extension System Change: Fact or fiction. Journal of Extension 27, 3-6.

Buford, J. \& Bedeian, A. (1988). Management in Extension. 2nd Edition. Auburn University: Alabama Cooperative Extension Service.

Brenning, T. \& Hoover, T. S. (1991). Personal life factors as related to effectiveness and satisfaction of secondary school teachers. Journal of Agricultural Education, 32(4) 44-52.

Borish, G. D. (1980) Needs assessment model for conducting follow-up studies. Journal of Teacher Education, 31, 39-46. 
Brown, N. (1989). Too little too late? Journal of Extension. 27, 5-6.

Calderon, M. (1982). Application of innovation configurations to a trainer of trainers program. Bilingual Education Paper Series, 6(3).

Calson, R. A. (1970). Cooperative Extension. A Historical Assessment. Journal of Extension, 8, (31), 10-14.

Claycomb, D. \& Stewart, B. (1980). Meaning and value of work and job satisfaction of young farmers and vocational agriculture instructors. The Journal of the American Association of Teacher Educators in Agriculture.21, March.

Cohen, J.\& Cohen P, (1983). Applied Multiple Regression/Correlation Analysis for the Behavioral sciences. Hillsdale, New Jersey: Lawrence Eribaum Sssociates, Inc.

Conklin, N. S. (1990). Perspectives on issues programming in the ohio Cooperative Extension Service, Doctoral

Dissertation. The Ohio State University, Columbus.

Dalgaard, K. et. at. (1988). Issues programming in Extension. A Joint publication with Extension Service-USDA, Extension Committee on policy, and the Minnesota Extension Service, St Paul, Minnesota.

Decker, D. \& Noble, L. A. \& Call, D. L. (1989). Forward with the original Land-Grant concept. Journal of Extension, 27, 6-8.

Deshler, D. J. (1989). Future Risk Assesment: Issues Programming Opportupity. Journal of Extension, $27,23-25$.

Desher, D. J. (1989). The Future of Futuring. Journal of Extension, 27, 6 .

Extension Committee on organization and policy ECOP (1987). Extension in transition: Bridging The Gap Between vision and Reality (Report of the Future Task Force) Virginia Cooperative Extension Service.

Fitzsimmoms, E. L. (1989). Alternative Extension Scenarios. Journal of Extension, 27, 13-15.

Geasler, M. R. (1983). Futures Task Force Recommendations today, Journal of Extension, 27, 3-5. 
Gerber, J. M. (1985). Extension Specialists: a selfAnalysis. Journal of Extension, 23.

Godke, M. (1990). Attitudes of County Extension Advisory Committee Members Regarding the Clustered Staffing Pattern in Ohio. Doctoral Dissertation, The Ohio state University, Columbus.

Gray, K. \& Long, J. S. \& Stahlhurt, M. (1989) Strategic Management for Extension. Foundation and Changing Practices in Extension, 17,149-154, University of Guelph.

Higgenbotham, J. and Cox, K. (1979). Focus Group Interviews-A Reader. American Marketing Association, 222 South Riverside Plaza, Chicago, Illinois 60606.

Higgenbotham, J. and Cox, K. (1979). Focus Group Interviews-A Reader. American Marketing Association, 222 South Riverside Plaza, Chicago, Illinois 60606 .

Gordon, J. (1990) Management and organization behavior, Boston College, Simmons \& Schusterm, Massachusets.

Hutchings, G. (1990). Agent Specialization and the 4-H PRK Model. Journal of Extension, 28, 12-14.

Hutchings. G. (1992). Evaluating county Clustering. Journal of Extension, 30, 17-20.

Isaac, S. \& Michael W. B. (1990). Handbook in Research and Evaluation, for Education and the Behavioral Sciences, Second Edition

Johnsrud, M. \& Rauschkolb, R. S. (1989). Extension in Transition: Review and Renewal, Journal of Extension, 27, 34 .

King. D.R. (1990). Attitudes of Extension Faculty and Staff regarding the clustered Staffing Pattern in Ohio, Doctoral Dissertation, The Ohio State University, Columbus.

Kittrell, D. \& McCracken, D. (1983). Are agent's interests, job satisfaction and performance related? Journal of Extension, 21, 22-26.

Krueger, R. (1989). They've done again, Journal of Extension, 27, 27-29.

Krueger, R. (1988). Focus Group Interviewing, step by Step Instruction for Extension Workers, Minnesota Agricultural 
Extension Service, 320c Vo Teach Building, 1954 Buford Avenue, St. Paul, Minnesota, 555108.

Lamble, W. (1984). Diffusion and adoption of innovations. Extension Handbook, University of Guelph, Canada.

Laughlin, S. G. (1984) Yes, but...yes, and, Journal of Extension, 27, 6 .

Little, C. (1992). Perspectives on Cluster Units in the ohio Cooperative Extension Service. Master Thesis. The Ohio State University, Columbus.

Meyer, J. M. , \& Pigg, R. (1990). Redefining Education for Action Issues Programming in Extension, The Rural Sociologist, 42-45.

Miller, G. A. , \& Rockwell, S. K. (1987, January). Citizens reactions to reorganization of county Extension offices. Nebraska Cooperative Extension Service, Institute of Agriculture and Natural Resources, University of NebraskaLincoln, Lincoln, NE.

Miller, L. E. \& Smith, K. L. (1983). Handling nonresponse issues, Journal of Extension, 21, 45-50.

Minnesota Extension Service (1987). Comprehensive Staffing Plan. Report of the Minnesota Extension Service Comprehensive Stafing Plan Task Force, St Paul: Minnesota Extension Service.

Minnesota Extension Service (1990). Extending Excellence: A plan for Staffing the Minnesota Extension Service, Saint Paul, University of Minnesota.

Naisbitt, J. (1982). Megatrends. New York, Warner Books, Nunnally, J.C. (1967). Psychometric Theory. New York:McGrawHill.

Peters, T. J. \& Waterman, R. J. (1982). In Search of Excellence. New York, New York, Harder \& Row.

Pittman, J. D. \& Cunningham, C. J. \& Young, R. E. (1976). Extension Staffing Patterns. Clientele views, Journal of Extension, 14, 24-29.

Ohio Cooperative Extension Service Administrative Cabinet (1989). Minutes of Cabinet Meetings, The Ohio State University, Columbus. 
Osborne, L. J. (1991) Advisory Committee Members and Extensionist perceptions of the delivery of quality programs for the two staffing patterns of The ohio cooperative Extension Service, Doctoral Dissertation. The Ohio State University, Columbus.

Prawl, W., R. Medlin, and J. Gross. (1984). Adult and continuing education through The Cooperative Extension Service. University Printing Services: Columbia, Missouri.

Purdue University Cooperative Extension Service (1991). A renewed commintment to excellence in putting knowledge to work. Phase I implementation, Octuber, 1991.

Report to the Secretary of Agriculture (1988). Accomolishments for Research, Extension, and Higher Education.

Rogers, \& Everett, M. \& Shoemaker, F. (1991). Communication of Innovations, A Cross Cultural Approach (Second Edition). New York, Free Press.

Rothman, R. (1992). Innovations. Teacher Magazine, May, June, 1992, 22-23.

Richardson, B. Ladewig, H. (1989). Let the people speak. Journal of Extension, 27, 15-17.

Smith, K. L. \& Woeste J. T. (1983). In-service training. Does it make a difference? Journal of Extension, 21, 22-27.

South Dakota Cooperative Extension Service (1987). clustering of counties in South Dakota. Brockings, SD,

Spiege1, M. R. (1989). Work motivational factors associated with the job performance of county Extension Agents in Ohio. Doctoral Dissertation, The University of Toledo, Ohio.

Taylor, P. E. \& Richardson, B. (1990). Issues programming changes Extension, Journal of Extension, 28, 16-18.

Teacher's Guide to School Reform (1992). Changing the profession. Teacher Magazine, May-June, 38-39.

Teacher's Guide to School Reform (1992). Changing Schools and Classrooms, Teacher Magazine, May- June, 32.

Thompsom, O. \& Gwynn D. (1989). Improving Extension: Views from Agricultural Deans. Assessing Extension's Strength and weaknesses, Journal of Extension, 27, 7-10. 
Tondl, R. M. (1991). Climate for change in Extension. Journal of Extension, 29, 14-16.

Tondl, R. M. (1989). Perceptions of climate for change in the workplace. Doctoral Dissertation. University of Nebraska, Lincoln.

United States Department of Agriculture and Extension Service and Land Grant University (1989).

USDA/NASULGC Joint Committee (1983). Extension in the 808: A perspective for the Future of The cooperative Extension Service. Madison: University of Winsconsin, Cooperative Extension Service.

Vroom. V. (1983). Leaders and Leadership in Academe. The Review of Higher Education, 6, (4), 367-386.

Warner, P. D. \& Christenson, J, A. (1984). The Cooperative Extension Service: A National Assessment. Westview press.

Watson, W. L. \& Hillison, J. (1991). Temperament type and job satisfaction among selected West Virginia Agricultural Education Teachers, Journal of Agricultural Education, 32, (4), 25-30.

Webb, B. (1989). Beyond Tradition. Journal of Extension, 27, 5-6.

White, J. (1991). Planning for change, privatization of The Extension Service (ADAS) in England and wales. University of Reading, February, 1991.

Wriston, W. B. (1990). The State of American Management, Harv-Bus-Review, Boulder, Colo, The Journal, 68, (1), 7883, Jan-Feb, 1990 .

Walenski, H. (1957). Human Relations in the workolace, INC. Aremberg, it al. Research in industrial Human Relations, $A$ critical appraisal, New York, New York. Harper, Row, INC.

York, E. T. (1966). A look to the Future, Cooperative Extension Service, Lousiana State University and $A \& M$ College. Prentice-Hall, INC. 